\title{
REVISION OF THE DRAGONETS (PISCES : CALLIONYMIDAE) FOUND IN THE WATERS OF JAPAN
}

$\operatorname{AUTHOR(S):~}$

Nakabo, Tetsuji

\section{CITATION:}

Nakabo, Tetsuji. REVISION OF THE DRAGONETS (PISCES : CALLIONYMIDAE) FOUND IN THE WATERS OF JAPAN. PUBLICATIONS OF THE SETO MARINE BIOLOGICAL LABORATORY 1983, 27(4-6): 193-259

\section{ISSUE DATE:}

1983-01-31

URL:

http://hdl.handle.net/2433/176056

RIGHT: 


\title{
REVISION OF THE DRAGONETS (PISGES: CALLIONYMIDAE) FOUND IN THE WATERS OF JAPAN
}

\author{
TETSUjI NAKABO \\ Department of Fisheries, Faculty of Agriculture, Kyoto University, Kyoto 606, Japan
}

With Text-figures $1-28$ and Table 1

\begin{abstract}
The Japanese callionymid fishes are revised, and the following 13 genera and 27 species (including a new species) are recognized: Bathycallionymus kaianus; $B$. formosanus as new to Japan; $B$. sokonumeri; Foetorepus altivelis; $F$. kamoharai as n. sp.; F. delandi as new to Japan; Neosynchiropus ocellatus; $N$. morrisoni as new to Japan; N. ijimai; Pterosynchiropus splendidus; Paradiplogrammus enneactis calliste; Diplogarmmus xenicus; Dactylopus dactylopus; Calliurichthys japonicus; Pseudocalliurichthys variegatus; Repomucenus huguenini; $R$. virgis; $R$. richardsoniz; R. beniteguri; R. ornatipinnis; $R$. valenciennei; R. lunatus; $R$. planus; Spinicapitichthys draconis; Anaora tentaculata; Eleutherochir opercularis as new to Japan; E. mirabilis. The genus Neosynchiropus Nalbant, 1980 (=Neosynchiropus Nakabo, 1982) is redescribed. Keys to the genera and species are given.
\end{abstract}

\section{Introduction}

The dragonets are very common on sandy-muddy bottoms along the coastal waters of Japan. They are very rich both in number of species and in abundunce. However, very few taxonomic works of this family in the Japanese waters have been done and dragonets species have been very much confused. This may be because the dragonets vary morphologically according to growth and sex.

Jordan and Fowler (1903) first reviewed the Japanese dragonets including two genera, Calliurichthys and Callionymus. Later, Jordan, Tanaka and Snyder (1913) listed the above two genera and Draculus (=Draculo) and 14 species. Matsubara (1955) recognized five genera, Calliurichthys, Callionymus, Synchiropus and Draculo, and twenty-five species. Ochiai et al. (1955) regarded Calliurichthys as a synonym for Callionymus. Ochiai (1963) also regarded Calymmichthys as a synonym for Diplogrammus. Nakabo and Iwata (1979) added a genus Anaora. Recently, Tominaga and Uyeno (1981) recognized the six genera, Anaora, Callionymus, Dactylopus, Diplogrammus, Draculo and Synchiropus, and twenty-seven species.

In the present paper, I have revised the Japanese dragonets according to the classification presented in my previous paper (Nakabo, 1982), and recognized the thirteen genera and twenty-seven species; twenty-six species are given the detailed and revised descriptions and a species is described as new to science. Keys to the genera and species are also given.

Publ. Seto Mar. Biol. Lab., XXVII (4/6), 193-259, 1983.

(Article 11) 
- Table 1. Proportional measurements as the percent of standard lengths in Japanese callionymid species.

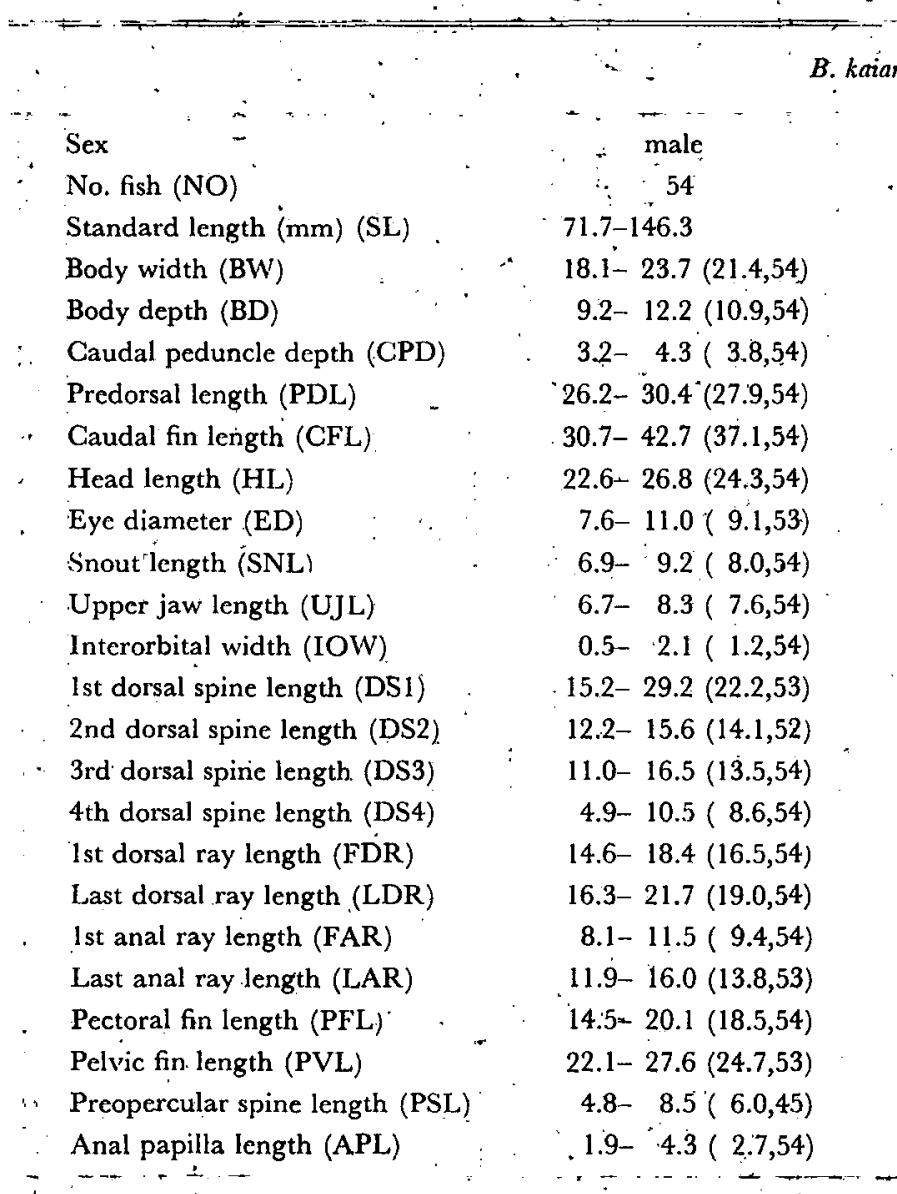

female
37
$67.2-135.0$
$20.4-26.0(22.4,37)$
$9.6-12.6(11.4,35)$
$3.2-4.4(3.8,37)$
$26.8-32.2(29.3,37)$
$29.9-36.7(33.3,37)$
$23.2-27.7(25.2,37)$
$8.0-11.4(9.5,37)$
$6.8-9.5(8.0,37)$
$6.1-8.6(7.8,37)$
$0.7-1.8(1.2,37)$
$14.7-21.1(17.5,37)$
$12.7-15.7(13.9,37)$
$11.1-14.9(13.2,37)$
$6.3-10.1(8.4,37)$
$15.0-17.8(16.2,36)$
$16.5-21.3(19.2,37)$
$7.7-11.1(9.5,36)$
$10.4-19.2(13.6,36)$
$17.3-20.4(18.8,37)$
$22.7-27.5(24.8,37)$
$4.9-8.2(6.4,31)$
$0.7-1.6(1.1,34)$
$-2 \ldots$
¿. .

$99.8-149.5$

$19.7-22.4(21.0,8)$

$10.1-12.1(11.0,8)$

$3.1-4.3(3.9,8)$

$26.0-27.9(27.0,8)$

$33.9 \div 56.9(46.0,8)$

23.4- $24.8(23.9,8)$

$8.2-9.7(9.0,8)$

$7.9-9.1(8.5,8)$

$6.9-7.8(7.3,8)$

$0.8-1.4(1.1,8)$

$29.9-37.3(32.7,7)$

$16.1-21.2(18.3,7)$

$16.5-17.9(17.2,7)$

8.9- $11.9(10.7,7)$

$21.2-24.4(23.0,8)$

$18.9-22.6(21.2,8)$

$10.3-12.6(11.3,7)$

$17.3-19.9(18.8,7)$

$17.9-19.9(18.9,8)$

$24.5-27.9(26.2,8)$

$5.0-6.4(5.7,7)$

$2: 3-3.4(2.8,8)$
B. formosantus
- female$$
\text { . } 8
$$

96.6-171.4 -

$22.9-24.9(24.0,8)^{\circ}$

$11.7-15.2(13.1,8)$

$4.0-4.4(4.2,8)$

$27.1-30.1(28.4,8)$

$29.4-47.9(35.5,8)$

$23.8-26.9(25.1,8)$

$8.4-10.4(9,5,8)$

$7.9-9.9(8.7,8)$

$7.3-8.0(7.5,8)$

$0.6-1.5(1.2,8)$

$21.6-29.9(24.7,8)$

$14.0-17.6(16.3,8)$

$13.1-16.3(14.4,8)$

$6.9-10.7(8.6,8)$

$17.5-19.6(18.3,8)$

$13.7-19.8(16.7,8)$

$8,3-10.0(9.3,8)$

$11.4-13.4(12.7,8)$

$17.5-20.8(18.9,8)$

$21.6-25.4(23.7,8)$

$5.2-7.3(6.2,6)$

$0.7-1.3(1.1,8)$ 
Table 1. Continued.

\begin{tabular}{|c|c|c|c|c|c|c|c|}
\hline \multirow[b]{3}{*}{ Șex } & \multirow{2}{*}{\multicolumn{2}{|c|}{ B. sokonumeri }} & \multirow{2}{*}{$F$. altivelis } & & \multicolumn{2}{|c|}{ F. kamoharai } & \multirow{2}{*}{$F$. delandi } \\
\hline & & & & . ... & Holotype & Paratype & \\
\hline & male & female & male - & ale. & male & male & female \\
\hline NO & 13 & . 8 & 36 & . 19 & $1^{\prime}$ & 1 & 8 \\
\hline SL & $87.2-140,1$ & $53.0-123.1$ & $55.2-185.7$ & $91.7-150.0$ & 142.3 & 115.4 & $97.8-156.8$ \\
\hline BW & $20.6-23.3(22.1,13)$ & $21.9-24.0(23.2,8)$ & $21.4-27.6(24.6,36)$ & $22.7-28.3(25.0 ; 19)$ & 23.2 & 25.6 & $21.2-28.6(24.4,8)$ \\
\hline $\mathrm{BD}$ & $10.8-13.1(11.8,13)$ & $11.2-14.3(12,7,8)$ & $13.9-17.8(16.2,36)$ & $15.0-18.1(16.8,19)$ & 16.4 & 17.0 & $12.9-16.0(14.8,8)$ \\
\hline CPD & $3.7-4.6(4.1,13)$ & $3.7-4.5(4.0,8)$ & $6.2-7.5(6.9,36)$ & $6.3-7.1(6.7,19)$ & 6.5 & 6.9 & $5.4 \quad 6.0(5.7,8)$ \\
\hline PDL & $26.1-29.0(27.5,13)$ & $28.1-31.1(29.5,8)$ & $25.3-29.0(26.7,36)$ & $26.0-28,1(27,0,19)$ & 28.1 & 28.1 & $27.7-30.3(28.7,8)$ \\
\hline CFL & $31.6-59.7 .(47.8,13)$ & $30.8-40.6(35.0,8)$ & $34.4-67.5(49.9,36)$ & $32.6-43.4(35.3,19)$ & - & 48.9 & $32.9-37.2(34.8,8)$ \\
\hline HL & $23.2-26.8 \cdot(24.6,13)$ & $24.2-27.0 .(25.3,8)$ & $25.4-32.2(27.8,36)$ & $27.2-29.4(28.2,19)$ & $\cdot 28.1$ & 27.7 & $25.8-29.0(27.2,8)$ \\
\hline ED & $8.3-.10 .7(9.2,13)$ & $8.4-10.6(9.6,8)$ & $7.2-10.7(8.8,36)$ & $8.1-10.6(9.0,19)$ & 9.7 & 9.9 & $9.6-11.4(10.4,8)$ \\
\hline SNNL & $8.0-9.5(8.4,13)$ & $7.7-\quad 8.9(8.3,8)$ & $7: 9-11.0(9.2,36)$ & $8.1-10.1(8.9,19)$ & 9.7 & 9.1 & $7.1-8.9(7.7,8)$ \\
\hline UJL & $7.2--8.2(7.9,13)$ & $6.7-8.6(7.8,8)$ & $7.8-9.5(8.4,36)$ & $7.8-9.1(8.4,19)$ & 8.5 & 8.5 & $7.1-7.9(7.6,8)$ \\
\hline IOW & $0.8-1.8(1.4,13)$ & $0: 5-1.9(1.1,8)$ & $1.9-3.9(2.6,36)$ & $2.0-3.3(2.7,19)$ & .2 .0 & $=1.7$ & $1.3-2.6(2.2,8)$ \\
\hline DSI & $17.6-22.4(20.5,13)$ & $13.4-17.5(15.7,8)$ & $30.1-50.0(38.2,35)$ & $27: 1-44.2,(36,5,19)$ & 25.7 & 29.1 & $16.1-21.5(18.6,8)$ \\
\hline DS2 & $15.6-21.8(19.7,13)$ & $12.3-17.3 .(14.8,8)$ & $16.1-22.1(19.5,36)$ & $.17 .1-23.8 \cdot(20.0,18)$ & 22.8 & 27.3 & $14.2-18.7(15.6,8)$ \\
\hline DS3 & $15.6-.21 .0(18.9,13)$ & $10.8-16.5(13.8,8)$ & $12.0-22.1(14.4,36)$ & $.13 .0-21.3(15.5,18)$ & 16.4 & 20.5 & $12.4-17.3(13.5,8)$ \\
\hline DS4 & $7.3-12.7(10.9,13)$ & $6.2-10.1(8.1 ; 8)$ & $9.5-14.0(11.5,36)$ & $8.7-12.4(10.7,18)$ & 14.1 & 15.3 & $8.6-12.8(10.7,8)$ \\
\hline FDR & $18.3-25.2(22.2,13)$ & $16.0-19.1(17.7,8)$ & $21.0-47.5(32.6,35)$ & $22.1-25.1(23.7,19)$ & 21.8 & 23.1 & $19.1-20.9(20.1,7)$ \\
\hline LDR & $16.6-26.4(21.4,13)$ & $10.7-.18 .6(14.9,8)$ & $14.5-25.3(30.0,36)$ & $21.0-25.0(22.4,19)$ & 24.5 & 29.8 & $17.8-20.9(19.5,7)$ \\
\hline FAR & $10.1-\cdot 13.6(11.4,12)$ & $7.4-9.8(8.9,8)$ & $7.1-11.6(9.6,36)$ & $8.0-10.8(9.5,19)$ & 9.8 & 11.5 & $7.4-8.5(8.0,8)$ \\
\hline İAR & $16.4-22.4(19.3,11)$ & $10.2-14.1(12.5,8)$ & $14.5-25.3(20.9,34)$ & $15.3-18.1(16.6,19)$ & 22.8 & 26.6 & $13.5-15.4 .(14.3,8)$ \\
\hline PFL & $16.8-21.1 \cdot(19.3,13)$ & $17.5-20.5(18.6,8)$ & $21.1-26.8 \cdot(24.7,36)$ & $20.3-23.3(22.3,19)$ & 24.9 & 25.0 & $20.1-21.9(21.0,8)$ \\
\hline PVL & $23.9-28.1(25.5,13)$ & $22.6-24.6(23.5,8)$ & $26.6-34.3(30.9,36)$ & $28.4-34.0(30.4,19)$ & 31.6 & 33.8 & $24.3-26.6(26.0,8)$ \\
\hline PSL & $4.2-6.1(4.8,11)$ & $5.0-\quad 7.4(5.9,6)$ & 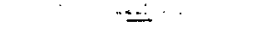 & - & $\because$ & - & $\because \because-$ \\
\hline APL & $1.7-2.8(2.4,13)$ & $0.3-1.5(0.9,7)$ & $1.0 \div 3.1(1.8,34)$ & $0.4-1.3(0.7,17)$ & 1.7 & 2.0 & $0.6-1.5(0.8,8)$ \\
\hline
\end{tabular}


Table 1. Continued.

\begin{tabular}{|c|c|c|c|c|c|c|c|}
\hline \multirow[b]{2}{*}{ Sex } & \multicolumn{2}{|c|}{ N. ocellatus } & N. morrisoni & \multicolumn{2}{|c|}{ N. ijimai } & \multicolumn{2}{|c|}{ P. splendidus } \\
\hline & male & female \& young & female & male & female & & $?$ \\
\hline NO & 20 & 26 & 2 & 7 & 2 & & 3 \\
\hline SL & $21.7-78.7$ & $9.6-55.0$ & $30.8-43.2$ & $48.0-76.9$ & $52.5-53.4$ & $33.6-4$ & \\
\hline BW & $22.7-26.7(25.2,20)$ & $22.9-31.9(27.1,26)$ & $24.5-26.0(25.2,2)$ & $22.7-25.4(24.3,6)$ & $25.7 \quad(25.7,2)$ & $25.9-2$ & $.9(27.0,3)$ \\
\hline $\mathrm{BD}$ & $16.7-23.0(19.8,20)$ & $18.4-23.8(20.0,26)$ & $19.5-21.1(20.3,2)$ & $18.9-21.7(20.0,7)$ & $20.6-23.2(21.9,2)$ & $22.6-2$ & $.3(25.0,3)$ \\
\hline $\mathrm{CPD}$ & $8.3-10.8(9.9,20)$ & $8.9-10.4(9.6,26)$ & $10.4-11.4(10.9,2)$ & $8.5-10.0(9.1,7)$ & $8.4-9.6(9.0,2)$ & $16.6-1$ & $1(17.1,3)$ \\
\hline PDL & $28.0-38.0(31.1,20)$ & $31.4-35.2(33.6,26)$ & $32.6-36.7(34.7,2)$ & $26.1-30.4(28.3,7)$ & $30.3-34.1(32.2,2)$ & $37.6-9$ & $.6(38.8,3)$ \\
\hline $\mathrm{CFL}$ & $29.9-34.7(32.9,20)$ & $30.0-34.8(31.6,26)$ & $30.8-35.2(33.0,2)$ & $29.1-32.0(29.9,7)$ & $28.4-29.4(28.9,2)$ & $30.9-3$ & $.6(32.8,2)$ \\
\hline $\mathrm{HL}$ & $26.7-33.8(29.4,20)$ & $27.8-35.4(29.8,26)$ & $28.2-32.5(30.4,2)$ & $24.4-26.3(25.2,7)$ & $25.5-25.7(25.6,2)$ & $30.7-3$ & $.7(32.4,3)$ \\
\hline ED & $7.5-12.9(9.3,20)$ & $8.8-13.5(10.6,26)$ & $10.0-12.3(11.2,2)$ & $7.7-9.6(8.1,7)$ & $8.0-8.4(8.2,2)$ & $11.6-1$ & $.4(12.7,3)$ \\
\hline SNL & $8.8-12.9(10.2,20)$ & $6.3-10.9(9.4,25)$ & $10.4-13.3(11.9,2)$ & $9.1-10.8(10.3,7)$ & $8.8-9.3(9.1,2)$ & $10.4-1$ & $.5(11.4,3)$ \\
\hline UJL & $7.1-9.9(8.3,20)$ & $7.2-10.4(8.0,26)$ & $8.3-9.1(8.7,2)$ & $7.1-8.9(7.7,7)$ & $7.5-7.6(7.6,2)$ & $8.2-1$ & $.2(9.3,3)$ \\
\hline IOW & $2.8-4.8(4.2,20)$ & $1.1-4.9(3.3,26)$ & $2.1-3.2(2.7,2)$ & $3.0-3.6(3.3,7)$ & $(1.9,2)$ & $5.0-1$ & $.2(7.1,3)$ \\
\hline DS1 & $13.8-39.0(29.7,20)$ & $10.5-16.5(14.5,26)$ & $11.4-18.1(14.8,2)$ & $32.7-64.7(53.3,6)$ & $26.4-30.1(28.3,2)$ & $10.6-2$ & $.4(19.9,3)$ \\
\hline DS2 & $14.8-42.9(32.0,20)$ & $11.5-16.0(13.6,26)$ & $12.3-17.8(15.1,2)$ & $34.0-69.7(56.1,6)$ & $24.3-26.3(25.3,2)$ & $11.6-1$ & $.4(14.9,3)$ \\
\hline DS3 & $14.3-40.4(31.2,20)$ & $8.5-16.0(11.6,26)$ & $10.1-16.2(13.2,2)$ & $45.0-64.7(53.4,5)$ & $20.8-21.0(20.9,2)$ & $10.4-1$ & $.9(12.8,3)$ \\
\hline DS4 & $13.4-37.4(27.1,20)$ & $6.9-12.1(9.0,26)$ & $6.5-12.5(9.5,2)$ & $22.1-53.8(44.0,6)$ & $12.9-14.3(13.6,2)$ & $6.2-1$ & $.9(9.6,3)$ \\
\hline FDR & $16.1-21.0(18.9,19)$ & $15.6-20.0(18.0,26)$ & $18.3-18.5(18.4,2)$ & $16.6-21.1(19.3,6)$ & $17.6-17.7(17.6,2)$ & 20.1 & $(20.1,3)$ \\
\hline LDR & $17.2-23.9(21.1,18)$ & $11.5-20.4(18.1,23)$ & $16.2-18.3(17.3,2)$ & $21.0-31.2(25.4,4)$ & $18.1-18.7(18.4,2)$ & 16.0 & $(16.0,1)$ \\
\hline FAR & $9.2-13.0(10.7,20)$ & $10.4-13.9(11.2,26)$ & $10.7 \quad(10.7,1)$ & $9.1-11.9(10.7,6)$ & $10.5-10.9(10.7,2)$ & 14.0 & $(14.0,1)$ \\
\hline LAR & $17.5-21.0(19.4,20)$ & $15.6-19.6(17.9,26)$ & $18.2-20.1(19.2,2)$ & $18.8-21.5(19.8,6)$ & $16.0-16.9(16.4,2)$ & 18.6 & $(18.6,1)$ \\
\hline PFL & $20.8-25.3(23.6,20)$ & $20.6-27.1(23.2,26)$ & $20.5-23.8(22.2,2)$ & $24.1-28.5(25.5,6)$ & $23.4-24.0(23.7,2)$ & 20.6 & $(20.6,1)$ \\
\hline PVL & $34.0-39.5(36.4,20)$ & $34.9-40.5(36.7,26)$ & $35.0-35.7(35.4,2)$ & $31.9-36.7(34.9,6)$ & $30.7-33.0(31.9,2)$ & 33.4 & $(33.4,1)$ \\
\hline PSL & - & - & - & $2.9-4.2(3.4,7)$ & $3.7-3.8(3.8,2)$ & & - \\
\hline APL & $0.9-3.8(2.4,20)$ & - & - & $1.8-3.1(2.3,7)$ & $1.1-1.3(1.2,2)$ & & - \\
\hline
\end{tabular}


Table 1. Continued.

\begin{tabular}{|c|c|c|c|c|c|}
\hline \multirow[b]{2}{*}{ Sex } & \multicolumn{2}{|c|}{ P. enneactis calliste } & \multicolumn{2}{|c|}{ D. xenicus } & \multirow{2}{*}{$\frac{D . \text { dactylopus }}{\text { female }}$} \\
\hline & male & female & male & female & \\
\hline NO & 42 & 23 & 13 & 9 & 2 \\
\hline SL & $17.9-66.8$ & $20.6-57.6$ & $32.1-79.7$ & $15.2-78.5$ & $80.2-94.5$ \\
\hline BW & $19.0-23.8(21.4,42)$ & $21.6-26.5(23.6,23)$ & $17.1-20.6(18.9,13)$ & $18.0-21.3(19.8,9)$ & $25.9-28.6(27.3,2)$ \\
\hline BD & $11.7-16.8(13.7,41)$ & $12.0-17.5(14.5,23)$ & $11.2-13.7(12.3,13)$ & $11.4-15.8(13.6,9)$ & $17.2-18.0(17.6,2)$ \\
\hline CPD & $5.2-7.2(6.1,42)$ & $5.4-7.0(6.4,23)$ & $5.9-6.8(6.2,13)$ & $5.9-7.9(6.4,9)$ & $7.4-7.5(7.5,2)$ \\
\hline PDL & $27.3-33.7(30.2,42)$ & $29.2-38.8(32.4,23)$ & $26.8-30.0(28.3,13)$ & $28.5-35.5(30.6,8)$ & $22.9-23.1(23.0,2)$ \\
\hline CFL & $28.9-47.9(36.1,42)$ & $26.1-34.7(30.3,23)$ & $23.5-33.7(28.6,13)$ & $27.3-31.6(29.0,9)$ & $34.7-42.1(38.4,2)$ \\
\hline HL & $23.5-31.8(26.1,42)$ & $24.8-29.2(26.9,23)$ & $23.2-26.7(24.9,13)$ & $24.4-32.2(26.9,9)$ & $27.7-28.4(28.1,2)$ \\
\hline ED & $6.7-11.7(8.4,42)$ & $7.5-10.7(9.1,23)$ & $6.3-8.1(7.2,13)$ & $6.8-11.8(8.4,9)$ & $7.7-8.7(8.2,2)$ \\
\hline SNL & $8.0-11.3(9.5,42)$ & $7.8-10.4(9.2,33)$ & $8.5-10.1(9.0,13)$ & $8.1-11.2(9.0,9)$ & $9.0-10.0(9.5,2)$ \\
\hline UJL & $6.6-9.6(7.6,41)$ & $6.3-9.5(7.7,23)$ & $7.6-9.8(8.8,13)$ & $7.9-9.2(8.4,9)$ & $7.9-8.4(8.2,2)$ \\
\hline IOW & $1.0-2.5(1.8,42)$ & $0.5-2.5(2.0,23)$ & $1.0-1.9(1.6,13)$ & $1.3-1.9(1.6,9)$ & $3.5-3.6(3.5,2)$ \\
\hline DSI & $14.5-40.5(28.1,42)$ & $11.2-16.3(14.3,23)$ & $14.9-31.0(24.8,13)$ & $7.2-17.2(13.7,9)$ & $43.4-45.9(44.7,2)$ \\
\hline $\mathrm{DS} 2$ & $12.8-36.7(25.7,42)$ & $10.2-15.5(13.2,23)$ & $10.7-13.7(12.1,13)$ & $6.6-12.5(11.2,9)$ & $37.5-42.4(40.0,2)$ \\
\hline DS3 & $12.3-50.2(31.5,41)$ & $9.4-14.4(11.7,23)$ & $9.2-11.8(10.3,13)$ & $8.5-11.2(9.8,8)$ & $27.7-31.9(29.8,2)$ \\
\hline DS4 & $8.9-31.2(18.4,41)$ & $5.9-11.9(7.3,23)$ & $6.2-9.0(7.8,13)$ & $4.2-6.4(5.4,8)$ & $15.7-20.4(18.1,2)$ \\
\hline FDR & $12.7-24.0(19.4,42)$ & $18.5-22.1(19.9,23)$ & $16.3-20.4(17.8,13)$ & $17.8-20.0(19.1,9)$ & $21.3-25.6(23.5,2)$ \\
\hline LDR & $12.8-28.9(20.6,39)$ & $12.7-17.2(15.8,23)$ & $18.1-25.5(20.6,13)$ & $13.2-21.3(17.2,9)$ & $21.2-24.2(22.7,2)$ \\
\hline FAR & $8.9-12.1(10.3,42)$ & $8.7-12.0(10.3,23)$ & $8.6-11.4(9.8,13)$ & $9.8-12.5(10.9,9)$ & $12.3-12.8(12.6,2)$ \\
\hline LAR & $14.3-31.9(22.7,42)$ & $13.3-17.2(15.2,23)$ & $13.7-22.1(15.9,12)$ & $12.4-15.7(13.7,9)$ & $21.0-26.2(23.6,2)$ \\
\hline PFL & $18.6-25.1(23.0,42)$ & $20.7-24.6(22.7,23)$ & $20.4-22.7(21.7,13)$ & $19.3-23.7(21.9,9)$ & $21.0-24.9(23.0,2)$ \\
\hline PVI & $28.2-34.6(31.3,42)$ & $28.6-34.4(30.9,23)$ & $26.5-31.8(29.3,12)$ & $28.3-31.1(29.5,9)$ & $42.4-45.0(43.7,2)$ \\
\hline PSL & $3.7-10.6(5.9,41)$ & $5.0-8.7(6.8,20)$ & $7.4-10.6(8.9,12)$ & $8.5-11.0(9.6,9)$ & $7.1-7.3(7.2,2)$ \\
\hline APL & $2.1-4.2(3.4,42)$ & $0.2-0.8(0.5,10)$ & $1.4-3.5(2.1,13)$ & $0.3-0.9(0.6,4)$ & $0.2-0.9(0.6,2)$ \\
\hline
\end{tabular}


Table 1. Continued:

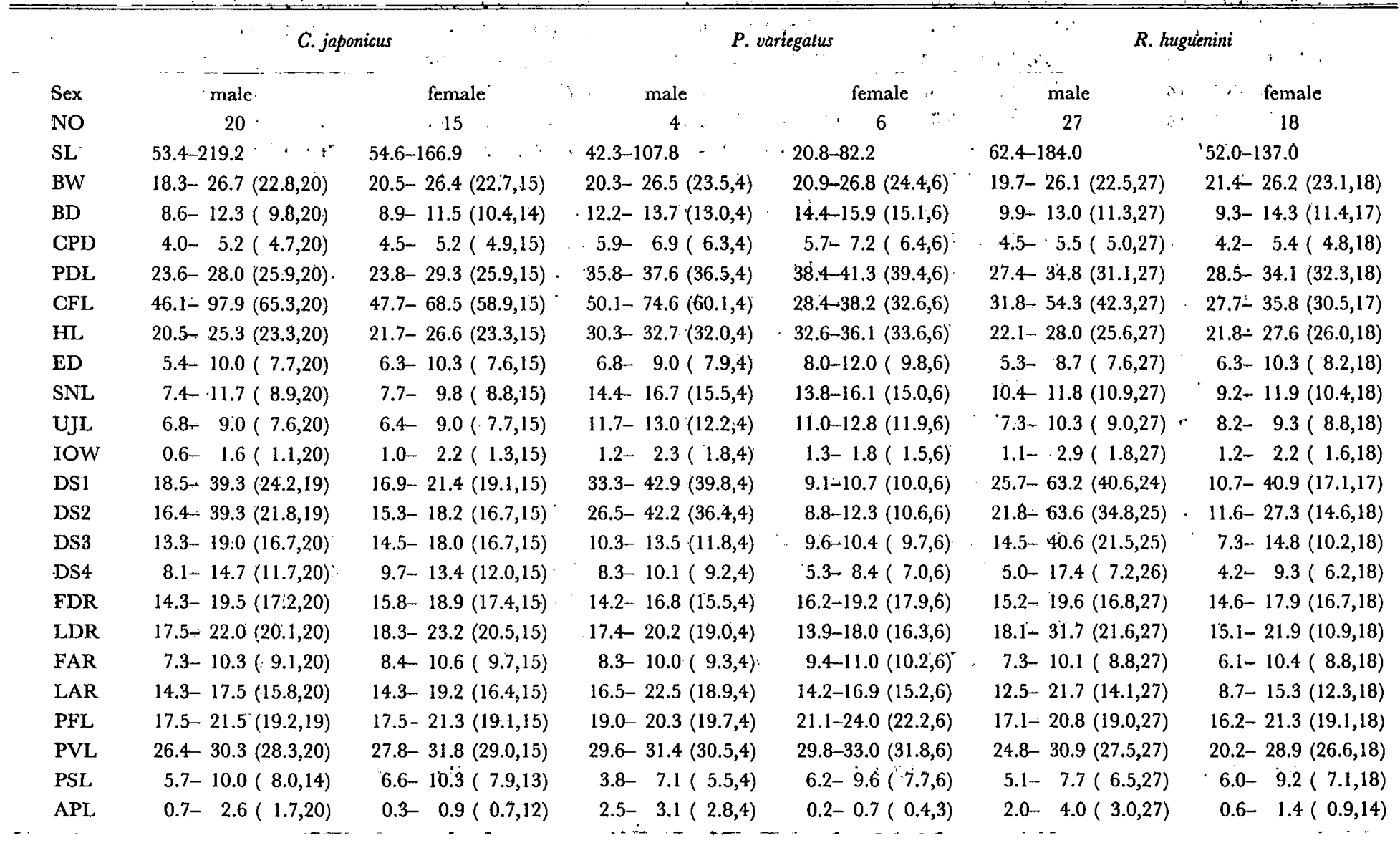


Table 1. Continued.

\begin{tabular}{|c|c|c|c|c|c|c|}
\hline \multirow{2}{*}{ Sex } & \multicolumn{2}{|c|}{$R$. virgis } & \multicolumn{2}{|c|}{ R. richardsonii } & \multicolumn{2}{|c|}{ R. beniteguri } \\
\hline & male & female & male & female & male & female \\
\hline NO & 28 & 23 & 31 & 30 & 52 & 46 \\
\hline SL & $47.2-81.4$ & $21.2-65.0$ & $59.9-174.3$ & $70: 5-169.6$ & $61.0-159.2$ & $58.2-160.5$ \\
\hline BW & $17.4-26.0(23.4,28)$ & $19.7-28.9(25.3,23)$ & $20.3-24.7(22.4,31)$ & $20.1-24.2(22.3,30)$ & $20.9-25.1(22.8,51)$ & $20.6-25.0(23.2,46)$ \\
\hline $\mathrm{BD}$ & $9.0-12.0(10.9,28)$ & $8.0-12.9(11.1,23)$ & $9.3-12.4(10.3,31)$ & $8.5-12.3(10.3,30)$ & $9.4-15.3(12.2,51)$ & $9.5-13.9(11.8,46)$ \\
\hline CPD & $3.9-5.5(4.8,28)$ & $3.9-4.9(4.5,23)$ & $4.4-5.3(4.8,31)$ & $4.4-5.2(4.8,30)$ & $4.4-\quad 6.5(5.3,51)$ & $4.3-5.7(5.1,46)$ \\
\hline PDL & $24.2-29.9(26.1,28)$ & $29.1-36.3(30.9,23)$ & $26.1-30.6(28.9,31)$ & $25.3-30.7(28.7,30)$ & $29.3-35.2(31.5,52)$ & $28.6-34.9(32.0,46)$ \\
\hline CFL & $21.1-37.0(31.4,28)$ & $25.1-30.1(27.8,23)$ & $30.3-50.1(38.4,31)$ & $28.2-40.1(33.6,30)$ & $28.3-43.4(34.5,52)$ & $26.9-36.5(31.4,45)$ \\
\hline HL & $21.4-25.4(23.1,28)$ & $22.9-28.7(25.4,23)$ & $22.8-26.0(24.5,31)$ & $22.1-25.4(24.1,30)$ & $23.5-28.4(26.0,52)$ & $23.7-27.5(25.9,46)$ \\
\hline $\mathrm{ED}$ & $7.3-9.5(8.4,28)$ & $8.7-11.8(9.8,23)$ & $6.0-8.4(7.0,31)$ & $5.8-8.0(6.9,30)$ & $5.0-8.4(6.2,52)$ & $5.0-7.6(6.5,46)$ \\
\hline SNL & $7.5-9.7(8.5,28)$ & $7.7-9.2(8.5,23)$ & $9.0-11.0(9.6,31)$ & $7.9-10.8(9.0,30)$ & $9.5-13.9(12: 1,52)$ & $10.2-12.7(11.5,46)$ \\
\hline UJL & $7.6-10.0(8.4,28)$ & $7.7-11.8(8.8,23)$ & $7.3-9.0(8.0,31)$ & $6.8-8.2(7.7,30)$ & $8.6-11.1(9.5,52)$ & $8.5-11.0(9.3,45)$ \\
\hline IOW & $0.8-2.1(1.4,28)$ & $0.3-2.1(1.4,23)$ & $0.9 \rightarrow \quad 1.9(1.4,31)$ & $0.9-2.4(1.3,30)$ & $1.6-4.5(3.0,52)$ & $1.5-3.5(2.6,43)$ \\
\hline DS1 & $16.0-71.0(51.7,26)$ & $10.3-14.7(13.1,23)$ & $11.7-16.4(14.1,31)$ & $10.6-12.1(13.2,30)$ & $10.2-31.7(18.0,50)$ & $8.9-12.6(11.3,45)$ \\
\hline DS2 & $17.8-88.4(63.8,26)$ & $11.9-14.4(13.1,23)$ & $8.9-13.5(11.6,31)$ & $9.5-15.0(12.3,30)$ & $11.5-31.9(18.7,51)$ & $9.2-13.3(11.5,46)$ \\
\hline DS3 & $17.6-84.8(63.6,24)$ & $9.3-12.8(10.8,23)$ & $10.1-15.5(12.2,31)$ & $10.2-15.9(10.3,30)$ & $8.7-21.3(12: 1,52)$ & $7.9-11.6(9.5,45)$ \\
\hline DS4 & $16.1-73.9(59.4,26)$ & $5.2-10.1(7.9,23)$ & $4.4-15.2(10.0,31)$ & $6.1-11.6(8.4,30)$ & $5.1-11.2(7.2,52)$ & $3.7-\quad 7.7(5.8,46)$ \\
\hline FDR & $16.5-23.5(20.1,28)$ & $16.3-20.4(18.5,23)$ & $12.9-18.2(15.6,31)$ & $14.1-17.4(16.1,30)$ & $13.4-17.8(15.8 ; 52)$ & $13.7-17.7(16.2,46)$ \\
\hline LDR & $15.6-29.7(23.8,27)$ & $12.8-16.9(14.7,23)$ & $17.7-30.6(25.4,31)$ & $17.0-25.8(21.5,30)$ & $14.8-27.4(21.9,51)$ & $12.7-22.3(18.2,46)$ \\
\hline FAR & $7.2-9.2(8.1,28)$ & $7.1-10.7(8.2,23)$ & $6.2-11.6(9.3,30)$ & $8.3-11.2(9.6,30)$ & $6.7-9.5(8.4,50)$ & $7.5-9.8(8.7,45)$ \\
\hline LAR & $10.6-15.9(12.9,27)$ & $7.4-11.9(10.4,23)$ & $12.4-19.6(15.2,29)$ & $11.5-16.0(13.8,30)$ & $10.7-23.3(14.5,52)$ & $11.5-19.5(13.4,45)$ \\
\hline PFL & $17.5-22.5(20.7,28)$ & $20.0-23.2(21.4,23)$ & $16.5-20.5(19.0,31)$ & $17.3-20.9(19.3,30)$ & $17.6-25.1(19.5,51)$ & $17.4-22.6(20.0,46)$ \\
\hline PVL & $25.5-28.8(27.0,28)$ & $24.7-31.6(27.5,23)$ & $24.2-28.2(26.3,31)$ & $24.1-27.8(26.1,30)$ & $25.4-29.8(27.3,51)$ & $25.5-30.3(27.7,46)$ \\
\hline PSL & $3.9-5.8(4.8,26)$ & $4.7-8.0(6.3,20)$ & $3.9-6.7(5.7,30)$ & $5.2-\quad 7.4(5.9,29)$ & $3.1-5.8(4.3,46)$ & $3.8-5.6(4.7,43)$ \\
\hline APL & $1.7-4.1(3.2,26)$ & $0.6-2.1(1.0,19)$ & $1.4-5.0(3.4,31)$ & $0.6-2.4(1.2,28)$ & $1.5-4.4(3.1,51)$ & $0.2-\quad 1.3(0.9,42)$ \\
\hline
\end{tabular}


Table 1. Continued.

\begin{tabular}{|c|c|c|c|c|c|c|}
\hline \multirow[b]{2}{*}{ Sex } & \multicolumn{2}{|c|}{ R. ornatipinnis } & \multicolumn{2}{|c|}{ R. valenciennei } & \multicolumn{2}{|c|}{ R. lunatus } \\
\hline & male & female & male & female & male & female \\
\hline NO & 60 & 29 & 12 & 15 & 26 & 20 \\
\hline SL & $72.1-159.8$ & $75.3-171.4$ & $69.3-102.2$ & $64.0-108.7$ & $46.2-156.3$ & $43.6-137.4$ \\
\hline BW & $19.6-24.2(21.8,59)$ & $21.0-26.3(22.5,29)$ & $18.4-21.5(19.9,12)$ & $19.5-23.0(21.9,15)$ & $20.3-25.6(23.2,26)$ & $21.4-26.6(23.8,20)$ \\
\hline $\mathrm{BD}$ & $8.2-15.4(10.8,57)$ & $8.7-14.7(10.9,29)$ & $9.9-12.4(11.2,12)$ & $11.2-13.6(12.5,14)$ & $10.0-13.6(12.0,26)$ & $11.2-14.7(12.5,20)$ \\
\hline CPD & $3.2-\quad 5.4(4.6,60)$ & $4.0-\quad 5.2(4.5,29)$ & $4.8-5.6(5.1,12)$ & $4.7-5.4(5.1,15)$ & $4.2-5.4(4.9,26)$ & $4.5-\quad 5.4(5.0,20)$ \\
\hline PDL & $30.2-35.0(32.1,60)$ & $31.4-35.3(32.9,29)$ & $27.5-32.6(29.5,12)$ & $27.9-34.0(31.7,15)$ & $28.6-35.6(31.3,26)$ & $30.0-36.7(32.0,20)$ \\
\hline CFL & $28.7-47.5(35.5,58)$ & $26.2-35.8(30.0,29)$ & $46.0-62.1(54.5,11)$ & $27.5-34.1(30.1,15)$ & $26.3-39.8(31.4,26)$ & $27.2-31.7(30.1,19)$ \\
\hline HL & $24.6-28.8(26.2,60)$ & $24.2-28.7(26.4,29)$ & $22.9-26.4(24.6,12)$ & $23.1-26.9(25.3,15)$ & $24.2-29.7(26.1,26)$ & $24.1-30.0(26.1,20)$ \\
\hline $\mathrm{ED}$ & $5.7-8.3(7.1,60)$ & $6.3-8.4(7.5,29)$ & $6.8-8.0(7.4,12)$ & $7.0-9.0(8.1,15)$ & $6.5-11.0(8.5,26)$ & $7.9-11.0(8.8,20)$ \\
\hline SNL & $10.2-14.0(11.7,60)$ & $9.9-13.7(11.3,29)$ & $8.4-10.1(9.0,12)$ & $7.7-9.0(8.4,15)$ & $8.3-10.7(9.0,26)$ & $8.5-10.4(9.2,20)$ \\
\hline UJL & $7.1-10.9(9.6,60)$ & $7.6-10.5(9.5,29)$ & $7.1-9.1(8.1,12)$ & $7.5-8.8(8.1,15)$ & $6.0-11.5(8.1,26)$ & $7.2-9.8(7.9,20)$ \\
\hline IOW & $1.4-\quad 4.2(2.7,60)$ & $1.5-3.1(2.2,29)$ & $1.2-2.2(1.7,12)$ & $1.1-2.2(1.6,15)$ & $1.5-2.8(2.0,26)$ & $1.1-2.5(1.7,20)$ \\
\hline DSI & $10.2-25.2(17.7,52)$ & $9.6-12.4(11.2,29)$ & $27.8-84.1(55.8,10)$ & $14.8-22.7(17.5,15)$ & $12.9-53.6(35.8,25)$ & $10.7-14.4(12.8,20)$ \\
\hline DS2 & $11.8-32.7(19.1,52)$ & $9.6-12.9(11.5,29)$ & $15.3-41.8(25.0,11)$ & $11.2-15.1(12.9,15)$ & $7.5-15.9(12.7,26)$ & $7.9-10.6(9.5,20)$ \\
\hline DS3 & $9.4-20.2(14.2,55)$ & $7.0-11.0(9.6,29)$ & $19.4-61.6(34.0,11)$ & $10.9-13.3(11.8,15)$ & $6.5-18.9(13.1,26)$ & $6.3-10.0(8.3,20)$ \\
\hline DS4 & $4.9-11.6(8.0,59)$ & $3.7-6.1(4.9,29)$ & $11.3-68.7(45.1,11)$ & $8.1-14.0(10.2,15)$ & $5.2-18.5(11.9,26)$ & $2.6-6.6(5.4,20)$ \\
\hline FDR & $12.8-16.1(14.3,56)$ & $13.4-15.9(14.6,29)$ & $15.9-19.3(17.9,12)$ & $16.3-22.1(18.6,15)$ & $14.9-19.8(17.1,26)$ & $16.1-18.6(17.3,20)$ \\
\hline LDR & $15.3-29.7(24.4,59)$ & $15.4-22.5(18.2,29)$ & $37.6-29.8(32.9,12)$ & $13.1-17.4(15.1,14)$ & $12.8-30.0(22.8,26)$ & $13.4-18.6(16.0,20)$ \\
\hline FAR & $5.7-9.1(8.0,57)$ & $7.4-9.4(8.3,28)$ & $6.3-8.9(7.7,12)$ & $6.9-10.1(8.8,14)$ & $6.9-10.1(8.7,26)$ & $7.2-10.0(9.0,20)$ \\
\hline LAR & $11.4-19.5(14.9,59)$ & $11.9-15.0(12.9,28)$ & $15.6-26.8(20.1,11)$ & $10.4-13.9(12.1,14)$ & $10.2-19.6(15.6,26)$ & $11.1-13.8(12.8,20)$ \\
\hline PFL & $17.9-21.6(19.7,60)$ & $17.1-21.3(19.9,29)$ & $19.8-22.8(21.1,12)$ & $19.3-22.4(21.1,15)$ & $19.5-22.1(20.9,26)$ & $20.1-22.4(21.3,20)$ \\
\hline PVL & $26.0-31.5(28.5,60)$ & $26.7-31.1(28.7,29)$ & $25.7-32.6(28.2,12)$ & $24.8-29.9(27.4,15)$ & $22.7-28.9(26.3,26)$ & $23.4-28.0(26.2,20)$ \\
\hline PSL & $3.3-4.8(4.1,59)$ & $3.7-5.5(4.5,29)$ & $3.4-4.5(4.0,9)$ & $3.8-5.6(4.5,15)$ & $3.9-6.5(5.2,26)$ & $4.6-6.9(5.4,20)$ \\
\hline APL & $2.3-5.0(3.8,58)$ & $0.7-1.7(1.1,27)$ & $4.4-6.5(5.5,12)$ & $0.7-1.3(1.0,14)$ & $2.1-5.7(4.2,26)$ & $1.0-2.0(1.3,20)$ \\
\hline
\end{tabular}


Table 1. Continued.

\begin{tabular}{|c|c|c|c|c|c|c|c|c|c|}
\hline \multirow[b]{2}{*}{ Sex } & \multicolumn{2}{|c|}{ R. planus } & S. draconis & \multicolumn{2}{|c|}{ A. tentaculata } & \multicolumn{2}{|c|}{ E. opercularis } & \multicolumn{2}{|c|}{ E. mirabilis } \\
\hline & male & female & male & male & female & male & young & male & female \\
\hline NO & 23 & 20 & 1 & 2 & 13 & 1 & 1 & 15 & 18 \\
\hline SI. & $23.4-102.1$ & $25.5-95.9$ & 93.8 & $27.0-38.5$ & $19.0-34.9$ & 66.3 & 19.7 & $37.5-48.2$ & .1 \\
\hline BW & $24.9-33.6(28.3,23)$ & $26.1-33.0(28.9,20)$ & 25.6 & $21.3-23.7(22.5,2)$ & $21.0-28.4(24$ & 24.9 & 29.9 & $14.3-20.0(16.2,15)$ & $16.6-21.0$ \\
\hline $\mathrm{BD}$ & $5-11.8(10.6,23)$ & $9.3-13.5(11.1,20)$ & 17.2 & $16.3-18.7(17.5,2)$ & $17.2-21.0$ & 17.2 & 22.8 & $9.2-11.7(10.3,15)$ & 18) \\
\hline CPD & $4.2-6.1(4.8,22)$ & $4.2-5.7($ & 5.8 & $7.4-8.3(7.9,2)$ & $7.6-8.9($ & 9.5 & 11.7 & $4.7-5.8(5.4,15)$ & 5.9( \\
\hline PDL & $30.3-36.8(32.8,22)$ & $30.4-35.6(3$ & 29.4 & $34.0-39.6(36.8,2)$ & $34.7-43.0$ & 41.2 & 48.2 & - & - \\
\hline $\mathrm{CFL}$ & $26.3-31.7(28.4,21)$ & $25.7-31.3(2$ & 94.0 & $45.2-58.2(51.7,2)$ & $29.9-38.4$ & 27.6 & 35.0 & $19.2-26.8(23.6,15)$ & $28.0(2$ \\
\hline HL & $23.6-30.2(26.7,23)$ & $23.2-28.4$ & 33.5 & $30.1-33.3(31.7,2)$ & $27.8-35.8$ & 33.2 & 43.7 & $23.8-26.4(25.0,15)$ & $23.8-28.4$ \\
\hline ED & $6.3-11.1(8.1,23)$ & $6.7-9$ & 11.7 & $9.4-12.6(11.0,2)$ & $9.6-12.7$ & 7.2 & 11.2 & $5.1-6.4(5.7,15)$ & $4.8-6.9 !$ \\
\hline SNL & $7.3-10.5(9.6,22)$ & $7.8-10.5(9$ & 13.3 & $13.5-14.8(14.2,2)$ & 10.5 & 10.9 & 13.2 & $6.7-8.2(7.3$ & 18) \\
\hline UJL & $7.3-9.5(8.1,23)$ & $7.2-8.6(7.8,20)$ & 10.2 & $9.9-11.1(10.5,2)$ & $7.1-11.8$ & 11.8 & 14.7 & $5.8-8.0(6.9,15)$ & $6.1-9.0($ \\
\hline IOW & $1.1-2.5(1.8,23)$ & $0.9-2$ & & $-3.7(3.4,2)$ & $1.7-7$ & 6.6 & 8.6 & $2.5-4.6(3.7,15)$ & $2.0-4.9($ \\
\hline DS1 & $10.5-15.7(12.9,23)$ & $9.3-12$ & 21. & $-15.6(1$ & $11.7-1$ & 8.3 & 10.2 & - & - \\
\hline DS2 & $5.8-13.7(9.0,23)$ & 7.7 & 24.4 & ,2) & 13.3 & 8.3 & 9.6 & - & - \\
\hline DS3 & $5.2-10.2(7.1,23)$ & $6.0-11.4($ & 25.7 & $11.9-14.3(13.1,2)$ & 10.4 & 7.4 & 8.1 & - & - \\
\hline DS4 & $3.8-8.7(5.9,23)$ & $3.2-5.8(4.4,20)$ & 17.0 & $7.4-7.8(7.6,2)$ & $4.2-7.9(6.1,13)$ & 5.3 & 4.1 & - & - \\
\hline FDR & $12.3-15.8(13.7,23)$ & $11.7-17.3(13.8,20)$ & 22.2 & $20.5-20.7(20.6,2)$ & $13.4-21.1(18.5,12)$ & 10.3 & 10.2 & $5.3-8.6(6.9,14)$ & $5.2-7.8(6.3,16)$ \\
\hline LDR & $12.0-24.4(19.0,21)$ & $12.5-18.5(16.0,20)$ & 21.3 & $18.5-21.8(20.2,2)$ & $13.0-15.2(13.9,13)$ & 10.7 & 10.2 & $6.7-9.9(8.6,14)$ & $7.4-10.0(8.3,16)$ \\
\hline FAR & $7.4-9.3(8.3,22)$ & $5.2-9.4(8.3,20)$ & 9.6 & $13.0-13.8(13.4,2)$ & $11.4-13.7(12.7,13)$ & 5.4 & 8.6 & $6.9-9.4(8.5,14)$ & $6.3-9.0(7.9,17)$ \\
\hline LAR & $12.2-15.7(14.1,20)$ & $11.8-15.0(13.9,20)$ & 19. & $22.6-27.3(25.0,2)$ & $12.4-15.8(13.9,13)$ & 12.2 & 10.7 & $9.2-11.2(10.1,14)$ & $6.5-10.8(9.6,17)$ \\
\hline PFL & $20.5-25.4(23.6,21)$ & $19.9-25.5(23.6,20)$ & 23.2 & $22.2-25.5(23.9,2)$ & $17.8-24.2(2$ & 21.6 & 22.3 & $18.4-24.4(21.4,15)$ & $18.0-23.3(20.8,18)$ \\
\hline PVL & $28.6-33.6(31.7,22)$ & $30.6-33.4(32.0,19)$ & 29.2 & $34.1-36.6(35.4,2)$ & $28.9-34.1(32,0,13)$ & 23.1 & 34.5 & $17.3-21.2(19.6,15)$ & $16.1-20.4(18,3,18)$ \\
\hline PSL & $8.0-10.8(9.0,22)$ & $7.3-11.2(9.0,17)$ & 8.0 & $4.1-4.2(4.2,2)$ & $3.7-5.9(4.7,13)$ & - & - & - & - \\
\hline APL & $1.0-4.1(2.8,23)$ & $0.3-1.1(0.8,19)$ & 3.2 & $2.1-2.2(2.2,2)$ & 一 & 1.8 & - & $1.6-2.3(2.1,15)$ & $0.1-1.8(0.8,11)$ \\
\hline
\end{tabular}


Since Neosynchiropus Nakabo, 1982 proved to be a synonym for Neosynchiropus Nalbant, 1980, this genus was redescribed in the present paper.

The abbreviations for museum and institutional collections are: BSKU, Department of Biology, Faculty of Science, Kochi University; CAS-SU, Stanford University Collection, deposited at California Academy of Sciences; FAKU, Department of Fisheries, Faculty of Agriculture, Kyoto University; FRSKU, Fisheries Research Station, Kyoto University; MSM, Marine Science Museum, Tokai University; MTUF, Museum of Tokyo University of Fisheries; MU, Miyazaki University, NSMT, Depart ment of Zoology, National Science Museum, Tokyo; RMNH, Rijksmuseum van Natuurlijke Historie, Leiden; UMMZ, Museum of Zoology, University of Michigan, URB, Department of Biology, University of the Ryukyus; YGM, Yokosuka City Museum; ZUMT, Department of Zoology, University Museum, University of Tokyo.

The measuring methods for the dragonet's body parts follow Nakabo (1982), and counting of fin rays Hubbs and Lagler (1947). Length of body of each dragonet in the text is shown in standard length. Proportional measurements of the Japanese species are shown in Table 1.

\section{Taxonomy}

1) Key to the genera of Callionymidae in Japan

$A_{1}$ Upper edge of lower jaw with many fleshy papillae; mouth expanded lateral-

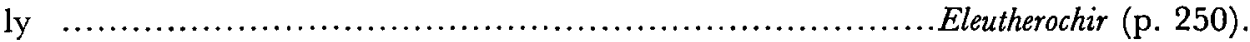

$\mathrm{A}_{2}$ Upper edge of lower jaw without fleshy papillae; mouth small, not expanded laterally.

$B_{1}$ Longitudinal dermal fold on lower part of lateral side of body; opercular flap Diplogrammus (p. 221).

$\mathrm{B}_{2} \quad$ No longitudinal dermal fold on lower part of lateral side of body; no opercular flap.

$\mathrm{C}_{1}$ Tip of each dorsal ray, except last one divided at base, bifurcate or trifurcate. $\mathrm{D}_{1}$ Tip of each dorsal ray, except last, trifurcate ......Pterosynchiropus (p. 218).

$\mathrm{D}_{2}$ Tip of each dorsal ray, except last, bifurcate.

$\mathrm{E}_{1}$ Pelvic spine and 1st pelvic ray fused into elongate rod, separated from the other pelvic rays Dactylopus (p. 223).

$\mathrm{E}_{2} \quad$ Pelvic spine and five rays connected by membrane.

$\mathrm{F}_{1}$ Tip of each branch of last anal ray simple .........Foetorepus (p. 208).

$\mathrm{F}_{2}$ Tip of each branch of last anal ray bifurcate ... Neosynchiropus (p. 212).

$\mathrm{C}_{2}$ Tip of each dorsal ray, except last branched one, simple.

$G_{1}$ Preopercular spine with several processes on both outer and inner sides Spinicapitichthys (p. 247).

$\mathrm{G}_{2} \quad$ Preopercular spine with an antrorse process at base, many upward processes on inner side.

$\mathrm{H}_{1}$ No transverse lateral line commissure on dorsal surface of caudal peduncle. 
$I_{1}$ Pair of supraorbital cirri; body with many short cirri

$\mathrm{I}_{2}$ No supraorbital cirrus; body with no short cirrus.

$\mathrm{J}_{1}$ Preopercular spine straight with many short upward processes on inner side .................Pseudocalliurichthys (p. 227).

$\mathrm{J}_{2}$ Preopercular spine strongly curved upward at posterior end; several upward processes on inner side. Paradiplogrammus (p. 219).

$\mathrm{H}_{2}$ Transverse lateral line commissure on dorsal surface of caudal peduncle.

$\mathrm{K}_{1}$ Tips of two median caudal rays simple.

$\mathrm{K}_{2}$ Tips of seven median caudal rays bifurcate.

$\mathrm{L}_{1}$ Some short separated transverse branches of lateral line canal present on dorsal surface of body; 9 dorsal and 8 anal rays .......................... Galliurichthys (p. 225).

$\mathrm{L}_{2}$ No separated transverse branch of lateral line canal on dorsal surface of body; 9 dorsal and 9 anal rays.........

Repomucenus (p. 229).

2) Genus Bathycallionymus Nakabo, 1982

Key to the species of Bathycallionymus

A $\quad$ First dorsal spine elongate.

$\mathrm{B}_{1}$ Tip of anterior branch of last ray bifurcate ...... . kaianus (Günther) (p. 203).

$\mathrm{B}_{2}$ Tip of anterior branch of last ray simple ...... formosanus (Fricke) (p. 205). $\mathrm{A}_{2}$ First dorsal spine short ........................ sokonumeri (Kamohara) (p. 206).

\section{Bathycallionymus kaianus' (Günther)}

(Japanese name: Tongari-numeri)

(Fig. 1)

Callionymus kaianus Günther, 1880: 44, pl. 19, fig. B (type locality: Ki Isls.); de Beaufort, 1951: 66 (reference); Matsubara, 1955: 713 (key); Ochiai et al., 1955: 111, figs. 8-10 (Shibushi; Mimase, Owase); Smith, 1963: 553, pl. 84, J (reference); Tatara et al., 1965: 105 (Tosa Bay and adjacent waters); Arai and Abe, 1970: 91 (Tsushima); Masuda et al., 1975: 261, pl. 84, D (Japan); Fricke, 1981b: 357, fig. 6 (redescription of the holotype).

Callionymus kaianus kaianus: Johnson, 1971 : 112 (Japan).

Bathycallionymus kaianus: Nakabo, 1982 : 79 (listed).

Callionymus ochiaii Fricke, 1981b: 316, fig. 13 (type locality: Shibushi, Kagoshima Pref., Japan).

Materials examined: FAKU 23257-23260 (paratypes of Callionymus ochiaii), 23261 (holotype of $C$. ochiaii), 23272, 23275 (paratype of C. ochiaii), 23276, 23283, 6 males and 3 females, 7.7.0-122.7 $\mathrm{mm}$ in standard length, Shibushi, Kagoshima Pref., Sep. 1-3, 1954. FAKU 24783, a male, 75.5 mm, Owase, Mie Pref., Oct. 25, 1954. FAKU 48661-48672; 48675-48691, 48695-48703, 48705, 48707-48720, NSMT-P 


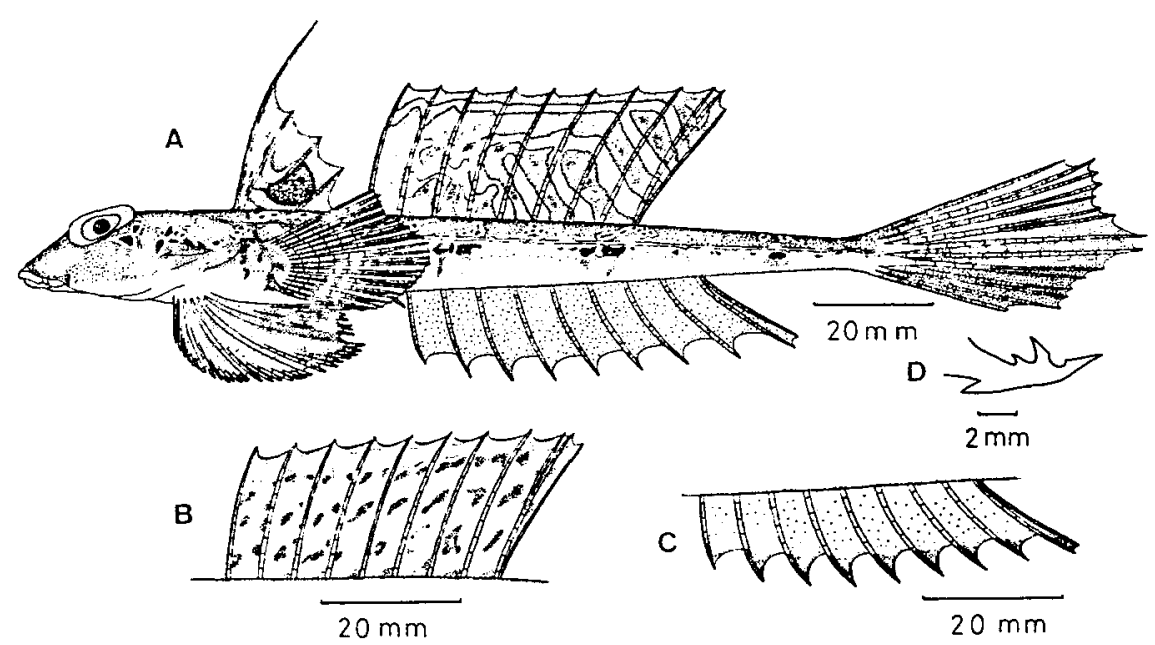

Fig. 1. Bathycallionymus kaianus (Gunther). A, a male, $140.1 \mathrm{~mm} \mathrm{SL,} \mathrm{FAKU} \mathrm{49422;} \mathrm{B,} \mathrm{se-}$ cond dorsal fin of a female, $119.1 \mathrm{~mm}$, FAKU 49030; $\mathrm{C}$, anal fin of a female, FAKU 49030; D, preopercular spine, 114.9 mm FAKU 48701.

21020-21023, 34 males and 23 females, 67.2-145.2 mm, Mimase Kochi Pref., Nov. 13-14, 1975. FAKU 49022-49028, 49030, 49031, 5 males and 4 females, 106.6$145.3 \mathrm{~mm}, 26^{\circ} 53^{\prime} 8 \mathrm{~N}, 125^{\circ} 03^{\prime} \mathrm{OE}$, East China Sea, July 26, 1975. FAKU 49033, 49034 , a male and a female, $104.0-120.9 \mathrm{~mm}, 27^{\circ} 13^{\prime} 2 \mathrm{~N}, 124^{\circ} 59^{\prime} 2 \mathrm{E}$, East China Sea, July 26, 1975. FAKU 49418-49427, 7 males and 5 females, 84.9-160.8 mm, Mimase, Oct. 25, 1976.

Description: D. IV, 9 (rarely 10 ); A. $9 ; \mathrm{P}_{1}$. ii $+17-19$ (rarely $\mathrm{i}+18-19$, $\mathrm{ii}+$ 17); $\mathrm{P}_{2}$. I, 5; C. i+3+ii $+2+\mathrm{ii}$.

Preopercular spine with one feeble and one strong upward process on inner side; posterior end barbed, elongate, and not curved upward.

First dorsal spine elongate in both sexes. Anterior branch of last dorsal ray bifurcate. Pectoral fin reaching 3rd dorsal ray. Pelvic fin short, not reaching 1st anal ray. Middle part of caudal fin protruded and pointed; tips of two median caudal rays simple.

Color in $10 \%$ formalin. Body olive brown with some dark marks above, white below. Dark marks on dorsal surface of body not fine. Ventral surface of head faintly dark in males; white in females. Some dark spots on mid-axis of lateral side of body. First dorsal fin with large lunate black mark between 3rd and 4th spines. Second dorsal fin dark with several vermicular, darker-edged white lines in males, but transparent with many dark spots, and slightly black distal margin in females. Upper half of pectoral fin faintly dark. Pelvic fin faintly dark; posterior half darker. Anal fin faintly dark in males; almost transparent with faintly dark distal margin in females. Lower half of caudal fin dark.

Remarks: Johnson (1971) divided this species into two subspecies, Callionymus kaianus kaianus Günther and $C$. $k$. moretonensis Johnson, mainly on differences in coloration. From my examination of the paratypes of $C$. $k$. moretonensis, these two subspecies 
should be two species. Johnson's subspecies are closer in the color pattern of the anal fin to $B$. sokonumeri and $B$. formosanus than to $B$. kaianus, and closer in the shape of the unpaired fins of the male to $B$. kaianus than to $B$. sokonumeri and $B$. formosanus.

Alcock (1899) reported this species from the Malabar coast, but his specimens are somewhat different in body color from B. kaianus; the body is reddish. Therefore, his specimen must belong to species yet to be identified.

A specimen $150 \mathrm{~mm}$ long in the collection of the Leidaen Museum labelled "Java", "Callionymus vittatus", apparently a museum name given by Schlegel, was identified with this species by de Beaufort (1951). However, it also must belong to a species yet to be identified because of the difference in the preopercular spine.

Fricke (1981b) described Callionymus ochiaii from Japan on the basis of the specimens identified with this species by Ochiai et al. (1955). C. ochiaii is, however, a synonym for $B$. kaianus, because the specimen figured by him is a young male; adult males from Japan are greatly agreed with the holotype of $B$. kaianus.

\section{Bathycallionymus formosanus (Fricke)}

(New Japanese name: Kujaku-soko-numeri)

(Fig. 2)

Callionymus kaianus (not of Günther), Chu et al., 1962: 723, fig. 585 (South China Sea). Callionymus formosanus Fricke, 1981b: 369, fig. 14 (type locality: Formosa Str.). Bathycallionymus formosanus: Nakabo, 1982: 79 (listed).

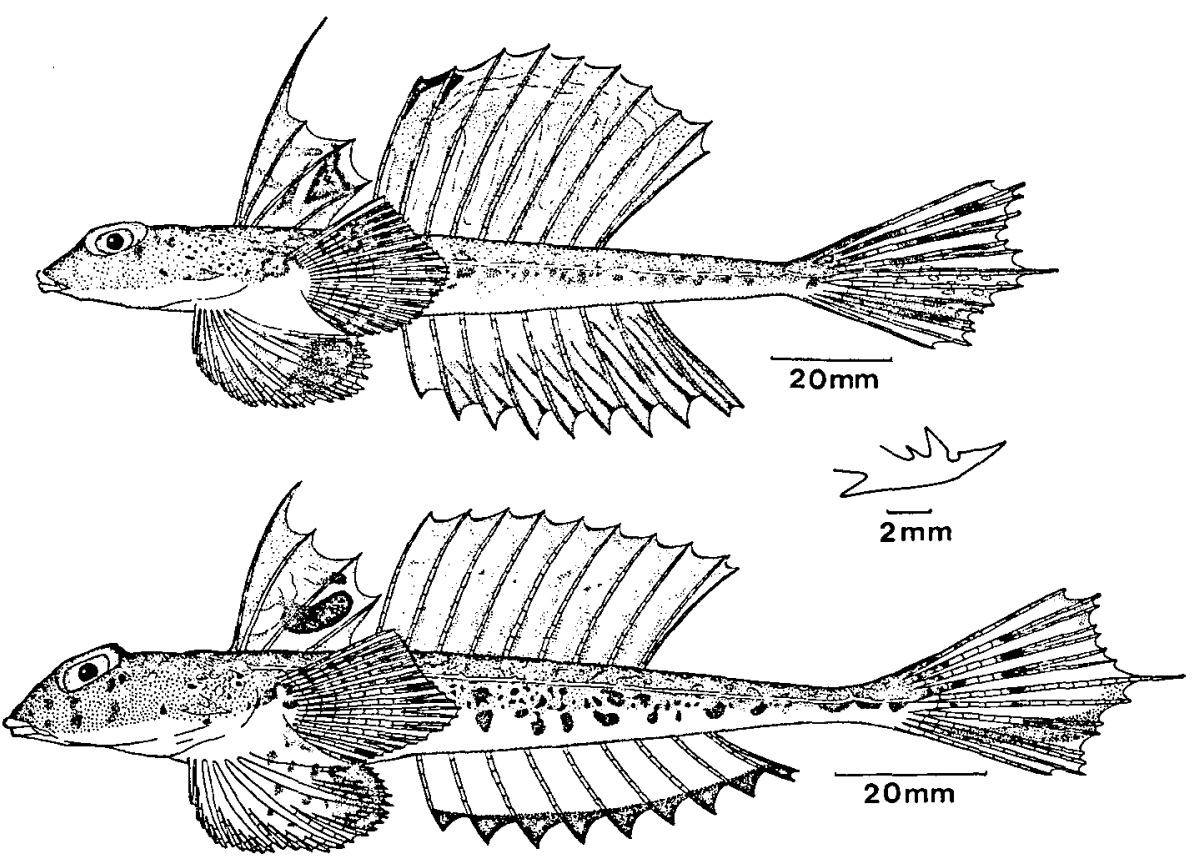

Fig. 2. Bathycallionymus formosanus (Fricke). Upper, a male, $127.3 \mathrm{~mm} \mathrm{SL}$, FAKU 49407 ; middle, preopercular spine, FAKU 49407; lower, a female, $116.3 \mathrm{~mm}$, FAKU 49416. 
Materials examined: FAKU 21866, a female, $80.0 \mathrm{~mm}$ in standard length, Mimase, Apr. 10-20, 1954. FAKU 49407, 49416, 49417, a male and two females, 114.5-127.3 mm, Mimase, Oct. 25, 1976. FAKU 49440, a female, $171.4 \mathrm{~mm}$, Mimase, Oct. 28, 1976. FAKU 49449, a female, 133.2 mm, Mimase, Oct. 30, 1976. FAKU 50468-50475, 6 males and 2 females, 96.6-116.3 mm, Tongking Bay, 1957. NSMT-P 21024, a male, $149.5 \mathrm{~mm}$, Mimase, Nov. 13, 1975. NSMT-P 21025, a female, $130.9 \mathrm{~mm}$, Mimase, Oct. 30, 1976.

Diagnosis: This species is easily distinguished from other species of Bathycallionymus by the following points: 1) an elongate filamentous first dorsal fin, 2) an elongate preopercular spine, 3) a simple anterior branch of the last dorsal ray, 4) large, expanded and colorful second dorsal and anal fins in males, 5) a black blotch at the dorśoanterior edge of the second dorsal fin in males.

Description: D. IV, 9; A. 9; $\mathrm{P}_{1}$. ii $+16-19 ; \mathrm{P}_{2} . \mathrm{I}, 5 ; \mathrm{C} . \mathrm{i}+3+\mathrm{ii}+2+\mathrm{ii}$ (rarely $\mathrm{i}+3+\mathrm{iii}+1+\mathrm{ii})$.

Preopercular spine with one feeble and one strong upward process on inner side; posterior end barbed, elongate, and not curved upward.

First dorsal spine elongate in both sexes. Second dorsal fin high and broad in males, but not in females. Anterior branch of last dorsal ray simple. Pectoral fin reaching 2 nd anal ray. Pelvic fin short, not reaching lst anal ray. Median caudal ray elongate, longer in males than in females; tips of 2 median rays simple.

Color in $10 \%$ formalin. Body marbled olive-brown above, white below. Dark marks on dorsal surface of body not fine. First dorsal fin faintly dark with some oblique white bands at anterior part and a large, blackish-brown lunate mark between 3rd and 4th spines in males; faintly dark with a large elliptic blackish-brown mark in females. Second dorsal fin faintly dark with black mark at its drosoanterior edge; several transverse white bands in males; almost transparent with 3 series of dark marks in females. Upper half of pectoral fin with many small dark spots. Posterior half of pelvic fin dark. Lower half of anal fin dark with 1 or 2 oblique darker lines on each membrane in males, but anal fin in females transparent with blackish distal margin. Lower half of caudal fin dark.

REMARKs: This species is closely allied to Bathycallionymus sokonumeri in its large, expanded and beautiful second dorsal and anal fins. The two fish have almost the same fin coloration. The preopercular spine, the elongate first dorsal spine and the dark marks on the dorsal surface of the body of $B$. formosanus are, however, more like $B$. kaianus than like $B$. sokonumeri.

$B$. formosanus is distributed from the southern part of the Pacific coast of Japan to the South China Sea.

\section{Bathycallionymus sokonumeri (Kamohara)}

(Japanese name: Soko-numeri)

(Fig. 3)

Callionymus sokonumeri Kamohara, 1936b: 448, fig. 2 (type locality: Mimase, Kochi Pref.); 


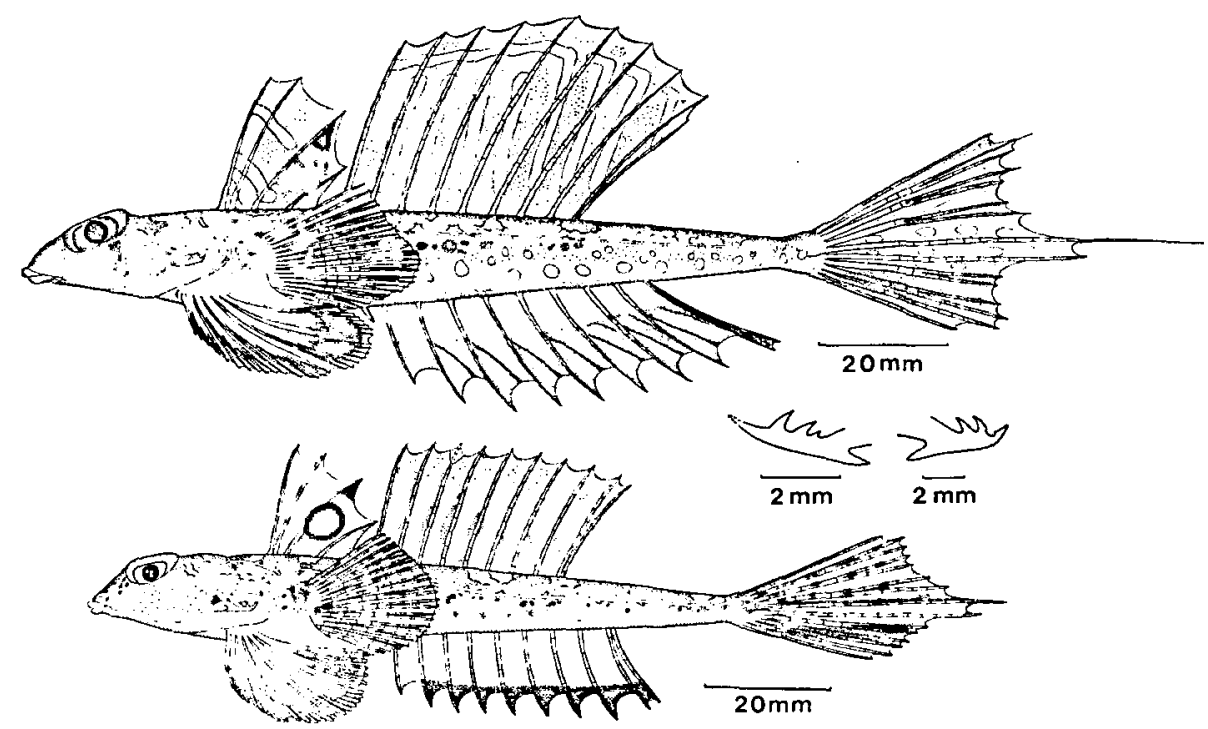

Fig. 3. Bathycallionymus sokonumeri (Kamohara). Upper, a male, $122.6 \mathrm{~mm}$ SL. FAKU 49408; middle, preopercular spines of a young, $41.8 \mathrm{~mm}$, FAKU 50607 (left) and an adult, 98.5 mm, FAKU 49412 (right); lower, a female, $103.5 \mathrm{~mm}$, FAKU 49414.

Kamohara, 1938: 65, fig. 36 (Tosa Bay); Ochiai et al., 1955: 109, figs. 6-7 (Mimase; Owase); Tatara et al., 1965: 105 (Tosa Bay and adjacent waters).

Bathycallionymus sokomumeri: Nakabo, 1982: 79 (11sted).

Materials examined: FAKU 18178, 18595, a male and a female, 109.8-123.1 mm in standard length, Mimase, Kochi Pref., Oct. 10, 1952. FAKU 19687-19688, 2 females, 95.3-97.4 mm, Nobeoka, Miyazaki Pref., Dec. 10, 1952. FAKU 21870, 21873, 21875, 3 females, 53.0-65.2 mm, Mimase, Apr. 10-20, 1954. FAKU 23296, a male, $96.2 \mathrm{~mm}$, Shibushi, Kagoshima Pref., Sep. 1-3, 1954. FAKU 24779, a male, 87.2 mm, Owase, Mie Pref., Óct. 20, 1954. FAKU 25174, a male, $101.3 \mathrm{~mm}$, Mimase, Mar. 20, 1955. FAKU 48721, a male, $98.0 \mathrm{~mm}$, Nov. 14, 1975. FAKU 49407-49414, 49438, NSMT-P 21026-21027, 8 males and 2 females, 98.5-140.1 mm, Mimase, Oct. 25-26, 1976. FAKU 50607 (only in preopercular spine), a young, $41.8 \mathrm{~mm}$, off Kuki, Mie Pref., Mar. 10, 1976.

Description: D. IV, 9; A. 9; $\mathrm{P}_{1}$. ii $+17-19$ (rarely i+18-19); $\mathrm{P}_{2}$. I, 5; C. i $3+\mathrm{ii}+2+\mathrm{ii}$.

Preopercular spine with two strong upward processes on inner side; posterior end barbed, strongly curved upward.

Dorsal spines not elongate in either sex. Second dorsal fin high and broad in males, but not in females. Anterior branch of last dorsal ray simple. Pectoral fin reaching 2nd anal ray. Pelvic fin short, not reaching 1 st anal ray. Median caudal ray elongate, longer in males than in females; tips of two median caudal rays simple.

Color in $10 \%$ formalin. Body marbled olive-brown above, white below. Dark marks on dorsal surface of body very fine. First dorsal fin faintly dark with two oblique white bands at anterior part and darker lunate mark between 3rd and 4th 
spines in males; faintly dark with round blackish-brown mark (in one specimen, a square mark) in females. Second dorsal fin faintly dark with several transverse white bands in males; almost transparent with three series of dark marks in females. Upper half of pectoral fin with many small dark spots. Posterior half of pelvic fin dark. Lower half of anal fin dark with one or two oblique blackish lines on each membrane in males, but in females anal fin transparent with black distal margin. Lower half of caudal fin dark.

REMarks: This species is found only in Japan, especially along the southern part of its Pacific coast.

\section{3) Genus Foetorepus Whitley, 1931}

Key to the species of Foetorepus

$A_{1}$ First dorsal spine elongate .......... altivelis (Temminck and Schlegel) (p. 208). $A_{2}$ No dorsal spine elongate.

$\mathrm{B}_{1}$ First dorsal fin rather high with four transverse dark bands; gill-opening a little behind origin of first dorsal fin; posterior half of the lateral line with some upward and downward very short branches...........F. kamoharai n. sp. (p. 210).

$\mathrm{B}_{2} \quad$ First dorsal fin small with no conspicuous dark mark; gill-opening a little before origin of first dorsal fin; posterior half of the lateral line with many downward very short branches F. delandi (Fowler) (p. 211).

\section{Foetorepus altivelis (Temminck and Schlegel)}

(Japanese name: Beni-teguri)

(Fig. 4)

Callionymus altivelis 'Temminck and Schlegel, 1845: 155, pl. 79, fig. 1 (type locality: Ohomura Bay, Nagasaki); Günther, 1861: 147 (same as the type); Nyström, 1887: 36 (Japan); Jordan and Fowler, 1903: 948 (reference); Franz, 1910: 84 (Yokohama); Jordan, Tanaka and Snyder, 1913: 374 (listed); Ui, 1929: 261 (Kishu); Kuroda, 1931: 124 (Suruga Bay); Kamohara 1938: 65 (Tosa Bay); Boeseman, 1947: 133 (review); Yanai, 1950: 22 (Matsue; Hamada); Mori, 1952: 133 (Pusan, Korea).

Synchiropus altivelis: Schultz and Woods, 1948: 419 (reference); Matsubara, 1955: 716 (key); Mori, 1956: 23 (Kasumi; Hamada); Chu et al., 1962: 729, fig. 590 (South China Sea); Tatara et al., 1965: 106 (Tosa Bay)

Foetorepus altivelis: Nakabo, 1982: 79 (listed).

Synchiropus pallidus Fowler, 1941: 23, fig. 14 (type locality: the Philippines).

Synchiropus calauropomus (not of Richardson): Kuroda, 1951 : 385 (Suruga Bay).

Callionymus calauropomus (not of Richardson): Kamohara, 1952a: 89 (Tosa Bay).

Materials examined: FAKU 48854-48868, 9 males and 6 females, 101.4$179.1 \mathrm{~mm}$, in standard length, Nov. 15, 1975. FAKU 49235, a male, $55.2 \mathrm{~mm}$, Mar. 24, 1976. FAKU 49340-49346, 5 males and 2 females, 106.4-185.7 mm, Feb. 10, 1976. FAKU 49325, 49347-49353, 49356, 4 males and 5 females, 75.2I67.4 mm, Feb. 12, 1976. FAKU 49404-49405, a male and a female, 95.8-99.4 


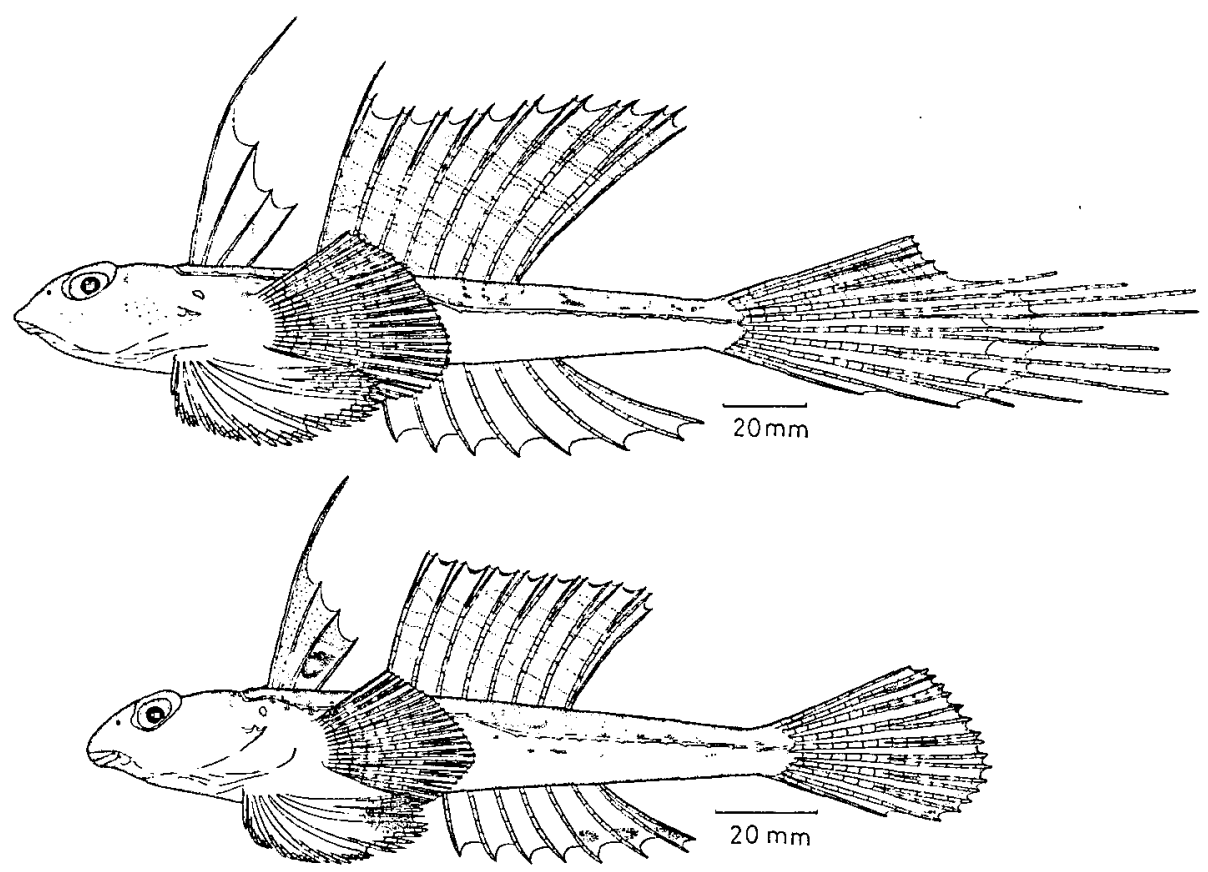

Fig. 4. Foetorepus altivelis (Temminck and Schlegel). Upper, a male, $170.1 \mathrm{~mm}$ SL, FAKU 48860 ; lower, a female, $134.1 \mathrm{~mm}$, FAKU 49441.

mm, Oct. 22. 1976. FAKU 49439, a male, $122.1 \mathrm{~mm}$, Oct. 27, 1976. FAKU 49941-49942, a male and a female, 113.8-134.1 mm, Oct. 28, 1976. FAKU 5002950031, 50326-50328, 5 males and 2 females, 91.7-154.3 mm, Mar. 27, 1980. All the above specimens collected from Mimase-market, Kochi Prefecture. FAKU $49903-49913,9$ males and 2 females, $140.0-170.8 \mathrm{~mm}, 28^{\circ} 20^{\prime}-29^{\circ} 58^{\prime} \mathrm{N}, 126^{\circ} 35^{\prime}-$ $127^{\circ} 30^{\prime}$ E, East China Sea, Feb. 6-Mar. 22, 1978.

Description: D. IV, 8; A. 7; $\mathrm{P}_{1}$. i+19-20; $\mathrm{P}_{2}$. I, 5; G. i+7+ii.

Preopercular spine with an upward process on inner side; posterior end curved upward. Gill-opening just or a little behind beginning of first dorsal fin. Lateral line reach-ing base of caudal fin; its posterior half with many very short downward branches.

First dorsal spine elongate in both sexes. Second dorsal fin high and broad in males, but not in females; first dorsal ray elongate in males, but not in females. Pectoral fin reaching 4th-5th dorsal rays. Pelvic fin reaching 1 st anal ray in males, but not in females. Five median caudal rays filamentous in males, but caudal fin rounded in females.

Golor in life. Body reddish with some olive brown marks above, white below. Ventral surface of head yellowish red in males, white in females. First dorsal fin yellow with some vermicular pinkish marks and large dark mark between 3rd and 4th spines. This large dark mark becomes thinner with maturity. Second dorsal fin yellow with many oblique pinkish lines. Pectoral fin reddish with olive-brown mark near upper origin. Pelvic fin reddish with white margin; in young, posterior 
part black. Anal fin reddish with white margin; in young, posterior part black. In males, upper part of caudal fin yellow with some oblique pinkish lines, middle part with several longitudinal yellow lines, lower part reddish; in females, dorsoanterior part yellow with some pinkish lines, ventroposterior part reddish.

Color in $10 \%$ formalin. Body creamy white and with some dark marks above.

Remarks: Synchiropus pallidus Fowler should be a synonym for this species since the general physiognomy, especially for the first and second dorsal fins is the same as in $F$. altivelis.

Fricke (1981a) reported this species from the Hawaii an Isls. The specimens he examined, however, should belong to a species yet to be identified, because they have short first dorsal spine in each sex and no filamentous caudal rays in a male.

This species is distributed in southern Japanese waters, East China Sea and northen South China Sea.

The type locality of this species, the Omura Bay, Nagasaki Prefecture, is quite doubtfull, because $F$. altivelis inhabits edge of the continental shelf. The type specimen might have been collected from the water near the Omura Bay.

\section{Foetorepus kamoharai, n. sp.}

(Japanese name: Amime-nodokusari)

(Fig. 5)

?Callionymus corallinus (not of Gilbert): Kamohara, 1951: 8, pl. 2, fig. 2 (Mimase, Kochi Pref., Japan).

Callionymus corallinus (not of Gilbert): Kamohara, 1952a: 90 (reference).

Foetorepus sp. 4: Nakabo, 1982: 79 (listed).

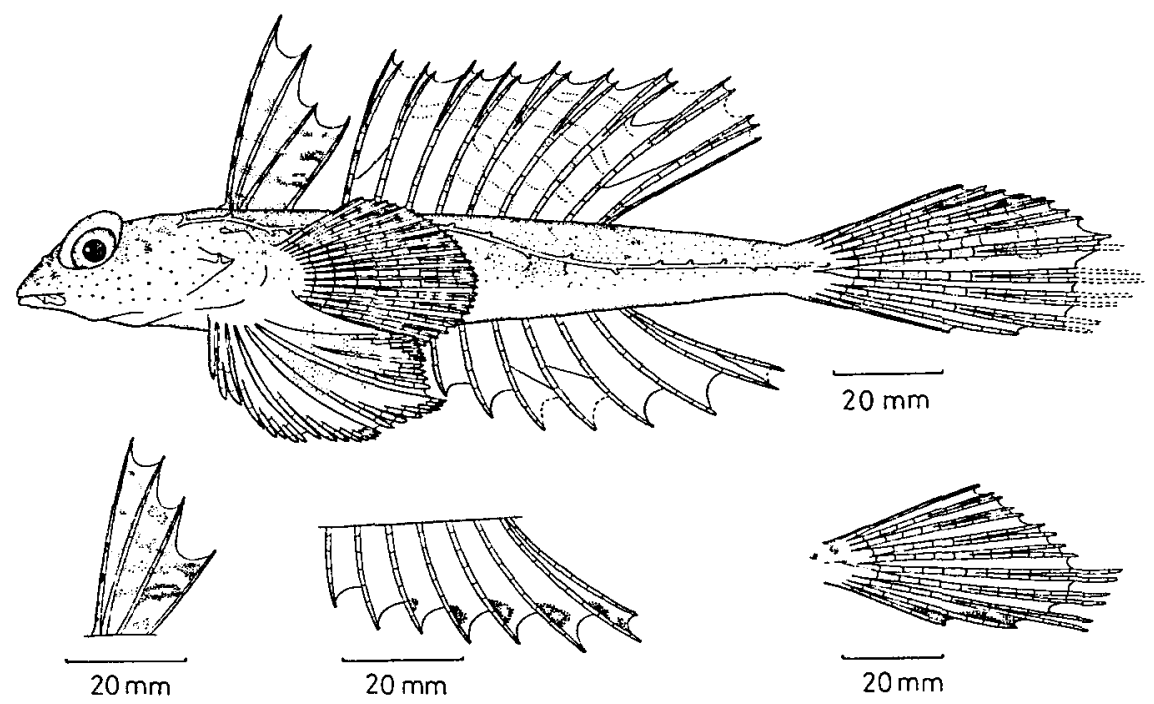

Fig. 5. Foetorepus kamoharai n. sp. Upper, holotype, a male, $142.3 \mathrm{~mm} \mathrm{SL}$, BSKU 7453 ; lower, first dorsal fin, anal fin and caudal fin of paratype, a male, $115.4 \mathrm{~mm}$, BSKU 50007. 
HoLotype: BSKU 7452, a male, $142.3 \mathrm{~mm}$ in standard length, Mimase, Kochi Pref., Oct. 5, 1956.

Paratype: BSKU 50007, a male, $115.4 \mathrm{~mm}$, Mimase, Kochi Pref., Feb. 20, 1965.

Diagnosis: This species is easily distinguished from other species of Foetorepus by its high, first dorsal fin with four longitudinal dark bands.

Description: D. IV, 9: A. 7; $\mathrm{P}_{1}$. i+20-21; $\mathrm{P}_{2}$. I, 5; G. $\mathrm{i}+7+\mathrm{ii}$.

Preopercular spine with upward process on inner side. Gill-opening a little behind beginning of 1st dorsal fin. Lateral line reaching base of caudal fin; posterior half with some upward and downward very short branches. Infraorbital canal extending to ventroposterior edge of eye, opened with a pore.

First dorsal fin moderately high; no dorsal spine elongate. First dorsal ray slightly longer than the second.

Pectoral fin reaching 5 th anal ray. Pelvic fin reaching 1 st anal ray. Caudal fin round.

Color in $10 \%$ formalin. Body brown with many small white circles above, white below. First dorsal fin with 4 longitudinal dark bands. Second dorsal fin with some oblique undulating white bands. Pectoral fin with some small dark marks at upper origin. Pelvic fin with cloud-like dark mark. Posterior lower margin of anal fin with dark marks. Upper half of caudal fin with some transverse white lines; lower margin with dark marks.

Remarks: This new species is closely related to Foetorepus altivelis and $F$. delandi in its general physiognomy, but differs in having a high first dorsal fin with 4 longitudinal dark bands and some upward and downward very short branches on the posterior half of lateral line.

Kamohara (1951) recorded a male specimen (BSKU 7452) of this species and identified it with Callionymus corallinus Gilbert. His specimen differs from C. corallinus in having bifurcate dorsal rays and no antrorse process at the base of the preopercular spine; therefore, it was a misidentification. My study shows that his specimen is new to science. The specific name, "kamoharai" is derived from the name of Dr. Toshiji Kamohara who first found and recorded this species. The Japanese name, Amimenodokusari, given by him, has not been changed.

Fricke (1981a) mistakenly identified this species with Synchiropus phasis (=Foetorepus phasis in Nakabo, 1982) judging from the figure given by Kamohara (1951), because $F$. phasis differs from this species in having very narrow membrane between the pelvic fin and the middle part of pectoral base, tricuspid preopercular spine, darker first dorsal fin and smaller body.

\section{Foetorepus delandi (Fowler)}

(New Japanese name: Ruson-beni-teguri)

(Fig. 6)

Synchiropus delandi Fowler, 1943: 81, fig. 20 (type locality: Mabul Isl., Sibuko Bay, Borneo and 


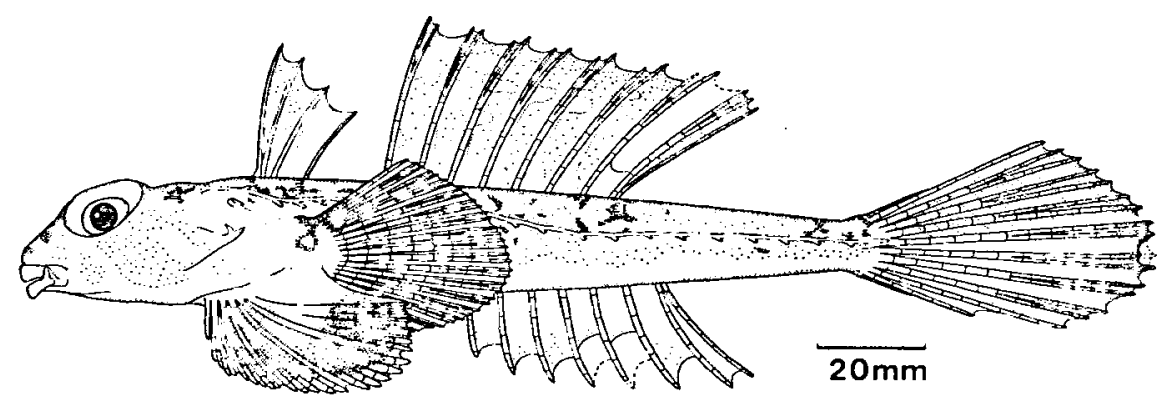

Fig. 6. Foetorepus delandi (Fowler). A female, 152.9 mm SL, BSKU 30012.

vicinity).

Synchiropus (Synchiropus) delandi: Fricke, 1981a: 65, fig. 18 (redescription of the holotype).

Foetorepus delandi: Nakabo, 1982: 79 (listed).

Materials examined: NSMT-P 21030, a female, $131.4 \mathrm{~mm}$ in standard length, Mimase, Mar. 12-14, 1955. FAKU 25516, 25519, 2 females, 89.7-143.4 mm, Miya, Aichi Pref., Jan. 10, 1956. BSKU 30011-30013, 3 females, 152.3-156.8 mm, off Okitsu, Tosa Bay, at 300-350 m depth, Apr. 26, 1980. BSKU 50005, a female, $143.6 \mathrm{~mm}$, Mimase, Apr. 10, 1980.

Description: D. IV, 8; A. 7; $\mathrm{P}_{1}$. i+20-21; $\mathrm{P}_{2}$. I, 5; C. i+7+ii.

Preopercular spine with upward process on inner side. Gill-opening before beginning of 1st dorsal fin. Lateral line reaching base of caudal fin; infraorbital canal extending to ventroposterior edge of eye, opened with a pore.

First dorsal fin small, no dorsal spine elongate. Pectoral fin reaching 2nd anal ray. Pelvic fin not reaching 1 st anal ray. Caudal fin rounded.

Color in life. Body reddish with some marbled dark olive marks above, white below. First dorsal fin orange-yellow. Second dorsal fin yellow with reddish distal margin; longitudinal white line on upper part, some transverse white lines on lower part. Pectoral fin reddish with olive-brown mark near upper origin. Pelvic fin reddish, posterior half dark. Lower half of anal fin reddish. Upper half of caudal fin yellow with some oblique white lines, distal margin reddish.

Remarks: This is the second recording of this species and is new to Japan. Male specimens have yet to be collected from Japanese waters.

Foetorepus delandi is very like $F$. altivelis, but differs in having a small first dorsal fin and no elongate dorsal spine.

\section{4) Genus Neosynchiropus Nalbant, 1980}

Neosynchiropus Nalbant, 1980, Trav. Mus. Hist. Nat. "Grigorie Antipa”, Bucuresti, 20(1), p. 349 (type species by original designation: Neosynchiropus bacescui Nalbant).

Neosynchiropus Nakabo, 1982, Publ. Seto Mar. Biol. Lab., 27(1/3), p. 92 (type species by original designation: Callionymus ocellatus Pallas).

Description: D. IV, 8; A. 7; $\mathrm{P}_{1}$. i+17-21, ii+17-19, iii+18; $\mathrm{P}_{2} . \mathrm{I}, 5 ; \mathrm{C}$. i+7+ii. 
Body cylindrical. Eye moderately large. Gill-opening a little behind middle between posterior edge of eye and upper origin of the pectoral fin. Tip of snout slightly anterior to tip of upper jaw. Preopercular spine with no antrorse process at base, and 1-2 upward processes on inner side; its posterior end pointed (in N. ijimai, with an antrorse process at base, and in $N$. sechellensis, with 2 small antrose ones). Infraorbital canal not extending below eye. Postocular commissure not connected to preoperculomandibular canal. Lateral line reaching tip of median caudal ray; the line of opposite side not connected by a transverse branch on dorsal surface of caudal peduncle.

First dorsal fin larger and more colorful than in the female, beginning behind the gill-opening. Tip of each dorsal ray bifurcate. Pectoral fin rounded. Caudal fin rounded.

Remarks: Neosynchiropus Nakabo, 1982 is a synonym for Neosynchiropus Nalbant, 1980. Nalbant (1980) described Neosynchiropus on the basis of a single specimen of Neosynchiropus bacescui, because it has a peculiar large and rounded vesicle on each side of body. But, this large vesicle is probably due to abnormality, because it is not regarded as a stable character showing the generic attribute; except for the large vesicle, the holotype of $N$. bacescui has almost the same characters as the species belonging to Neosynchiropus of Nakabo (1982).

Species of this genus inhabit coral and rocky reefs, tidal pools and weedy beds around islands in Indo-West Pacific.

Key to the species of Neosynchiropus

$\mathrm{A}_{1}$ Tips of most anal rays bifurcate ..................... ocellatus (Pallas) (p. 213).

$\mathrm{A}_{2}$ Tip of each anal ray, except last one divided at base, simple.

$\mathrm{B}_{1}$ Preopercular spine with no antrorse process at base; no supraorbital cirrus N. morrisoni (Schultz) (p. 215).

$\mathrm{B}_{2}$ Preopercular spine with antrorse process at base; a pair of supraorbital cirrus present N. ijimai (Jordan and Thompson) (p. 216).

\section{Neosynchiropus ocellatus (Pallas)}

(Japanese name: Kowan-teguri)

(Fig. 7)

Callionymus ocellatus Pallas, 1770: 26, pl. 4, figs. 1-3 (type locality: Amboyna); Valenciennes, 1837: 231 (Amboyna); Günther, 1861: 150 (western parts of the east Indian Archipelago).

Synchiropus ocellatus: Jordan and Richardson, 1908: 282 (Calayan, the Philippines); Roxas and Martin, 1937: 240 (listed); Herre, 1940: 51 (Singapore reef); Fowler, 1941: 26 (Gubat Bay, Luzon); de Beaufort, 1951: 71, fig. 14 (Celebes); Kamohara, 1954: 295, fig. 15 (Takarajima, Tokara Isls.); Matsubara, 1955: 715 (key); Ochiai, 1963: 70, figs. 7-8 (Amami Isls.); Masuda et al., 1975: 261, pl. 84-H (Japan).

Synchiropus (Synchiropus) ocellatus: Fricke, 1981a: 90, figs. 28-29 (western Pacific).

Neosynchiropus ocellatus: Nakabo, 1982: 79 (listed). 


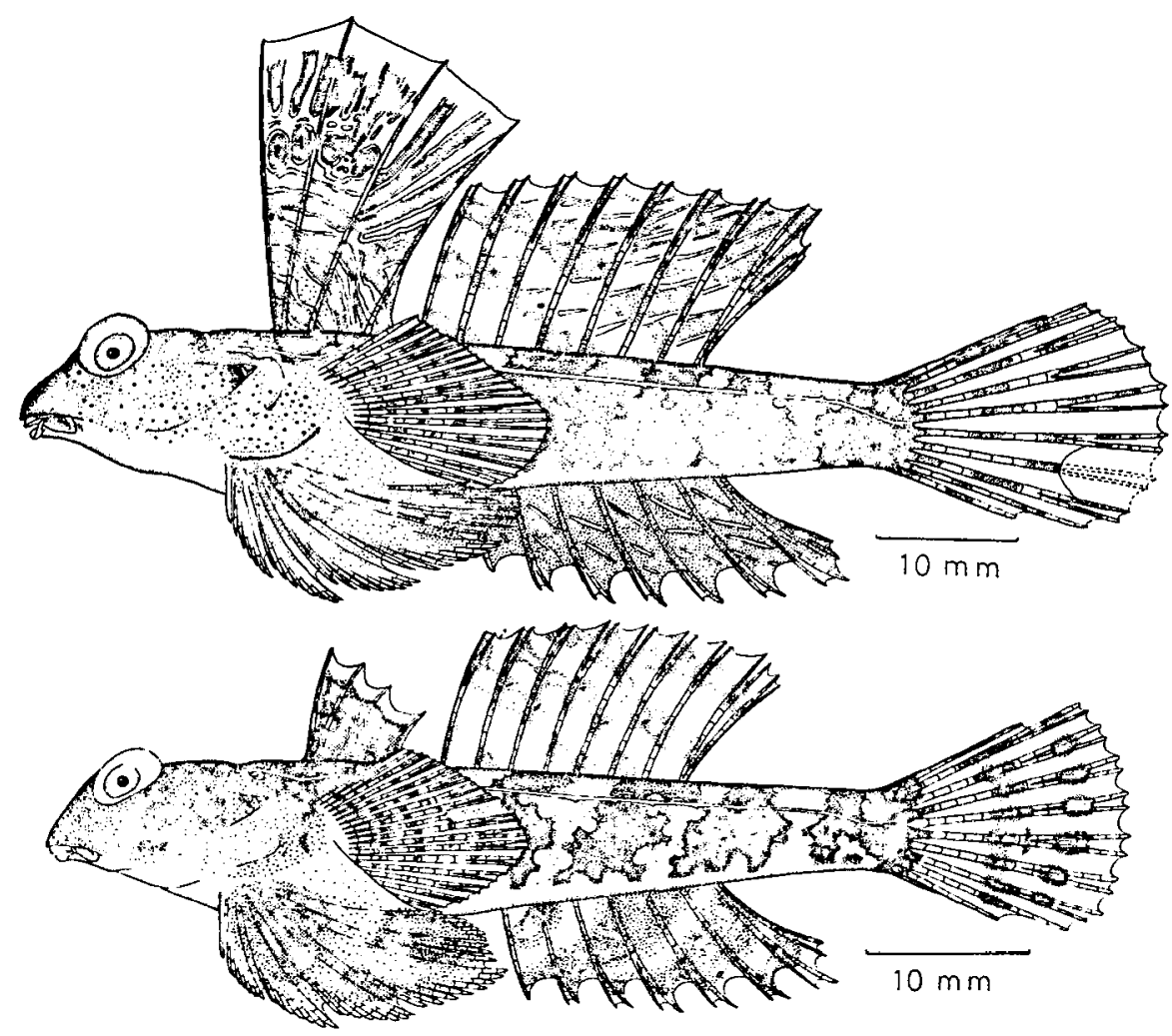

Fig. 7. Neosynchiropus ocellatus (Pallas). Upper, a male, $60.3 \mathrm{~mm} \mathrm{SL}$, FAKU 49687; lower, a female, $50.3 \mathrm{~mm}$, FAKU 49679.

Callionymus micropus Günther, 1876: 192, pl. 113, fig. C (Tonga Isl.). Synchiropus lili Jordan and Scalc, 1906b: 415, pl. 53, fig. 2 (Samoa).

Synchiropus shoe Okada and Ikeda, 1937: 90, figs. 4-5 (type locality: Ryukyu Isls.); Kamohara, 1952b: 9 (Kashiwajima).

Synchiropus rhodonotus Fowler, 1946: 196, fig. 61 (type locality: Aguni Shima, Ryukyu Isls.).

Synchiropus stellatus Smith, 1963: 559, pl. 85, figs. A, B (type locality: Pinda and Ibo, Mozambique). Synchiropus (Synchiropus) stellatus: Fricke, 1981a: 107, figs. 33-34 (western Indian Ocean).

Materials examined: FAKU 31335-31337, 2 males and a female, 37.0-52.7 $\mathrm{mm}$ in standard length, Hateruma Isl., Okinawa Pref., Aug. 4-26, 1960. FAKU 48822-48823, 2 females, 41.2-42.0 mm, Shirahama, Wakayama Pref., Oct. 22, 1973. FAKU 49370, a male, 21.7 mm, Yo, Amami Isl., Apr. 17, 1976. FAKU 4966849675, 2 males and 6 females, 39.6-69.2 mm, Urasokaru, Amami Isl., July 1, 1958. FAKU 49676-49684, 2 males and 7 females, 45.5-76.2 mm, Okinoerabu Isl., July 7-8, 1958. FAKU 49685-49687, a male and 2 females, 45.6-60.3 mm, Kikai, Amami Isl., July 6-7, 1958. FAKU 49688-49689, 2 males, 55.4-61.8 mm, Kasari, Amami Isl., July 11, 1958. FAKU 49690-49691, a male and a female, 43.2-68.5 mm, Ankyaba, Amami Isl., June 30, 1958. FAKU 49692-49693, 2 males, 45.0-45.7 mm, Ankyaba, Amami Isl., Feb. 9-12, 1959. FAKU 49704, a male, 70.2 mm, data 
unknown. FAKU 49713, 3 males, 21.6-49.9 mm, Mabuni, Okinawa Isl., July 28, 1973. FAKU 49714, a female, $41.2 \mathrm{~mm}$, Sesoko Isl., Okinawa, Aug. 27, 1974. FAKU 49715, a male, $78.7 \mathrm{~mm}$, Umino, Okinawa Isl., May 22, 1976. FAKU 49716, a female, $42.9 \mathrm{~mm}$, Kiyamu, Okinawa Isl., June 20, 1976. BSKU 27132714, a male and a female, 55.0-72.8 mm, Takarajima, May, 1953. BSKU 6910, a male, $74.5 \mathrm{~mm}$, Kashiwajima, Aug. 16, 1951. ANSP 72075-5 (paratypes of Synchiropus rhodonotus Fowler), 4 young specimens, 9.6-19.4 mm, Aguni Shima, Ryukyu Isls.

Description: D. IV, 8; A. 7; $\mathrm{P}_{1}$. ii $+17-20$ (rarely $\mathrm{i}+19-20, \mathrm{ii}+17$ ); $\mathrm{P}_{2} . \mathrm{I}$, 5; C. i+7+ii.

Preopercular spine with no antrorse process at base, an upward processes on inner side; posterior end slightly curved upward. Infraorbital canal simple, not extending below eye.

First dorsal fin high and broad in males, but not in females. Pectoral fin reaching 3rd-4th dorsal rays. Pelvic fin reaching 1st-2nd anal rays. Tip of each anal ray, except 1st, bifurcate.

Color in $10 \%$ formalin. Body marbled dark sepia-brown above, white below. First dorsal fin with 4 ocellus spots on 1st and 2nd membranes, several white margined, dark lines in males; dark brown with white distal margin in females. Second dorsal fin with some undulating, oblique dark lines; several short white lines in males, but only a few undulating oblique dark lines in females. Pectoral fin with 3-4 transverse dark lines. Pelvic fin faintly dark with 2 broad, darker marks. Anal fin dark with 2-4 oblique short white lines on each membrane in males; 4 oblique dark bands in females. Caudal fin with 2-3 transverse broad dark bands.

Remarks: Synchiropus liti Jordan and Seale is a male of $N$. ocellatus as judgcd from the coloration of its first dorsal fin and its bifurcate anal rays. Callionymus micropus Günther appears to be females of $N$. ocellatus based on the coloration of their first dorsal and anal fins and bifurcate anal rays. Synchiropus rhodonotus Fowler is a a young stage of $N$. ocellatus from my examination of the paratypes. The difference between Synchiropus stellatus and this species stated by Fricke (1981a) should be due to geographic variations.

\section{Neosynchiropus morrisoni (Schultz)}

(New Japanese name: Sesoko-teguri)

(Fig. 8)

Synchiropus morrisoni Schultz, 1960: 409, fig. 132 (type locality: Bikini Atoll).

Synchiropus (Synchiropus) morrisoni: Fricke, 1981: 98, fig. 30 (Caroline Isl.; American Samoa).

Neosynchiropus morrisoni: Nakabo, 1982: 79 (listed).

Materials examined: FAKU 48824, a female, $30.8 \mathrm{~mm}$ in standard length, Sesoko Isl., Okinawa Isl., Oct. 22, 1974. USNM 141126 (holotype), a female, 43.2 mm, Bikini Atoll, Arji Isl., Aug. 7, 1946. 


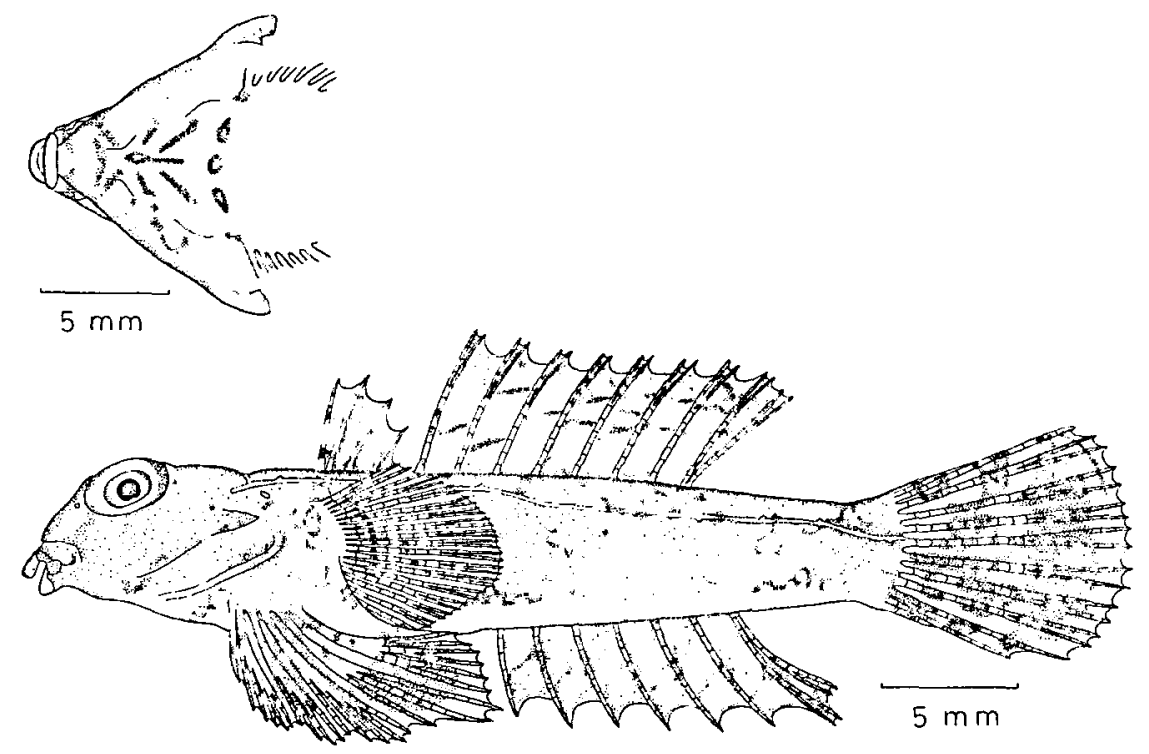

Fig. 8. Neosynchiropus morrisoni (Schultz). Upper, ventral view of the head of a female, $30.8 \mathrm{~mm}$ SL, FAKU 48824; lower, lateral view of a female, FAKU 48824.

Description of Japanese specimen: D. IV, 8; A. 7; $\mathrm{P}_{1}$. iii $+18 ; \mathrm{P}_{2}$. I, 5 ; C. $\mathrm{i}+7+\mathrm{ii}$.

Preopercular spine with no antrorse process at base, two upward processes on inner side. Infraorbital canal simple, and not extending below eye.

First dorsal fin short. Pectoral fin reaching lst anal ray. Pelvic fin reaching 1st anal ray. Tip of each anal ray, except last one divided at base, simple.

Color in 10\% formalin. Body marbled dark sepia-brown above, white below. Ventral surface of head with many dark marks. First dorsal fin dark except 1st membrane. Second dorsal fin with several longitudinal short dark lines. Pectoral fin with two transverse dark lines; one long, one short. Pelvic fin marbled brown. Anal fin with 6 oblique dark bands. Caudal fin marbled brown.

REMARKs: This species is new to Japan. The color pattern of the anal fin of the holotype shows 6 oblique dark bands like those of the Japanese specimen. The fourth membrane of the lst dorsal fin is absent in the figure of the holotype, but the holotype, USNM 141126, has it. The Japanese specimen compares well with the holotype, but the latter has a higher lst dorsal fin. This difference seems to be due to the stage of growth not to a basic distinction between them.

\section{Neosynchiropus ijimai (Jordan and Thompson)}

(Japanese name: Yamadori or Hana-numeri)

(Fig. 9)

Synchiropus ijimae Jordan and Thompson, 1914: 295, pl. 36, fig. 1 (type locality: Misaki, Kanagawa Pref., Japan). 


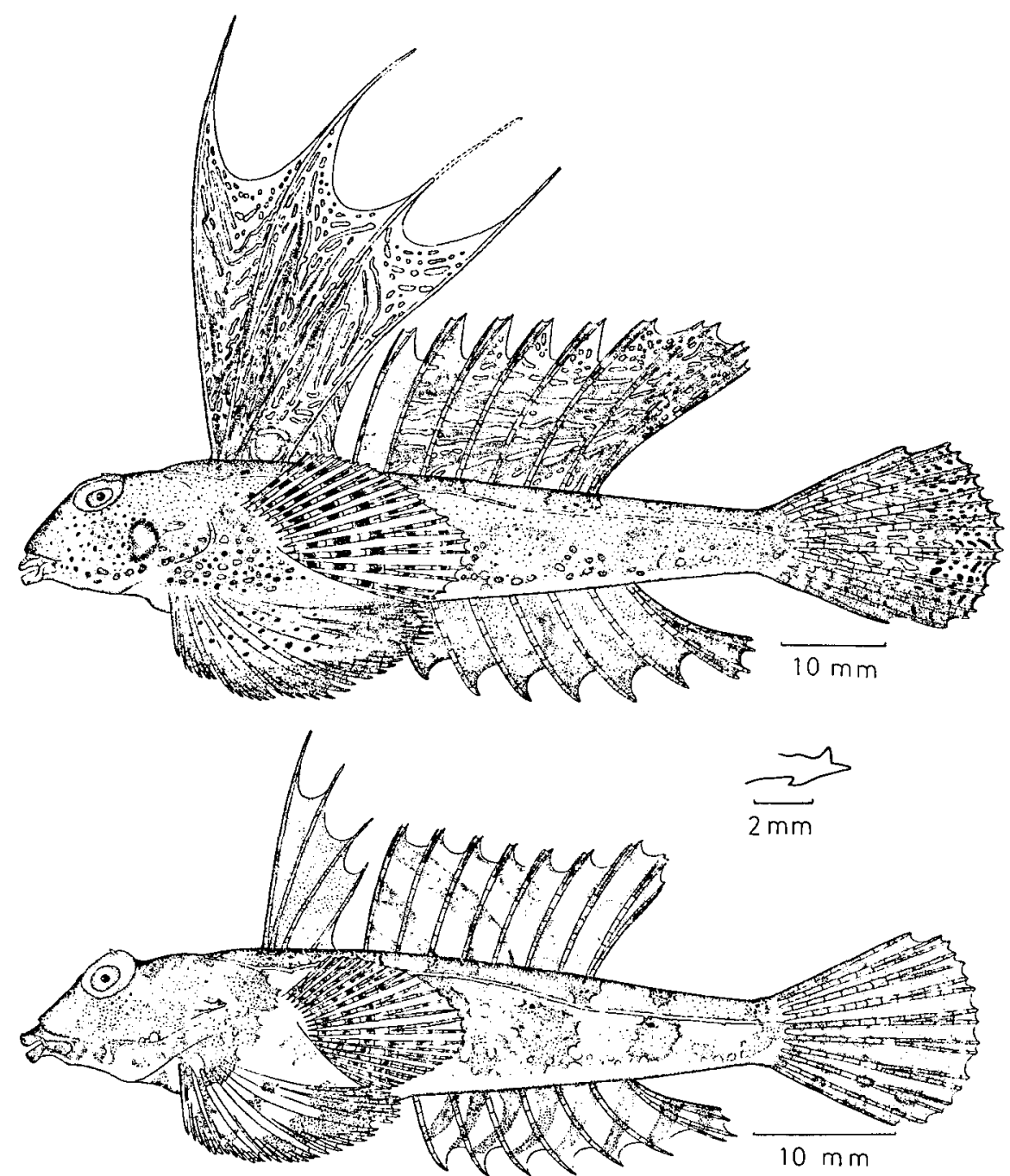

Fig. 9. Neosynchiropus ijimai (Jordan and Thompson). Upper, a male, $72.0 \mathrm{~mm} \mathrm{SL}$, FAKU 48820; middle, preopercular spine, $67.4 \mathrm{~mm}$, FAKU 48819; lower, a female, $52.5 \mathrm{~mm}$, FAKU 48821.

Synchiropus ijimai: Matsubara, 1955: 715 (key); Ueno, 1971: 83 (northern Shakotan Peninsula, Hokkaido).

Synchiropus (Synchiropus) ijimai: Fricke, 1981a: 88 (reference).

Neosynchiropus ijimai: Nakabo, 1982: 79 (listed).

Synchiropus lineolatus (not of Valenciennes): Tanaka, 1928: 821, pl. 174, fig. 479 (Tokyo market); Matsubara, 1955: 716 (key); Masuda et al., 1975: 261, pl. 84-I (Japan).

Materials examined: FAKU 48819-48820, 2 males, 67.4-72.0 mm in standard length, Kuranotani, Oki Isls., June 8, 1973. FAKU 48821, a female, $52.5 \mathrm{~mm}$, Kuranotani, Oki Isls., July 25, 1973. ZUMT 7297, a male, $76.9 \mathrm{~mm}$, Tokyo market. ZUMT 43206-43207, 2 males, 75.0-77.3 mm, near Tokyo. MSM 76-404, 405, 2 males, 48.0-61.3 mm, Zostera bed, Osezaki, Suruga Bay, Dec. 9, 1976. MSM 77- 
331, a female, $53.4 \mathrm{~mm}$, Zostera bed, Osezaki, Suruga Bay, May 18, 1977.

Description: D. IV, 8; A. 7; $\mathrm{P}_{1}$. i $+17-21$ (rarely 19); $\mathrm{P}_{2}$. I, 5; C. i+7+ii.

Short cirrus on dorsoposterior edge of eye. Preopercular spine with an antrorse process at base, an upward process on inner side. Infraorbital canal simple, and not extending below eye.

First dorsal fin high and broad in males, moderately high in females. Pectoral fin reaching 2 nd or 3 rd anal rays. Pelvic fin reaching lst anal ray in males, but not in females. Tip of each anal ray, except last one divided at base, simple.

Color in $10 \%$ formalin. Body marbled dark sepia-brown above, white below. One large dark mark and many small dark spots on cheek in males, but not in females. Many small gray spots on area after preopercular spine and lower part of lateral side of body in males, but not in females. First dorsal fin dark with many short and long white lines in males, but dark with several white marks in females. Second dorsal fin with several undulating oblique dark bands and short white lines in males, but with only several oblique dark bands in females. Pectoral fin with many dark spots. Pelvic fin dark with many small darker spots in males, but marbled brown in females. Anal fin dark in males; with 8 oblique dark bands in females. Caudal fin dark with many short white lines at middle, many dark spots near distal margin in males; marbled brown in females.

Remarks: Tanaka (1928) reported Synchiropus lineolatus (Valenciennes) from a Tokyo market. His specimen (ZUMT 7297) rightly belongs to Neosynchiropus ijimai; he mistakenly identified $N$. ijimai with $S$. lineolatus.

$N$. ijimai differs from the other species of Neosynchiropus in having an antrorse process at the base of the preopercular spine and a pair of supraorbital cirri.

$N$. ijimai is distributed only along the northern coast of Honshu Isl., Japan.

Fricke (1981a) mistakenly noted in his key that the lateral lines of sides of body are interconnected across caudal peduncle.

\section{5) Genus Pterosynchiropus Nakabo, 1982}

\section{Pterosynchiropus splendidus (Herre)}

(Japanese name: Nishiki-teguri)

(Fig. I0)

Callionymus splendidus Herre, 1927: 416, pl. 2 (type locality: Bungau, the Philippines).

Synchiropus splendidus: Whitley, 1928: 222, pl. 17, fig. 1 a b (Hayman Island reef, Whitsunday Group, Queensland); Fowler, 1941: 26 (Biri Channel); de Beaufort, 1951: 75 (reference); Marshall, 1965: 382, pl. 54 (Great Barrier Reef); Yoshino, 1976: 33, figs. 1-2 (Sesoko Isl., Okinawa Isl.).

Synchiropus (Synchiropus) splendidius: Fricke, 1981: 127 (western Pacific).

Pterosynchiropus splendidus: Nakabo, 1982: 80 (listed).

Synchiropus leopoldi Giltay, 1933: 83, figs. 23, 24 (type locality: Banda).

Materials examined: URB 78-0142, $34.4 \mathrm{~mm}$ in standard length, Sesoko Isl., Okinawa, May 28, 1975. FAKU 49804, 49805, 33.6-40.4 mm, the Philippines, Apr. 


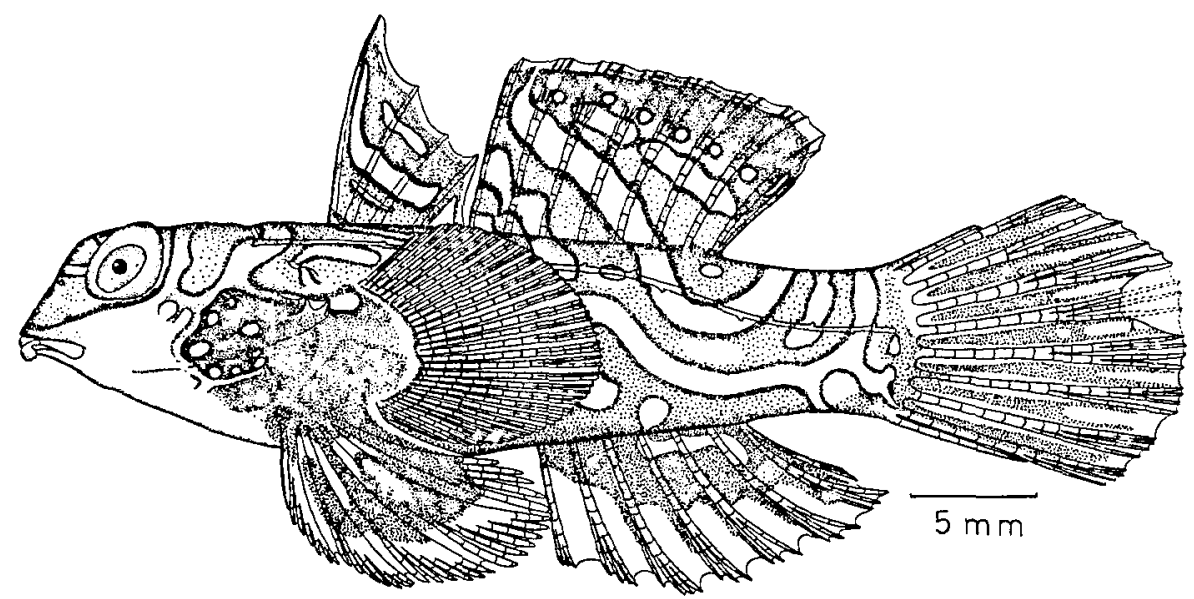

Fig. 10. Pterosynchiropus splendidus (Herre). URB 78-0142, $34.4 \mathrm{~mm}$ SL.

1978.

Description: D. IV, 8; A. 7; $\mathrm{P}_{1}$. i $+30 ; \mathrm{P}_{2}$. I, 5; G. $\mathrm{i}+8+\mathrm{i}$.

Preopercular spine with no antrorse process at base, 2-3 upward processes on inner side; posterior end curved upward. Infraorbital canal simple and not extending below eye. Caudal peduncle high and compressed.

First dorsal fin small. Pectoral fin broad, reaching 4th dorsal ray. Pelvic fin reaching lst anal ray, connected by very narrow membrane to lowermost part of pectoral fin base.

Color in 10\% formalin. Body, first and second dorsal fins dark brown with several broad, irregular dark-margined white bands. Pectoral fin transparent. Pelvic fin dark with white margin. Anal fin dark with white margin. Caudal fin dark on each membrane.

Remarks: Synchiropus leopoldi is a synonym for Pterosynchiropus splendidus as judged from the figure of the original description.

6) Genus Paradiplogrammus Nakabo, 1982

\section{Paradiplogrammus enneactis calliste (Jordan and Fowler)}

(Japanese name: Hanabi-numeri)

(Fig. 11)

Callionymus calliste Jordan and Fowler, 1903: 954, fig. 8 (type locality: Misaki, Japan); Jordan, Tanaka and Snyder, 1913: 377, fig. 337 (listed); Izuka and Matsuura, 1920: 108 (Isezu); Kuroda, 1931: 124 (Suruga Bay); Böhlke, 1953: 103 (listed); Ochiai et al., 1955: 104 (reference); Mori, 1956: 22 (Kasumi, Hyogo Pref.); Arai and Abe, 1970: 91 (Tsushima); Kimura and Suzuki, 1980: 37 (Ago Bay).

Paradiplogrammus calliste: Nakabo, 1982: 80 (listed).

Callionymus enneactis (not of Bleeker), Kuroda, 1951: 386 (Suruga Bay).

Callionymus phasis (not of Günther): Ochiai et al., 1955: 104, fig. 3 (Yawatahama). 


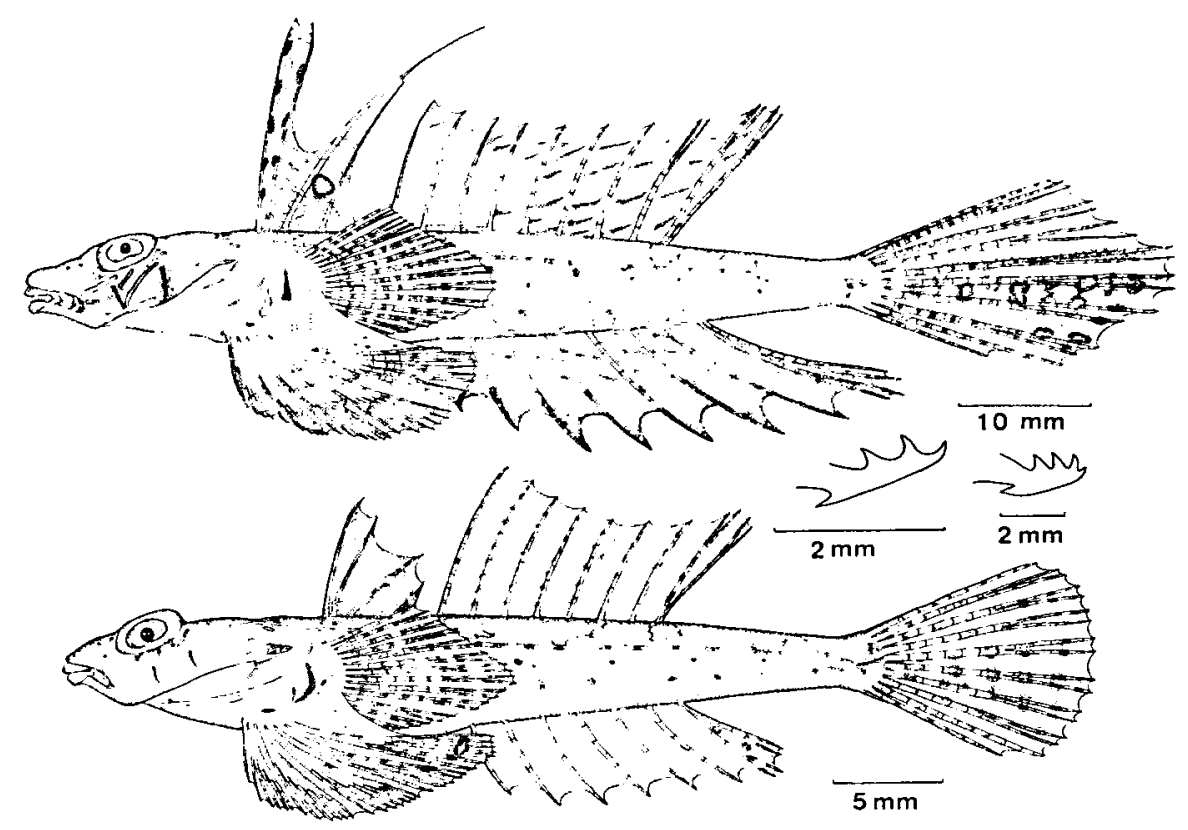

Fig. 11. Paradipolgrammus enneactis calliste (Jordan and Fowler). Upper, a male, $62.5 \mathrm{~mm} \mathrm{SL}$, FAKU 49365; middle, preopercular spines of a young, $17.9 \mathrm{~mm}$, FAKU 48845 (left) and an adult, $58.8 \mathrm{~mm}$, FAKU 48829 (right); lower, a female, $35.8 \mathrm{~mm}$, FAKU 49475b.

Materials examined: CAS-SU 7188 (holotype), a male, $66.8 \mathrm{~mm}$ in standard length, Misaki, Summer, 1900. ZUMT 20956, 20957, 2 males, 61.4-63.3 mm, Misaki, July 27-28, 1904. ZUMT 27415-27421, 7 males, 61.0-64.2 mm, Koajiro, July 27-28, 1904. MSM 77-91, 77-332 336, 5 males and a female, 33.7-63.5 mm, Zostera bed at Osezaki, Suruga Bay. YCM-P 1478, a female, $36.1 \mathrm{~mm}$, Kohama Isl., Okinawa, Apr. 23, 1974. YCM-P 1535, a male, 43.6 mm, Iriomote Isl., Apr. 27, 1974. YGM-P 4336, a male, 47.2 mm, Kabira Bay, Apr. 25, 1974. BSKU 12652, 12653, 12655, 2 males and a female, 25.1-60.1 mm, Usa, Kochi Pref., July 22, 1967. FAKU 24847, a female, $42.5 \mathrm{~mm}$, Yawatahama, Sep. 10, 1954. FAKU 48825, 48827-48846, 11 males and 9 females, 17.9-58.8 mm, Shijiki Bay, Hirado Isl., May 17-Dec. 17, 1975. FAKU 48847, 48848, 32.9-45.8 mm, Yuya Bay, Yamaguchi Pref., Apr. 25-Aug. 6, 1975. FAKU 49096-49098, 49138, 2 males and 2 females, 27.4-40.2 mm, Shijiki Bay, Jan. 24-Feb. 15, 1976. FAKU 49365, 49366, 2 males, 62.8-65.6 mm, Shirahama, Wakayama Pref., May 17, 1974. FAKU 49370, a female, $41.2 \mathrm{~mm}$, Shirahama, Apr. 30, 1973. FAKU 49475, 49476, 49553, 49554, 6 males and 5 females, 21.3-45.6 mm, Shirahama, Dec. 3-17, 1976. FAKU 49557, 2 males and a female, 42.0-59.5 mm, Shijiki Bay, June 18, 1976.

Description: D. IV, 8 (rarely 7 or 9); A. 7 (rarely 8); $P_{1}$. i+15-20, ii $+15-17$; $\mathrm{P}_{2}$. I, 5; C. i+7+ii.

Preopercular spine with an antrorse process at base, 2-3 upward processes on inner side; posterior end strongly curved upward. Infraorbital canal simple, not extending below eye. 
In males, first dorsal fin high; 3rd dorsal spine elongate and filamentous; 2nd membrane strongly emarginated. In females, first dorsal fin small. Pectoral fin reaching 2 nd anal ray. Pelvic fin reaching 1st-2nd anal ray. Caudal fin longer in males than in females.

Color in $10 \%$ formalin. Body marbled brown above, white with many small dark spots behind origin of anal fin in males, but only white in females. Two transverse dark lines on cheek; some oblique, dark-margined white lines in males, but not in females. Transverse oblong dark mark before pectoral base. First dorsal fin in males faintly dark with many small dark spots on 1st membrane, some undulating white lines and black blotch between 3rd and 4th species; in females 1st membrane faintly dark, other part blackish-brown. Second dorsal fin transparent with several short oblique dark lines in males; with some faint dark marks in females. Pectoral fin with many small dark spots. Pelvic fin dark with several white lines in males; faintly dark with some darker spots in females. Anal fin with many oblique dark lines, distal margin dark in males; transparent with 2-3 small dark spots on posteriormost part in females. Caudal fin with many small dark marks on middle part.

Remarks: Nakabo (1982) regarded Paradiplogrammus calliste as the separate species from Paradiplogrammus enneactis. However, recently, I could examine the specimens identified as $P$. enneactis collected from Singapore, the type locality. As compared $P$. calliste from Japan with $P$. enneactis from Singapore, the differences between them should be treated as those of subspecific level; they differ each other a little in colorations of first dorsal and caudal fins and in the number of processes on the preopercular spine. I am going to describe and discuss more details about the subspecific problem of $P$. enneactis in the revision of the genus in near future.

$P$.e. calliste is distributed in southern coast of Japan and Yaeyama Isls. This inhabits Zostera beds or sandy rubble bottom in shallow waters.

7) Genus Diplogrammus Gill, 1865

\section{Diplogrammus xenicus (Jordan and Thompson) \\ (Japanese name: Kobu-numeri)}

(Fig. 12)

Calymmichthys xenicus Jordan and Thompson, 1914: 296, pl. 36, fig. 2 (type locality: Sagami Bay, Japan); Kuroda, 1951: 386 (Suruga Bay); Matsubara, 1955: 711 (key).

Diplogrammus xenicus: Masuda et al., 1975: 260, pl. 84-A (Japan); Nakabo, 1982: 80 (listed).

Diplogrammus goramensis (not of Bleeker): Ochiai, 1963: 64, figs. 1-6 (Amami Isls.); Masuda et al., 1975: 260, pl. 84-B (Japan).

Materials examined: FAKU 49477-49479, 3 females, 15.2-34.7 mm in standard length, Shirahama, Wakayama Pref., Nov.-Dec., 1976. FAKU 49694, 49695, 49697, 49698, 2 males and 2 females, 32.1-75.3 mm, Ankyaba, Amami Isl., June 30, 1958. FAKU 49699, 49700, 49702, 49703, 3 males and a female, 45.7-65.7 mm, Ankyaba, Feb. 9-12, 1959. FAKU 49717-49720, 2 males and 2 females, 47.0-58.3 


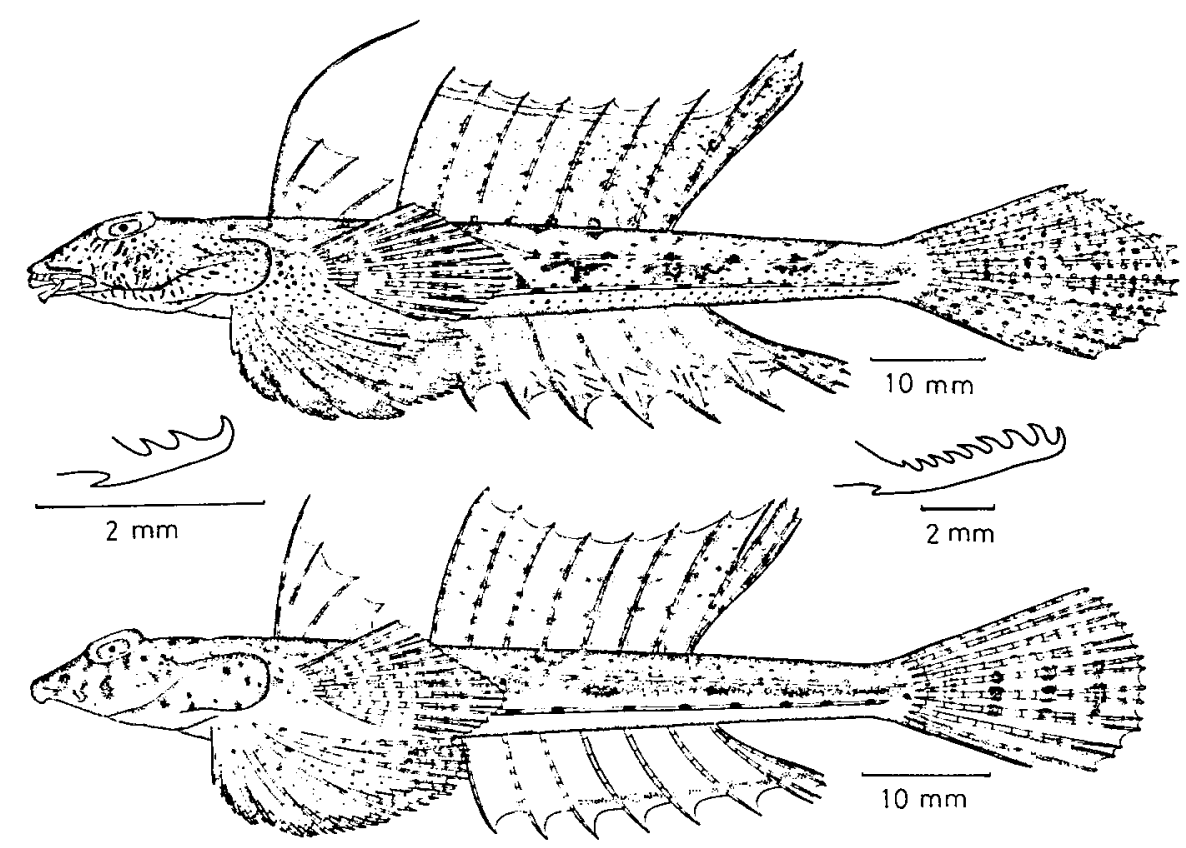

Fig. 12. Diplogrammus xenicus (Jordan and Thompson). Upper, a male, $75.3 \mathrm{~mm}$ SL, FAKU 49694; middle, preopercular spines of a young, $15.2 \mathrm{~mm}$, FAKU 49477 (left) and an adult, $55.5 \mathrm{~mm}$, FAKU 49698 (right); lower, a female, $65.7 \mathrm{~mm}$, FAKU 49697.

mm, Sesoko Isl., Okinawa, May 27, 1975. FAKU 50018-50022, 4 males and a female, 69.5-79.7 mm, off Ito, Izu Peninsula, Sagami Bay, Shizuoka Pref. at $15 \mathrm{~m}$ depth, Jan. 15, 1979. FAKU 50196, a male, 85.2 mm, off Ito, Izu Peninsula, Sagami Bay, Shizuoka Pref., Feb. 20, 1980. YCM-P 1763 a male, 53.6 mm, Kabira Bay, Ishigaki Isl., Mar. 1, 1975.

Description: D. IV, 8 (rarely 9); A. 7 (rarely 8); $\mathrm{P}_{1}$. ii+15-17 (rarely $\mathrm{i}+$ 16); $\mathrm{P}_{2}$. I, 5; C. i $+7+$ ii.

Gill-opening midway between dorsoposterior edge of eye and upper origin of pectoral fin, opercular flap below it. Preopercular spine long with an antrorse process at base, 3-9 processes (less in younger specimens) on inner side; posterior end strongly curved upward. Longitudinal dermal fold on lower part of lateral side of body. Lateral line nearly reaching tip of median caudal ray. Infraorbital canal bifurcate, not extending below eye.

First dorsal spine elongate in males, but not in females. Second dorsal fin emarginated. Pectoral fin double truncate, reaching 3rd-4th anal ray. Pelvic fin reaching 1st anal ray. Caudal fin rounded.

Color in 10\% formalin. Body marbled brown above, ventral body surface dark with many small darker spots behind origin of anal fin in males, but white in females. Many small dark spots on cheek in males from Amami Isl., but many vermicular dark marks in males from Izu Peninsula; not in females from both areas. Dermal fold with many dark spots. First dorsal fin dark with some oblique darker lines in 
males, dark with some white spóts in females. Second dorsal fin dark with 3-4 rows of dark marks and dark margined white line near distal margin in males, transparent with several dark marks in females. Upper half of pectoral fin with many dark marks. Pelvic fin dark with many small darker spots in males, faintly dark with many dark spots in females. Anal fin dark with some oblique, darker short lines near distal margin in males, but only transparent with a longitudinal dark line near distal margin in females. In males, upper half of caudal fin with many white and dark spots and dark margined white line near its distal margin, lower half dark with many darker spots; in females upper part almost transparent, middle part with some dark spots, lower part dark.

Remarks: Diplogrammus xenicus is closely related to Diplogrammus goramensis Bleeker in general physiognomy, but differs in having a bifurcate infraorbital canal; syntypes of $D$. goramensis (RMNH 4812, Goram Isl., leg. W.F.C. van Helsdingen, 1857, 47 and $50 \mathrm{~mm}$ in standard length) have a simple infraorbital canal (M.S. Hoogmoed's personal communication).

Specimens reported as $D$. goramensis from Amami Isl. by Ochiai (1963) should belong to $D$. xenicus, because they do not markedly differ from specimens from Izu Peninsula, Sagami Bay, near the type locality of $D$. xenicus, in the preopercular spine length, pectoral fin length and number of caudal fin rays which were recognized as differences between these two by Ochiai (1963). Furthermore, these two kinds of specimens share the same type of infraorbital canal. Differences between these two in coloration of male's cheek should be due to the geographic variations. Specimens from Okinawa Isl. reported as $D$. goramensis by Yoshino et al. (1975) are also $D$. xenicus. D. goramensis is not distributed in Japanese waters.

Ochiai (1963) mistakenly identified a juvenile specimen, $21.5 \mathrm{~mm}$ in standard length, from Amami Isl., with $D$. goramensis ( $D$. xenicus in this paper), because it has neither an antrose process at the base of preopercular spine nor a longitudinal dermal fold on the lower side of body which are shown even in a specimen, $15.2 \mathrm{~mm}$, of $D$. xenicus from Shirahama, Wakayama Prefecture. Unfortunately, this juvenile specimen reported by Ochiai (1963) has been lost in the laboratory, so we cannot identify it. It must be a species belonging to the genus Minysynchiropus Nakabo, 1982, judging from the figure.

8) Genus Dactylopus Gill, 1860

\section{Dactylopus dactylopus (Valenciennes)}

(Japanese name: Ippon-teguri)

(Fig. 13)

Callionymus dactylopts Valenciennes, 1837: 232 (type locality: unknown).

Dactylopus dactylopus: Jordan and Seale, 1907: 46, fig. 18 (Cavite, the Philippines): Ogilby, 1910: 46 (Molucca Seas to South-Eastern Queensland); McCulloch, 1915: 149, pl. 28 (Shark Bay, Western Australia); Suvatti, 1936: 160 (Canthaburi River, Laem Sing); Roxas and Martin, 1937: 241 (listed); 


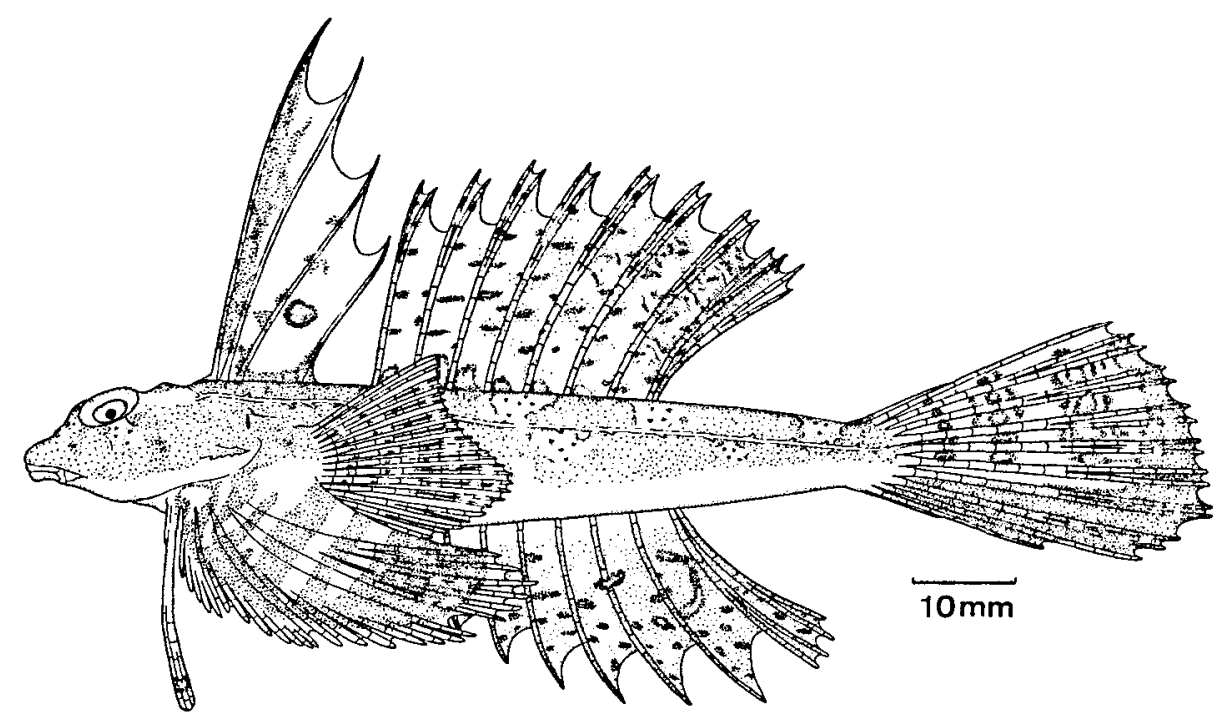

Fig. 13. Dactylopus dactylopus (Valenciennes). A female, $80.2 \mathrm{~mm}$ SL, FAKU 49807.

Fowler, 1938: 223 (Singapore); de Beaufort, 1951 : 80, fig. 16 (Celebes; Potti; Buru; Ceram; Ambon: Nusa Laut; Kei Isls.); Chu et al., 1962: 730, fig. 591 (South China Sea); Marshall, 1965: 379, color pl. 53, pl. 51 (Queensland); Yoshino et al., 1975: 92 (Ryukyu Isls.); Nakabo, 1982: 80 (listed).

Dactylopus Bennetti Gill, 1860: 130 (reference).

Vulsus dactylopus: Günther, 1861: 151 (Amboyna); Bleeker, 1879: 105 (Singapura; Celebes; Rotti; Buro; Amboyna; Nussalaut; Ke1-major).

Materials examined: FAKU 49807, a female, $80.2 \mathrm{~mm}$ in standard length, Okinawa Isls. FAKU 49977, a female, $94.5 \mathrm{~mm}$, Panay, the Philippines, April-June, 1977.

Description: D. IV, $8 ;$ A. $7 ; \mathrm{P}_{1} . \mathrm{ii}+17 ; \mathrm{P}_{2} . \mathrm{I}, 1-4 ; \mathrm{C} . \mathrm{i}+7+\mathrm{ii}$.

Preopercular spine with several antrorse processes on outer side, some feeble upward processes on inner side. Infraorbital canal simple, not extending below eye.

Pectoral fin reaching 4th anal ray. Pelvic fin reaching 2nd anal ray. Caudal fin rounded.

Color in $10 \%$ formalin. Body marbled dark sepia-brown above, white below. First dorsal fin dark on 1st membrane with dark circle between 3rd and 4th spines. Second dorsal with many short longitudinal dark lines and cloud-like faint dark marks. Upper half of pectoral fin with many small dark spots. Near tip of separated lst pelvic ray with a dark spot. Pelvic fin dark with some white lines at base. Anal fin dark with many vermicular darker spots. Caudal fin with 3 transverse dark bands on upper half, from upper distal margin through lower half uniformly dark.

Remarks: The person who named this species has been identified incorrectly. Several taxonomists (Jordan and Seale, 1907; Suvatti, 1936; Roxas and Martin, 1937) adopted Bennett for this because Valenciennes (1837) gave his name as the original 
namer of this species. According to Valenciennes (1837), he was communicated about this species from Edouard Bennett who did not describe it. Therefore, Valenciennes should be the author's name. Yoshino et al. (1975) adopted McCulloch as the describer of this species, which I consider a mistake.

9) Genus Calliurichthys Jordan and Fowler, 1903

Calliurichthys japonicus (Houttuyn)

(Japanese name: Yome-gochi)

(Fig. 14)

Callionymus japonicus Houttuyn, 1782: 1 (type locality: Japan); Jordan and Snyder, 1900: 370 (Yokohama); Ochiai et al., 1955: 98, fig. 1 (Japan); Katayama and Fujioka, 1958: 1157 (Oshimagun, Yamaguchi Pref.); Masuda et al., 1975: 261, pl. 84-G (Japan).

Callionymus reevesii Richardson, 1844: 60, pl. 36, figs. 1-3 (type locality: China Seas);)Richardson, 1846: 210 (reference).

Callionymus longicaudatus Temminck and Schlegel, 1845: 151, pl. 78, fig. 1 (type locality: Japan); Ishikawa and Matsuura, 1897: 37 (Tokyo-market); Boeseman, 1947: 130 (review).

Callionymus longecaudatus: Gunther, 1861: 148 (China); Nyström, 1887: 36 (Japan).

Calliurichthys japonicus: Jordan and Fowler, 1903: 947, fig. 2 (Wakanoura); Smith and Pope, 1906: 493 (Urado; Yamagawa); Franz, 1910: 84 (Yokohama; Misaki); Snyder, 1912: 446 (Shimizu); Jordan, Tanaka and Snyder, 1913: 373, fig. 330 (listed); Jordan and Thompson, 1914: 294, fig. 71 (Misaki); Izuka and Matsuura, 1920: 109 (Tokyo-market); Jordan and Hubbs, 1925: 316 (Tokyomarket; Wakanoura; Kagoshima Bay; Misaki); Fowler, 1928: 422 (reference); Ui, 1929: 262 (Kishu); Kuroda, 1931: 124 (Suruga Bay); Mori and Uchida, 1934: 21 (Korea); Koike, 1936: 13 (Fukui Pref.); Kamohara, 1936a: 7 (Tosa Bay); Kamohara, 1938: 65 (Tosa Bay); Yanai, 1950: 22 (Matsue; Hamada); Kuroda, 1951 : 385 (Suruga Bay); Kamohara, 1952a: 89 (Mimase; Urado; Susaki); Matsubara, 1955: 712 (key); Mori, 1956; 22 (Hamada; Kasumi); Chu et al., 1962: 726, fig. 588 (South China Sea); Tatara et al., 1965: 105 (Seto Inland Sea and adjacent waters); Takegawa and Morino, 1970: 382
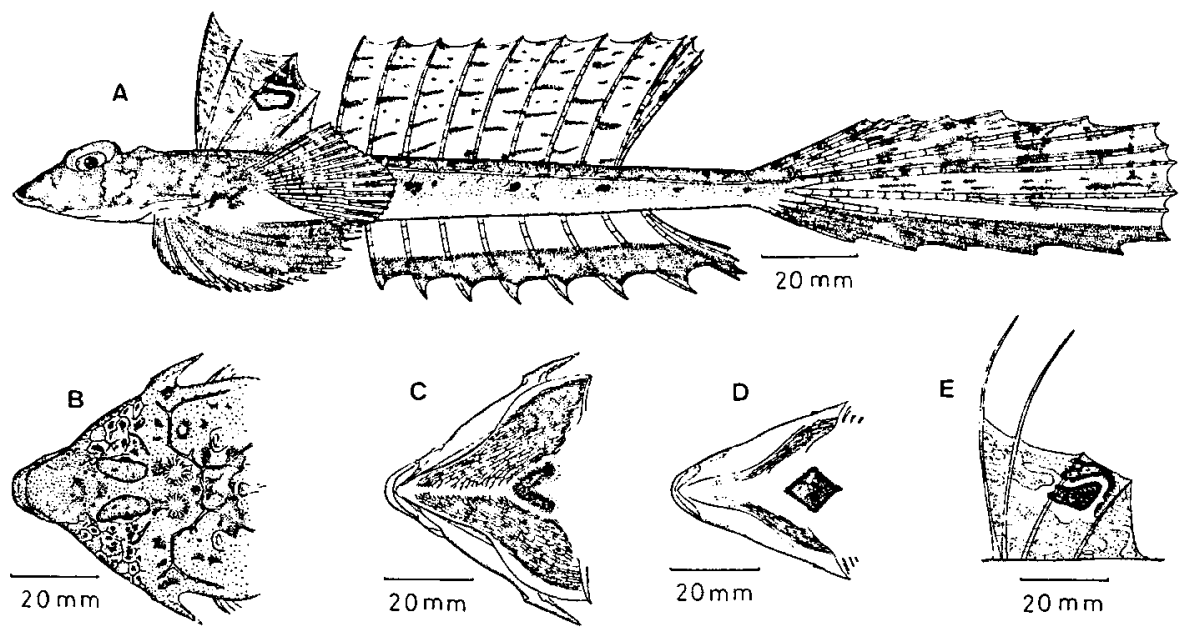

Fig. 14. Calliurichthys japonicus (Houttuyn). A, a female, $154.0 \mathrm{~mm}$ SL, FAKU 49354; B and $C$, dorsal and ventral view of the head of a male, $202.1 \mathrm{~mm}$, FAKU 48566; D, ventral view of the head of a male, $190.5 \mathrm{~mm}$, FAKU 48722; E, first dorsal fin of a male, FAKU 48566. 
(Wakasa Bay); Arai and Abe, 1970: 91 (Tsushima); Nakabo, 1982: 80 (listed).

Callionymus numeri Tanaka, 1917: 11 (type locality: Misaki); Matsubara, 1955: 712 (key).

Callionymus, Calliurichthys, japonicus: McCulloch, 1926: 196 (data unknown).

Callionymus japonicus japonicus: Johnson, 1971: 106 (Gulf of Papua).

Materials examined: FAKU 48552, 48563, 48566, a male and 2 females, 126.8-202.1 mm in standard length, Oki Isls., Shimane Pref., June 26-July 26, 1974. FAKU 48693, 48694, 48722-48728, 48809, 48869, 5 males and 6 females, 105.8190.5 mm, Mimase, Kochi Pref., Nov. 12-15, 1975. FAKU 48755, 48756, 2 males, 81.5-100.1 mm, Shijiki Bay, Nagasaki Pref., June 13, 1975. FAKU 49128-49137, 8 males and 2 females, 47.8-80.8 mm, Akaoka, Kochi Pref., Nov. 14, 1975. FAKU 49354, 49355, 2 females, 154.0-166.1 mm, Mimase, Feb. 12, 1976. FAKU 49368, a female, $97.1 \mathrm{~mm}$, Shirahama, Wakayama Pref., Mar., 1975. FAKU 49997 49998, a male and a female, 110.2-219.2 mm, Wakasa Bay, Nov. 21, 1979. FAKU 50044, 50045, 2 males, 196.0-213.0 mm, Pusan-market, Korea, Feb. 28, 1980. FAKU 50476, 50477, a male and a female, 113.2-120.0 mm, Tonking Bay, 1957.

Description: D. IV, 9; A. 8; $\mathrm{P}_{1}$. ii $+16-19 ; \mathrm{P}_{2}$. I, 5; C. i+7+ii.

Gill-opening before beginning of 1 st dorsal fin. Preopercular spine straight and elongate, 5-13 short processes on inner side. Occipital region with pair of bony tubercles. Lateral line reaching tip of median caudal ray; 4-5 separated short transverse branches on each side of dorsal area of body; T-shaped separated canal a little before commissure on dorsal surface of caudal peduncle. Infraorbital canal extending below middle part of eye with downward branch and antrorse branch near ventroposterior edge of eye. Postocular commissure connected to preoperculomandibular canal. Preoperculomandibular canal with a short downward branch at base, a long retrorse branch with 3 short downward branches above preopercular spine, and short retrorse branch below long retrorse branch.

Anterior 2 dorsal spines elongate and filamentous in males, but not in females. Pectoral fin reaching 2 nd anal ray. Pelvic fin nearly reaching 1st anal ray. Caudal fin very elongate, longer in males than in females; in some male specimens about as long as standard length.

Color in $10 \%$ formalin. Body marbled dark sepia-brown above, white below. Ventral surface of head with a large dark blotch and many dark reticulatus marks in males, but not in females. First dorsal fin dark with many undulating white lines, a white margined black mark between 3rd and 4th spines. Second dorsal fin with many short longitudinal dark lines and small dark spots. Upper half of pectoral fin with many small dark spots. Pelvic fin dark. Lower half of anal fin black. Upper half of caudal fin with many transverse dark bands and many dark spots, lower half black.

Remarks: A specimen from the Indo-Australian Archipelago, reported as Callionymus japonicus by de Beaufort (1951), differs from the Japanese specimens in having no retrorse branch on the upper part of the preoperculomandibular canal and a dark blotch between the 1st and 2nd dorsal spines. Therefore, these two should be separate species. The Japanese specimens are in good agreement with the original 
description by Houttuyn (1782). I do not agree with de Beaufort's statement that C. linea-thorax Fowler is a synonym for C. japonicus. These two differ in the coloration and shape of the first dorsal fin.

Munro (1955) reported C. japonicus from the coastal reefs of Ceylon. His specimen also differs somewhat from Japanese specimens in the coloration of the body and the first dorsal fin. It is questionable whether it should be identified with $C$. japonicus.

Smith (1963) described Callionymus japonicus from a female specimen taken off Durban. As his specimen has no transverse branch across the dorsal surface of the caudal peduncle, it must be a species different from $C$. japonicus.

The Callionymus longicaudatus reported from the Iranian Gulf by Blegvad (1944) differs from Japanese specimens in having 9 anal rays, in a more highly curved preopercular spine with 3-5 processes on the inner side, and in the coloration of the fins and body. This specimen should be classified as a different species, probably belonging to a different genus.

C. japonicus has been regarded to be distributed widely from the western Indian Ocean to Japan, but my study shows that it is distributed only in the South China Sea, the East China Sea, New Guinea and the waters around Japan.

10) Genus Pseudocalliurichthys Nakabo, 1982

Pseudocalliurichthys variegatus (Temminck and Schlegel)

(Japanese name: Itohiki-numeri)

(Fig. 15)

Callionymus variegatus Temminck and Schlegel, 1845: 153 (type locality: Japan); Izuka and Matsuura, 1920: 109 (Hojo, Boshiu); Boeseman, 1947: 130 (review); Ochiai et al., 1955: 101 (reference); Masuda et al., 1975: 261, pl. 84-F (Japan).

Callionymus (Calliurichthys) variegatus: Fricke, 1982: 134, fig. 5 (Nagasaki).

Calliurichthys variegatus: Jordan and Fowler, 1903: 944, fig. 3 (Nagasaki); Jordan et al., 1913: 373, fig. 331 (listed); Ui, 1929: 262 (Kishu); Matsubara, 1955: 712 (key).

Pseudocalliurichthys variegatus: Nakabo, 1982: 81 (listed).

Materials eXAmined: FRSKU-S 247, a male, $107.8 \mathrm{~mm}$ in standard length, Tsushima Isl., 1974. FAKU 48849-48852, a male and 3 females, 28.2-43.6 mm, Shijiki Bay, Nagasaki Pref., Sep. 20, 1975. FAKU 48853, a female, $20.8 \mathrm{~mm}$, Shijiki Bay, Dec. 17, 1975. FAKU 49364, a male, $85.2 \mathrm{~mm}$, Shirahama, Wakayama Pref., May 30, 1974. FAKU 49375, a female, 82.2 mm, Shirahama, Aug. 3, 1976. MSM 76-375, 376, a male and a female, 60.5-72.7 mm, Zostera bed, Osezaki, Suruga Bay, Nov. 12, 1976.

Description: D. IV, 8; A. 7 (rarely 6 ); $\mathrm{P}_{1} . \mathrm{i}+17-18 ; \mathrm{P}_{2} . \mathrm{I}, 5 ; \mathrm{C} . \mathrm{i}+7+\mathrm{ii}$ (rarely $\mathrm{i}+6+\mathrm{iii})$.

Preopercular spine straight, with 4-6 short processes on inner side. Snout very long. Lateral line nearly reaching distal end of median caudal ray. Infraorbital canal simple, not extending below eye. 

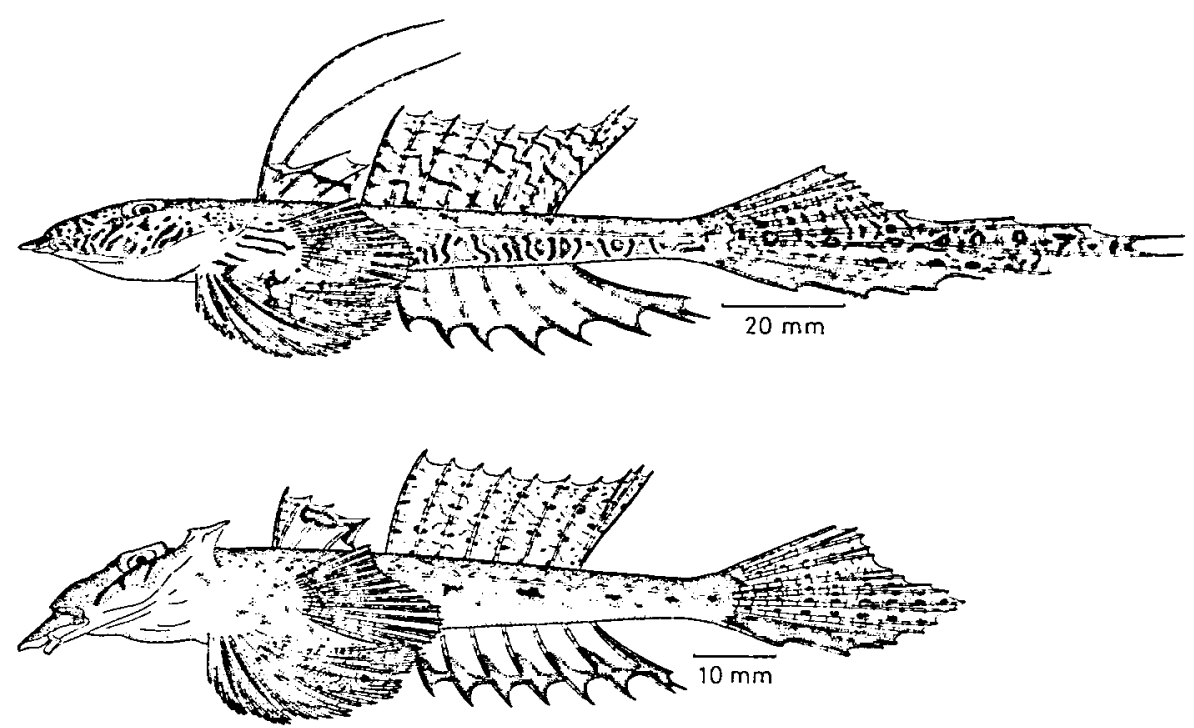

Fig. 15. Pseudocalliurichthys variegatus (Temminck and Schlegel). Upper, a male, $107.8 \mathrm{~mm}$ SL, FRSKU-S 247; lower, a female, 82.2 mm, FAKU 49375.

Anterior 2 dorsal spines elongate and filamentous in males, but not in females. Second dorsal fin slightly emarginated. Pectoral fin reaching 3 rd dorsal ray. Pelvic fin reaching lst anal ray. Caudal fin lanceolate; elongate in males, but short in females.

Color in $10 \%$ formalin. Body marbled dark brown above, white below. Many oblong, small dark spots on cheek in males; 2-3 transverse short dark lines in females. Lower part of lateral side of body with many vermicular dark spots in males, but some small dark spots on mid-axis of lateral side of body in females. In males, 1st and 2nd dorsal fins, and upper half of caudal fin with many dark and faint dark vermicular short lines. In females, 1st dorsal fin with large dark spot near distal margin; 2nd dorsal fin and upper half of caudal fin with many dark spots and faintly dark vermicular short lines. Upper half of pectoral fin with many small dark spots. Pelvic fin dark with many darker spots. Anal fin uniformly dark in males, but dark only on distal margin in females. Lower half of caudal fin dark.

REMARks: Franz (1910) reported Calliurichthys variegatus from Japan, but his description does not fit this species. His specimen seems to be a male of Repomucenus huguenini (Bleeker) with 9 dorsal rays, 9 anal rays and 3 filamentous anterior dorsal spines.

Jordan and Fowler (1903) stated that Günther (1861) erroneously regarded this species as the female of Calliurichthys japonicus (Houttuyn). I agree that this is an erroneous designation.

de Beaufort (1951) reported Callionymus variegatus from the Kei Islands, but his description differs greatly from that of the Japanese specimens. His specimen has a transverse commissure of the lateral line on the dorsal surface of the caudal peduncle 
(not found in Japanese specimens), and 8 processes on the inner side of the preopercular spine (4-6 in the latter). Temminck and Schlegel (1845) did not note the lateral line, but the type is taken from Japan and the specimens examined in my study agree with the original description. de Beaufort mistakenly identified his specimen from the Kei Islands with $P$. variegatus; it is a different species.

\section{1) Genus Repomucenus Whitley, 1931}

Key to the species of Repomucenus

$A_{1}$ Infarorbital canal with no short downward branch at anterior part (Fig. 16A).

$B_{1}$ Distal margin of anal fin blackish-brown; preopercular spine elongate and straight, with an antrorse process at base, many short upward processes on inner side .......................................... huguenini (Bleeker) (p. 230).

$\mathrm{B}_{2}$ Anal fin transparent with some dark spots; preopercular spine short, with an antrorse process at base, some upward processes on inner side in adult; but, preopercular spine elongate in young ...R. virgis (Jordan and Fowler) (p. 233).

$\mathrm{A}_{2}$ Infraorbital canal with 1 or 3 short downward branches at anterior part.

$\mathrm{C}_{1}$ Infraorbital canal with one short downward branch at anterior part (Fig. 16B).

$D_{1}$ Preopercular spine elongate and strongly curved upward (in specimens more than $50 \mathrm{~mm}$ standard length); no dorsal spine filamentous; first dorsal fin with black distal margin, lower half of lateral side of body with many oblique dark lines in male more than $150 \mathrm{~mm}$ long; first dorsal fin with large white margined black mark, lower half of lateral side of body with many oblique dark lines in male $100-150 \mathrm{~mm}$ long. First dorsal fin with large black mark, no oblique dark line on lower half of lateral side of body in female and young male less than $100 \mathrm{~mm}$ long ...R. richardsonii (Bleeker) (p. 235).

$\mathrm{D}_{2}$ Preoeprcular spine short (in specimens more than $50 \mathrm{~mm}$ standard length); anterior two dorsal spines elongate and filamentous in adult male; first dorsal fin with no large white margined black mark; posterior half
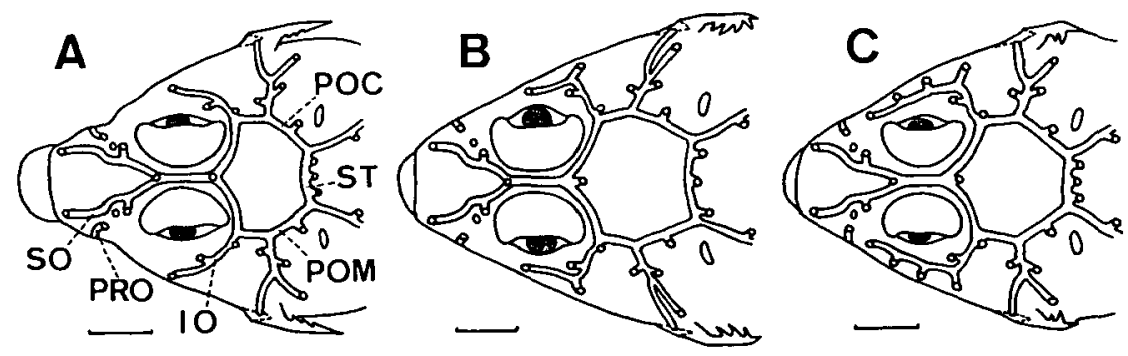

Fig. 16. Dorsal view of the cephalic lateral line of three callionymid species. A, Repomucenus huguenini; B, Repomucenus richrdsonii; C, Repomucenus lunatus. IO, infraorbital canal; POC, postocular commissure; POM, preoperculomandibular canal; R PRO, preorbital canal; SO, supraorbital canal; ST, supratemporal canal. Scales indicate $5 \mathrm{~mm}$. 
of first dorsal fin blackish-brown in female and young male.

$\mathrm{E}_{1}$ In adult male (more than $120 \mathrm{~mm}$ long), anal fin membranes with dark oblique lines and second dorsal fin with about two rows of dark spots; in female and young male, marbled brown-colored area, on lateral side of body, rimmed with many small white circles.

R. beniteguri (Jordan and Snyder) (p. 238).

$\mathrm{E}_{2}$ In adult male (more than $120 \mathrm{~mm}$ long), anal fin uniformly pale and second dorsal fin with a row of dark spots at middle; in female and young male, marbled brown area, on lateral side of body, rimmed with many white oblong marks ...................... ornatipinnis (Regan) (p. 239).

$\mathrm{C}_{2}$ Infarorbital canal with three downward branches at anterior part (Fig. 16C).

$F_{1}$ Caudal fin with many conspicuous dark spots in both sexes. First dorsal fin with a large white margined black mark in female and young; dorsal spines elongate and filamentous (1st and 4th more elongate than others), median caudal rays filamentous in adult male .R. valenciennei (Temminck and Schlegel) (p. 241).

$F_{2}$ Caudal fin with some unconspicuous dark spots in both sexes. First dorsal fin almost black in female and young.

$G_{1}$ Lower half of caudal fin with longitudinal broad blackish-brown band in both sexes. In adult male, first dorsal spine elongate and filamentous and anal fin uniformly blackish-brown. Preopercular spine short with 2-3 upward processes on inner side............... ..R. lunatus (Temminck and Schlegel) (p. 244).

$\mathrm{G}_{2}$ Lower half of caudal fin with no longitudinal broad blackishbrown band in both sexes. In an adult male, first dorsal fin very small and each anal fin membrane with dark spot. Preopercular spine elongate with 3-6 upward processes on inner side.

R. planus (Ochiai) (p. 246).

\section{Repomucenus huguenini (Bleeker)}

(Japanese name: Yari-numeri)

(Fig. 17)

Callionymus huguenini Bleeker, 1859: 7, pl. 2, fig. 1 (type locality: Nagasaki).

Repomucenus huguenini: Nakabo, 1982: 81 (listed).

Callionymus huguenii: Günther, 1861 : 145 (Nagasaki); Jordan and Fowler, 1903: 955 (reference); Jordan, Tanaka and Snyder, 1913: 377 (listed); Matsubara, 1955: 714 (key); Ochiai et al., 1955: 123 (reference).

Calliturichthys doryssus Jordan and Fowler, 1903: 945, fig. 4 (type locality: Nagasaki; Wakanoura; Aomori). Smith and Pope, 1906: 493 (Kochi); Snyder, 1912: 446 (Hakodate market; Shimizu); Jordan, Tanaka and Snyder, 1913: 372 (listed); Jordan and Thompson, 1914: 294, fig. 72 (Misaki); Jordan and Hubbs, 1925: 316 (Toba market); Ui, 1929: 262 (Kishu); Katayama, 1940: 24 (Toyama Bay); Yanai, 1950: 22 (Matsue; Hamada); Kuroda, 1951: 174 (Suruga Bay); Kuroda, 1952: 174 


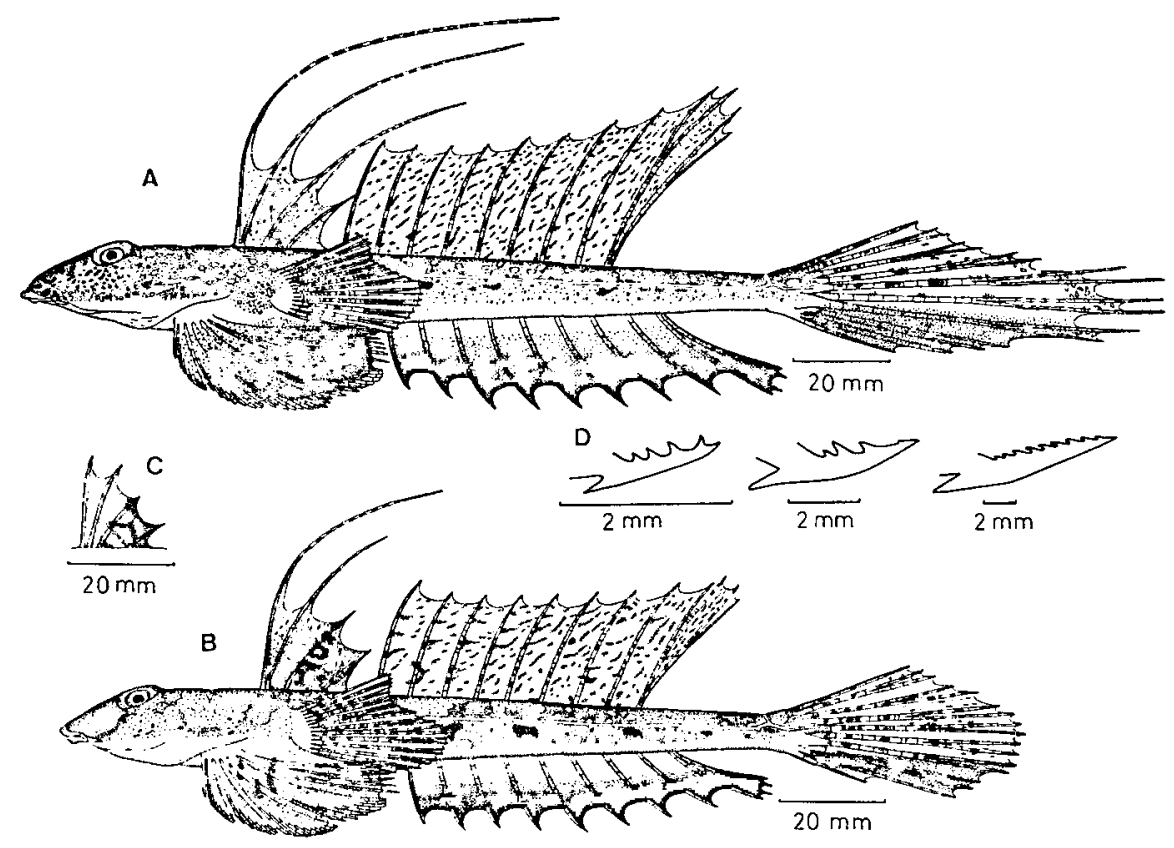

Fig. 17. Repomucenus huguenini (Bleeker). A, a male, $157.8 \mathrm{~mm}$ SL, FAKU 49878; B, a female, $137.0 \mathrm{~mm}$, FAKU 49902; C, first dorsal fin of a small female, $77.2 \mathrm{~mm}$, FAKU 49789; D, preopercular spines of a young, $16.6 \mathrm{~mm}$, FAKU 50609 (left), a small male, $73.4 \mathrm{~mm}$, FAKU 49245 (middle) and a large male, 177.6 mm, FAKU 49879 (right).

(Suruga Bay); Kuroda, 1954: 160 (Suruga Bay); Mori, 1956: 23 (Quelpart Isl.); Böhlke, 1953: 104 (listed); Mori, 1956: 23 (Kasumi; Hamada); Chu et al., 1962: 728, fig. 589 (South China Sea); Chu et al., 1963: 355, fig. 290 (East China Sea); Tatara et al., 1965: 106 (Seto Inland Sea and adjacent waters); Takegawa and Morino, 1970: 382 (Wakasa Bay); Ueno, 1971: 83 (southern Japan Sea coast of Hokkaido).

Callionymus doryssus: Ochiai et al., 1955: 102, fig. 2 (Japan); Katayama and Fujioka, 1958: 1157 (Oshima-gun, Yamaguchi Pref.).

Calliurichthys variegatus (not of Temminck and Schlegel): Franz, 1910: 84 (Japan).

Materials examined: FAKU 48553, a male, $82.6 \mathrm{~mm}$ in standard length, Oki Isls., at $5 \mathrm{~m}$ depth, June 26, 1974. FAKU 48556, 48557, 48559, 3 males, 80.3$86.7 \mathrm{~mm}$, Oki Isls., at $20 \mathrm{~m}$ depth, July 7, 1974. FAKU 48565, 48567, 48568, 2 males and a female, 70.0-73.3 mm, Oki Isls., at $15 \mathrm{~m}$ depth, June 26, 1974. FAKU 48733, 48738, a male and a female, 59.8-81.4 mm, Shijiki Bay, at $30 \mathrm{~m}$ depth, June 13, 1975. FAKU 48804-48808, 2 males and 3 females, 78.0-107.8 mm, Mimase, Nov. 12, 1975. FAKU 48874-48877, 48881, 2 males and 3 females, 80.2-103.5 mm, Oki Isls., June 18, 1973. FAKU 49241, 49250, a male and a female, 52.0-64.6 mm, Tottori, at $5 \mathrm{~m}$ depth, June 26, 1972. FAKU 49245-49249, 3 males and 2 females, 64.9-75.8 mm, Tottori, at $15 \mathrm{~m}$ depth. FAKU 49326-49331, 49333, 49335, 5 males and 3 females, 62.4-124.6 mm, Mogi, May 26, 1976. FAKU 49782, 49783, 49788, 49789, a male and 3 females, 77.2-100.7 mm, Hamada, at $60 \mathrm{~m}$ depth, Oct. 2, 1973. FAKU 49877, 49878, 2 males, 157.6-184.6 mm, Hamada, at $30 \mathrm{~m}$ depth, Aug. 28, 1973. FAKU 49879, a male, $177.6 \mathrm{~mm}$, Hamada, at $20 \mathrm{~m}$ depth, Oct. 2, 1973. 
FAKU 49902, a female, $137.0 \mathrm{~mm}$, Mogi, June 9, 1978. FAKU 49957, 49958, 2 males, 115.8-124.6 mm, 30 $38^{\prime} \mathrm{N}, 123^{\circ} 52^{\prime} \mathrm{E}$, July 26, 1978. HUMZ 87056, a male, $96.6 \mathrm{~mm}$, Kao-hsiung, Formosa, Dec. 6-9, 1978. FAKU 50609 (only in preopercular spine), a young, $16.6 \mathrm{~mm}$, Shijiki Bay, Nagasaki Pref., Dec. 17, 1975.

Description: D. IV, 9; A. 9; $\mathrm{P}_{1}$. i+17-19; $\mathrm{P}_{2}$. I, 5; G. i+7+ii.

Preopercular spine straight, with an antrorse process at base, 2-9 very short upward processes on inner side; number of short upward processes varied according to ontogenetic development or locality. Infraorbital canal extending below middle part of eye with an antrorse branch near ventroposterior edge of eye.

Anterior 3 dorsal spines elongate and filamentous in males; anterior 2 dorsal spines filamentous in females. No dorsal spine filamentous in small females and youngs. Pectoral fin reaching 3rd dorsal ray. Pelvic fin nearly reaching 1 st anal ray. Caudal fin elongate and lanceolate in males, only rounded in females.

Color in life. Body marbled brown above like the surface of a sandy bottom, white below. Some dark spots, an undulating longitudinal gold line on mid-axis of body. First dorsal fin almost transparent with some dark small spots in males; dark with some vermicular white lines in females; in young stages, inconspicuous dark mark on posterior half. Second dorsal fin with many small dark spots and white spots. Upper half of pectoral fin with many small dark spots. Pelvic fin dark with white margin in males, faintly dark on females. Distal half of anal fin black. Upper half of caudal fin with many small dark spots, many small white spots; lower half black.

Color in $10 \%$ formalin. White and gold colors disappeared.

Remarks: This species is closely related to Repomucenus filamentosus (Valenciennes), R. longi (Fowler), R. brunneus (Fowler) and R. punctilateralis (Fowler) in its general physiognomy, especially the preopercular spine and the cephalic lateral line pattern, but differs in having many filamentous dorsal spines in males and color in the other unpaired fins.

This species is closely related to Repomucenus virgis (Jordan and Fowler) and $R$. calcaratus (Macleay) in its cephalic lateral line pattern, but differs in its preopercular spine and first dorsal fin.

Bleeker (1859) reported that this species has 10 dorsal and 10 anal rays. Consequently, this species has been thought to be different from dragonets with 9 dorsal and 9 anal rays. Actually, Bleeker's figure for this species shows 9 dorsal and 9 anal rays; he miscounted the last branched ray as two rays; it agrees well with the adult male specimens examined in this study. Furthermore, as result of the examination of the holotype of Callionymus huguenini (RMNH 4803, Nagasaki, leg. O.F.U.J. Huguenin, ca. 1857, $54 \mathrm{~mm}$ in standard length) by M. Boeseman (personal communication), it has the same types of preopercular spine and infraorbital canal as the specimens examined in this study which are agreed well with Calliurichthys doryssus Jordan and Fowler. Therefore, C. doryssus is a synonym for $R$. huguenini.

Franz (1910) mistakenly identified this species with Pseudocalliurichthys variegatus as judging from his description. 
C. huguenii, reported from Hakodate, Japan, by Ishikawa and Matsuura (1879), could not be identified in this study.

This species produces an offensive odour when it is captured.

This species is distributed in the East China Sea and Japanese waters.

\section{Repomucenus virgis (Jordan and Fowler) \\ (Japanese name: Horo-numeri)}

(Fig. 18)

Callionymus virgis Jordan and Fowler, 1903: 957, fig. 9 (type locality: Misaki, Japan); Franz, 1910: 84 (Misaki); Jordan, Tanaka and Snyder, 1913: 376, fig. 336 (listed); Kamohara, 1938: 65 (Tosa Bay); Kuroda, 1951: 386 (Suruga Bay); Kamohara, 1952a: 89 (Tosa Bay); Kuroda, 1952: 174 (Izu); Böhlke, 1953: 104 (listed); Kuroda, 1954: 106 (Izu); Matsubara, 1955: 714 (key); Ochiai et al., 1955: 126, figs. 18-19 (Japan); Mori, 1956: 22 (Tsuiyama, Hyogo Pref.); Chu et al., 1963: 386, fig. 291 (East China Sea); Tatara et al., 1965: 106 (listed).

Repomucenus virgis: Nakabo, 1982: 81 (listed).

Callionymus octostigmatus (part) Fricke, 1981c: 150, fig. 3 (Taiwan).

Materials examined: FAKU 48752, 48754, a male and a female, 48.6-62.2 $\mathrm{mm}$ in standard length, Shijiki Bay, Nagasaki Pref., June 13, 1975. FAKU 49035, a male, $68.5 \mathrm{~mm}$, Kochi, Mar. 23, 1976. FAKU 49099-49100, 2 males, 66.2-74.7

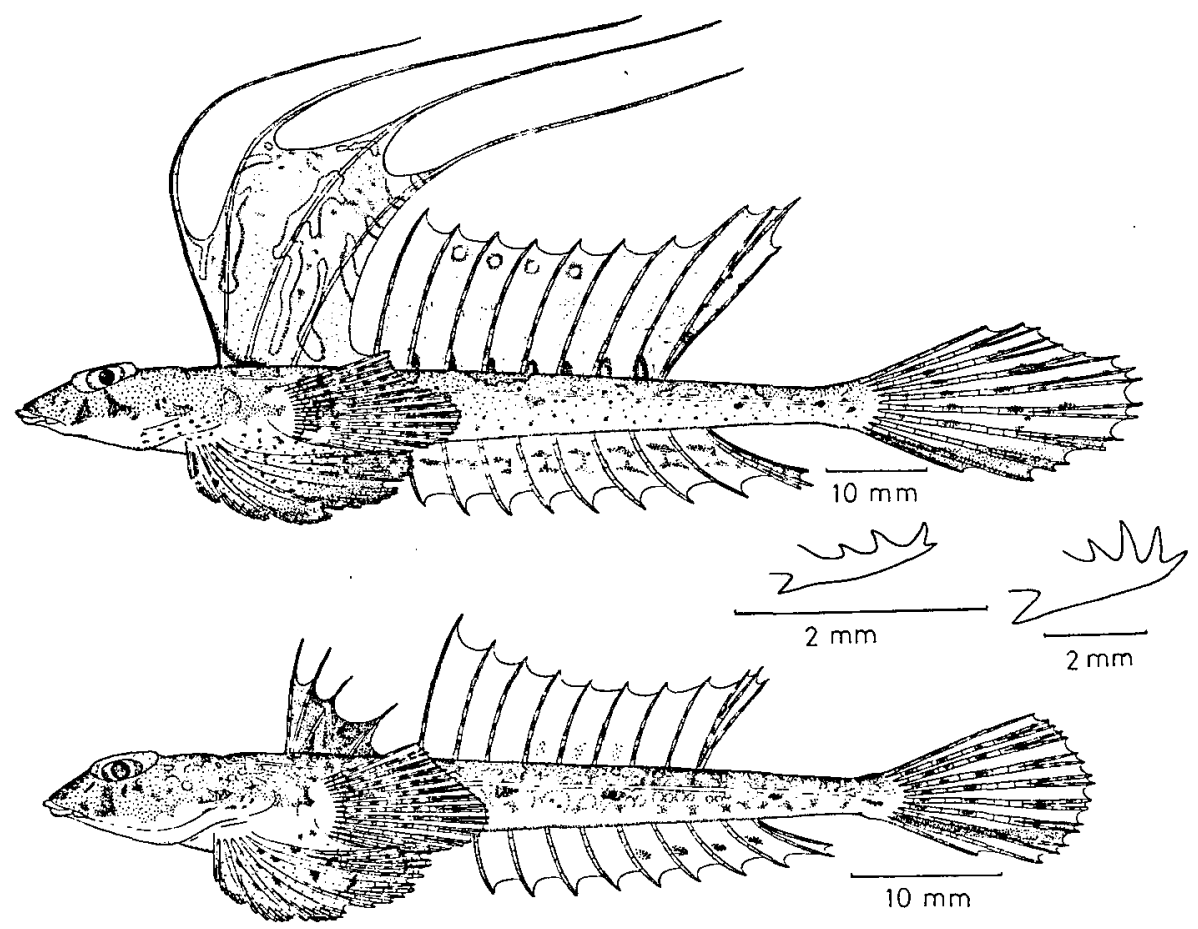

Fig. 18. Repomucenus virgis (Jordan and Fowler). Upper, a male, $82.6 \mathrm{~mm}$ SL, FAKU 49431 ; middle, preopercular spines of a young, $15.4 \mathrm{~mm}$, FAKU 50611 (left) and an adult, $74.0 \mathrm{~mm}$, FAKU 49108 (right); ;lower, a female, 55.4 mm, FAKU 49901. 
mm, off Hamada, Shimane Pref., at $80 \mathrm{~m}$ depth, June 28, 1973. FAKU 4910149120, 10 males and 10 females, 47.7-76.3 mm, off Hamada, Shimane Pref., at 100 m depth, July 9, 1974. FAKU 49122-49123, a male and a female, 46.9-54.4 mm, Akaoka, Kochi Pref., Nov. 14, 1975. FAKU 49322-49324, 3 males, 47.2-61.4 mm, Mogi market, Nagasaki Pref., Mar. 26, 1976. FAKU 49400-49402, 3 males, 61.0$81.4 \mathrm{~mm}$, Mimase market, Kochi Pref., Oct. 22, 1976. FAKU 49430-49431, 2 males, 77.7-82.6 mm, Mimase market, Kochi Pref., Oct. 25, 1976. FAKU 49790, 49792-49793, a male and 2 females, 55.5-77.4 mm, off Hamada, Shimane Pref., at $100 \mathrm{~m}$ depth. FAKU 49901, a female, $55.4 \mathrm{~mm}$, Mogi market, Nagasaki Pref., June 9, 1978. FAKU 50463-50465, 2 males and a female, 55.0-66.8 mm, 28 $37^{\prime} \mathrm{N}$, $124^{\circ} 48^{\prime} \mathrm{E}$, July 29,1972 . FAKU 50466, a male, $78.3 \mathrm{~mm}, 29^{\circ} 12^{\prime} \mathrm{N}, 123^{\circ} 39^{\prime} \mathrm{E}$, Aug. 2, 1972. FAKU 50467, 3 females, 21.2-36.8 mm, 27 $24^{\prime} \mathrm{N}, 122^{\circ} 59^{\prime} \mathrm{E}$, July 30, 1972. HUMZ 87021, 87022, a male and a female, $65.0-72.6 \mathrm{~mm}, 24^{\circ} \mathrm{N}, 126^{\circ} \mathrm{E}$, Dec. $3-4$, 1978. FAKU 50611 (only in preopercular spine), a young, $15.4 \mathrm{~mm}$, off Hamada, Shimane Pref., July 9, 1974.

Description: D. IV, 9; A. 9; $\mathrm{P}_{1}$. i+17-19; $\mathrm{P}_{2}$. I, 5; C. $\mathrm{i}+7+\mathrm{ii}$.

Preopercular spine short, with an antrorse process at base, 2-4 upward processes on inner side; posterior end not curved. Infraorbital canal extending below middle of eye with an antrorse branch near ventroposterior edge of eye.

In males, 1st dorsal fin high and broad like a sail, dorsal spines filamentous. In females lst dorsal fin small, no dorsal spine filamentous. Pectoral fin reaching 3rd dorsal ray. Pelvic fin reaching 1 st anal ray in males, but not in females. Caudal fin rounded.

Color in life. Body marbled brown above; ventral surface white with many orange spots in males, only white in females. Floor of mouth transparent. Dark spots on mid-axis of body. First dorsal fin yellow with many undulating white lines, ventroanterior edge black in males, in females almost black except for 1st membrane. Second dorsal fin yellow with 9 transverse white and dark lines on lower part, white circle on upper parts of 2nd-5th membranes in males, almost transparent in females. Upper part of pectoral fin with many small dark spots. Pelvic fin with some bluish-white lines on mid part, dark on posterior part in males, faintly dark with some small dark spots on females. Anal fin yellow with cloud-like dark mark on each membrane in males, but some small dark spots in females. Upper half of caudal fin with some small dark spots and some longitudinal yellow and white lines in males, some small dark and white spots in females; lower half dark in both sexes.

Remarks: This species is closely related to Repomucenus leucobranchialis (Fowler) in its general physiognomy, especially the first dorsal fin and preopercular spine, but it differs in its caudal fin and cephalic lateral line pattern.

Fricke (1981c) described Callionymus octostigmatus based on the specimens from the South China Sea, Andaman Isls. and Taiwan. But, the paratype from Taiwan, CAS 30328, should belong to Repomucenus virgis judging from the figure.

This species is distributed in the East China Sea and in southern Japanese waters. 


\title{
Repomucenus richardsonii (Bleeker)
}

\author{
(Japanese name: Nezumi-gochi)
}

(Fig. 19)

Callionymus richardsonii Bleeker, 1854: 414 (type locality: Nagasaki).

Repomucenus richardsonii: Nakabo, 1982: 81 (listed).

Callionymus richardsoni: Jordan and Hubbs, 1925: 317 (Tokyo; Yokohama; Kobe; Toba; Mikawa, Fukui); Schmidt and Lindberg, 1930: 1150 (Tsuruga); Schmidt, 1931: 122 (Nagasaki; Obama); Kuroda, 1951: 386 (Suruga Bay); Honma, 1952: 225 (Niigata Pref.); Tchang et al., 1955: 184, fig. 117 (Ch'ing-tao); Matsubara, 1955: 713 (key); Mori, 1956: 22 (Hamada; Kasumi); Chu et al., 1962: 724, fig. 586 (South China Sea); Tatara et al., 1965: 106 (Seto Inland Sea and adjacent waters); Kosaka, 1967: 152 (Sendai Bay); Arai and Abe, 1970: 91 (Tsushima Isls.); Takegawa and Morino, 1970: 382 (Wakasa Bay).

Callionymus valenciennesi: Jordan and Fowler, 1903: 950, fig. 6 (Japan); Jordan and Starks, 1905: 211 (Pusan, Korea); Franz, 1910: 84 (Japan); Snyder, 1912: 447 (Tokyo; Shimizu; Kagoshima; Nagasaki); Jordan, Tanaka and Snyder, 1913: 374, fig. 333 (listed); Jordan and Metz, 1913: 58, fig. 59 (Pusan; Korea); Jordan and Thompson, 1914: 293 (Misaki; Shimonoseki); Fujita and Wakiya, 1915: 13 (Kishu); Izuka and Matsuura, 1920: 108 (Hojo; Boshu); Ui, 1929: 260 (Kishu); Kuroda, 1931: 124 (Suruga Bay); Mori and Uchida, 1934: 21 (Korea); Koike, 1936: 13 (Fukui Pref.).

Callionymus punctatus (not of Langsdorff): Ochiai et al. 1955: 116, fig. 12 (Japan); Katayama and Fuijioka, 1958: 1157 (Oshima-gun, Yamaguchi Pref), Ueno, 1971: 83 (southern part of Hokkaido); Masuda et al., 1975: 261, pl. 84-E (Japan); Kimura and Suzuki, 1980: 37, fig. 20 (Ago Bay).

Callionymus reevesii (part) Richardson, 1844: 60, pl. 34, fig. 4 (China Sea); Richardson, 1846: 210 (Macao).

Materials examined: FAKU 48795-48802, 4 males and 4 females, 121.1$142.3 \mathrm{~mm}$ in standard length, Mimase, Kochi Pref., Nov. 12, 1975. FAKU 49011,
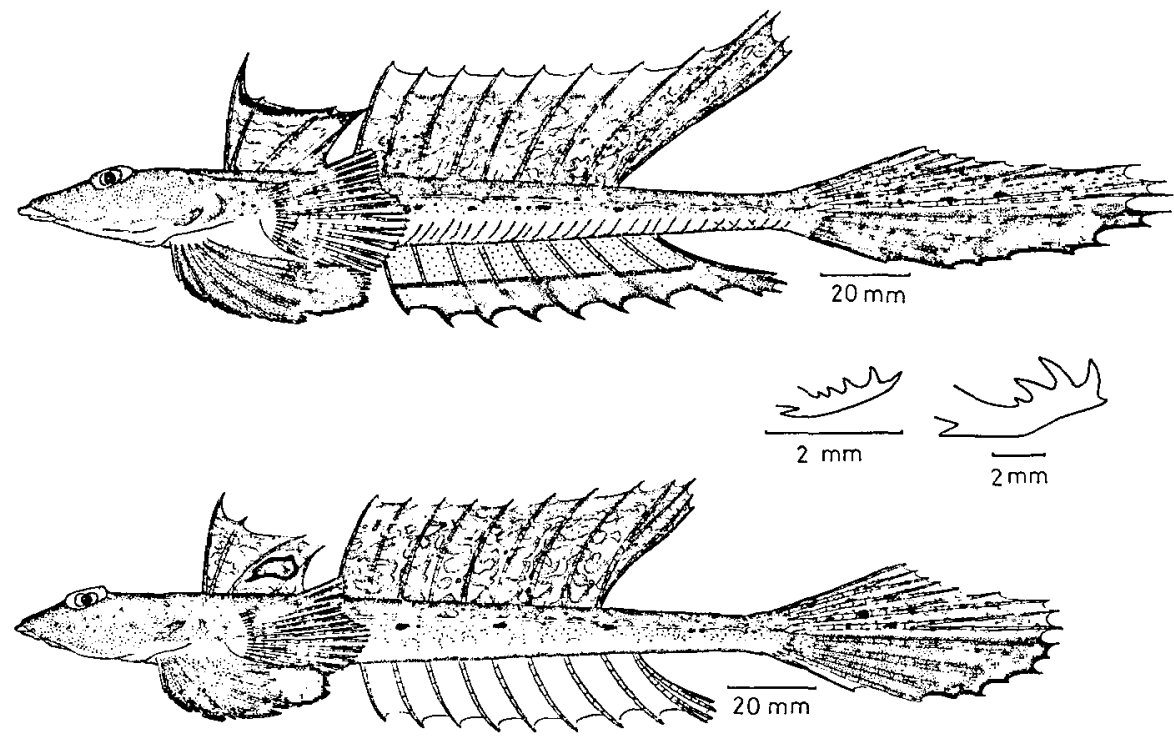

Fig. 19. Repomucenus richardsonii (Bleeker). Upper, a male, 174.3mm SL, FAKU 49313; middle, preopercular spines of a young, $20.0 \mathrm{~mm}$, FAKU 50608 (left) and an adult, 117.9 mm, FAKU 49071 (right); lower, a female, $169.6 \mathrm{~mm}$, FAKU 49314. 
a male, $150.5 \mathrm{~mm}$, Oki Isls., Sep. 19, 1975. FAKU 49066-49081, 7 males and 9 females, 81.3-117.9 mm, Aoshima, Miyazaki Pref., July 23, 1975. FAKU 4912449127, a male and 3 females, 99.1-119.5 mm, Akaoka, Kochi Pref., Nov. 14, 1975. FAKU 49253, a female, $72.1 \mathrm{~mm}$, Tottori Pref, at $10 \mathrm{~m}$ depth, June 26, 1972. FAKU 49312-49321, 4 males and 6 females, 59.9-174.3 mm, Mogi, Nagasaki Pref., May 26, 1976. FAKU 49610, a female, $75.3 \mathrm{~mm}$, Tottori Pref., June 13, 1975. FAKU 50093, a male, $150.7 \mathrm{~mm}$, Choshi, Chiba Pref., May 8-9, 1980. FAKU 50175, a female, 131.6 mm, Choshi, Mar. 1980. FAKU 50176-50180, 5 males, 122.0-135.4 mm, Choshi, May 1980. FAKU 50320-50325, 4 males and 2 females, 85.1-129.0 mm, Awaji Isl., Hyogo Pref., Dec. 13, 1979. ZUMT 39600, a male, $107.0 \mathrm{~mm}$, the Philippines, date unknown. HUMZ 87053-87055, 2 males and a female, 86.0-110.7 mm, Kao-hsiung, Formosa, Dec. 6-9, 1978. UMMZ 100631, a female, $83.3 \mathrm{~mm}$, Canton, China, Sep., 1931. FAKU 50608 (only in preopercular spine), a young, $20.0 \mathrm{~mm}$, Shijiki Bay, Nagasaki Pref., Feb. 15, 1976.

Description: D. IV, 9 (rarely 10); A. 9; $\mathrm{P}_{1}$. i+17-19; $\mathrm{P}_{2}$. I, 5; C. $\mathrm{i}+7$ + ii.

Preopercular spine long and curved inward, with an antrorse process at base; 2-4 upward processes on inner side. Infraorbital canal extending to anterior part of eye with a downward branch near ventroposterior part of eye and an antrorse short branch near posterior edge of eye.

First dorsal fin short and slightly emarginated in both sexes. Pectoral fin reaching 1st-2nd anal rays. Pelvic fin not reaching 1st anal ray. Caudal fin slightly longer in males than in females; upper half slightly emarginated, lower half rounded.

Color in life. Body brown with many small circles or oblong white spots above like the surface of a sandy bottom, white below. Floor of mouth transparent. Many oblong light blue and yellow marks on cheek in males, but not in females. Several dark marks on mid-axis of lateral side of body. Ventral part of lateral side of body with many oblique dark lines in males. First dorsal fin darker yellow with some undulating oblong white marks and blackish distal margin in males; orange with some undulating oblong white marks and a white-margined large black mark between 3rd and 4th spines in females. First dorsal fin of immature males like females. Second dorsal fin orange-brown with many small dark and white spots and orangeyellow distal margin in males; orange with many undulating white lines in females. Upper half of pectoral fin with many small dark spots. Pelvic fin dark. Anal fin dark on lower half in males, but with yellow marks in females. In some immature males and females, anal fin with oblong or circular dark spot on each membrane. Upper half of caudal fin with some dark spots, lower half dark.

Color in 10\% formalin. Yellow, orange and blue marks disappeared.

Remarks: This species is closely related to $R$. beniteguri and $R$. ornatipinnis in the pattern of its cephalic lateral line system, but it differs in its other characters.

Richardson (1844) described Callionymus reevesii, as two separate species; a male identified as Calliurichthys japonicus and a female identified as this species. Bleeker (1854) 
described this species as Callionymus richardsonii. He noted that $C$. richardsonii was a synonym for the "Female ?" of $C$. reevesii. If the male of $C$. reevesii is synonymous with $C$. japonicus, we must decide whether the name revesii is valid for this species. Richardson's description was based on Mr. Reeves' drawing, whereas Bleeker's description was based on the examination of 3 specimens from Nagasaki, Japan. Therefore, we should adopt richardsonii as the name of this species.

There is confusion about the name Callionymus punctatus Langsdorff. Langsdorff mistakenly identified the specimen of this family deposited at Berlin University with a fish of the platycephalids, Platycephalus pucntatus (Valenciennes, 1837). Valenciennes (1837) identified Langsdorff's specimen with Callionymus japonicus Houttuyn. But, Richardson (1846) pointed out that Valenciennes erroneously identified it with C. japonicus because of the shape of its preopercular spine. He gave the name Callionymus punctatus Langsdorff to Langsdorff's specimen, and seems to have believed that Langsdorff was the author of the name punctatus because of the remark of Valenciennes. Later, Jordan and Hubbs (1925) regarded Langsdorff's specimen as of being this species and they stated that the name $C$. punctatus Langsdorff had no standing because Langsdorff had mistakenly identified his specimen with Platycephalus punctatus. They chose Callionymus richardsoni Bleeker (may be altered from richardsonii) as the valid name of this species. Boeseman (1947) adopted C. punctatus Richardson as the correct name of this species. He also regarded Langsdorff's specimen as this species by Richardson. It is not known why he used Richardson as the author's name of $C$. punctatus. Ochiai et al. (1955) also took $C$. punctatus Langsdorff as the name of this species. I do not agree with Jordan and Hubbs (1925), Boeseman (1947), or Ochiai et al. (1955) in regarding Langsdorff's specimen as being of this species. It is impossible to identify Langsdorff's specimen with this species from the very short description by Richardson (1946). It seems that they so classified it because it has a curved preopercular spine with three spreading upper spinous processes turned forward; however, this description of the preopercular spine also applies to other species. In summary, the confusion about the name C. punctatus is due to Langsdorff's erroneous identification of his specimen of dragonet with Platycephalus punctatus; Richardson's misunderstanding that Langsdorff had named his specimen of dragonet punctatus; and Jordan and Hubbs, Boeseman and Ochiai et al. mistaken identification of Langsdorf's specimen as this species on the basis of the short description by Richardson. Therefore, the name C. punctatus should not be used for this species; rather the appelation should be platycephalid. Langsdorff's specimen still can not be identified.

This species is closely related to Repomucenus curvicornis (Valenciennes) in its general physiognomy, but differs in the males having many oblique dark lines on the lower half of the lateral side of the body. Ninni (1934) reported Callionymus curvicornis, but differs from this species somewhat in its coloration.

This species is distributed in the South China and East China Seas and in Japanese waters. 


\section{Repomucenus beniteguri (Jordan and Snyder)}

(Japanese name: Tobi-numeri)

(Fig. 20)

Callionymus beniteguri Jordan and Snyder, 1900: 370, pl. 17 (type locality: Tokyo Bay); Jordan and Fowler, 1903: 956 (Tokyo); Franz, 1910: 84 (Yokohama); Jordan, Tanaka and Snyder, 1913: 375 (listed); Jordan and Hubbs, 1925: 317 (Toba; Kobe; Tatoku Isl.; Mikawa Bay); Fowler, 1941: 22 (Miyazaki); Honma, 1952: 226 (Niigata Pref.); Böhlke, 1953: 103 (listed); Matsubara, 1955: 714 (key); Ochiai, et al., 1955: 123, figs. 16-17 (Japan); Mori, 1956: 22 (Hamada; Maizuru); Tatara et al., 1965: 106 (Seto Inland Sea and adjacent waters); Arai and Abe, 1970: 91 (Tsushima); Takegawa and Morino, 1970: 382 (Wakasa Bay); Masuda et al., 1975: 261, pl. 84-G (Japan); Kimura and Suzuki, 1980: 38 (Ago Bay).

Repomucenus beniteguri: Nakabo, 1982: 81 (listed).

Callionymus kanekonis Tanaka, 1917: 12 (type locality: Nagasaki).

Callionymus lunatus (not of Temminck and Schlegel): Schmidt and Lindberg, 1930: 1150 (Tsuruga).

Materials examined: FAKU 4692, 4697, 2 males, 103.1-114.4 mm in standard length, Owase, Mie Pref., July, 1936. FAKU 17399, a male, $65.7 \mathrm{~mm}$, Owase, Feb. 3-7, 1952. FAKU 20683-20684, 2 males, 98.1-1 12.9 mm, Miya, Aichi Pref., Apr. 10, 1953. FAKU 49367, a male, 89.9 mm, Shirahama, Wakayama Pref., May 4, 1974. FAKU 49559, a male, $134.0 \mathrm{~mm}$, Shirahama, June 8, 1977. FAKU 49625-49665, 21 males and 20 females, 82.5-160.5 mm, Shijiki Bay, Nagasaki Pref., May 7-Aug. 30, 1977. FAKU 49833-49852, 11 males and 9 females, Yuya Bay, Yamaguchi Pref., June 19, 1975-July 7, 1977. FAKU 49853-49861, 3 males and 6 females, 72.9-136.1 mm, Noto, Ishikawa Pref., Aug. 3-29, 1976. FAKU 49880-

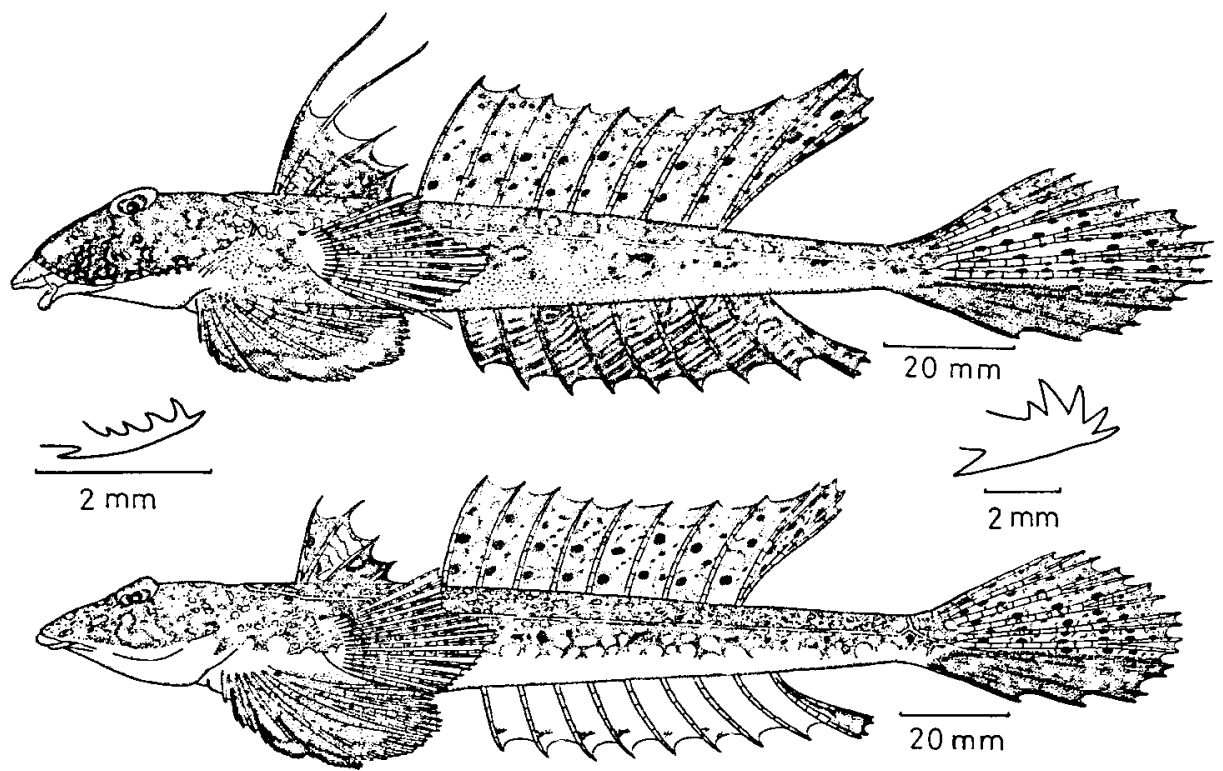

Fig. 20. Repomucenus beniteguri (Jordan and Snyder). Upper, a male, 134.0 mm SL, FAKU 49559; middle, preopercular spines of a young, $18.1 \mathrm{~mm}$, FAKU 50614 (left) and an adult, 110.5 mm, FAKU 49649 (right); lower, a female, 160.5 mm, FAKU 49630. 
49897, 8 males and 10 females, 47.2-102.6 mm, Suma, Hyogo Pref., May 20, 1978. ZUMT 54058-54060, 2 males and a female, 127.4-159.2 mm, Habu-ko, Aug. 17, 1933. FAKU 50614 (only in preopercular spine), a young, $18.1 \mathrm{~mm}$, off Yokohama, Kanagawa Pref.

Description: D. IV, 9 (rarely 10); A. 9 (rarely 8 ); $\mathrm{P}_{1}$. i+17-20; $\mathrm{P}_{2} . \mathrm{I}, 5$; C. $\mathrm{i}+7+\mathrm{ii}$.

Preopercular spine short, with an antrorse process at base, 2-3 upward processes on inner side; posterior end slightly curved upward. Interorbital width wide. Infraorbital canal extending to anterior part of eye with a downward branch near ventroposterior part and an antrorse short branch at posterior edge.

Anterior 2 dorsal spines filamentous in males, but not in females. Pectoral fin reaching 1 st-2nd anal rays. Pelvic fin short, not reaching lst anal ray. Caudal fin rounded.

Color in 10\% formalin. Body marbled brown above like the surface of a sandy bottom. Ventral surface of body behind origin of anal fin dark in males, uniformly white in females. Many white spots on cheek in males. Some dark marks on midaxis of lateral side of body. Many white circles on lower part of lateral side of body in females. First dorsal fin dark with some short undulating white lines in males. In females anterior half faintly dark with some short, broad undulating white lines; posterior half almost black. Second dorsal fin dark with 2 rows of dark spots. Upper half of pectoral fin with many dark spots. Pelvic fin dark with some oblong white lines at base, darker band near margin in males; dark in females. Anal fin dark with several oblique white lines on each membrane in males; in females almost transparent and dark on last membrane (some females and young males with 2-3 dark marks on each membrane). Upper half of caudal fin with many dark spots, lower half dark.

REMarks: This species shows somewhat color variations in the first dorsal fin of the male and the anal fin of the female.

Callionymus kanekonis Tanaka seems to be a synonym for this species, because it is very like this species in its general physiognomy, especially that of the first dorsal and anal fins.

This species is distributed only in Japan.

\section{Repomucenus ornatipinnis (Regan)}

(Japanese name: Seto-numeri)

(Fig. 21)

Callionymus ornatipinnis Regan, 1905: 23, pl. 4 (type locality: Seto Inland Sea); Jordan, Tanaka and Snyder, 1913: 375 (listed); Matsubara, 1955: 714 (key).

Repomucenus ornatipinnis: Nakabo, 1982: 81 (listed).

Callionymus beniteguri (not of Jordan and Snyder): Snyder, 1912: 447 (Otaru, Hakodate, Misaki); Izuka and Matsuura, 1920: 108 (Asamushi); Hikita, 1951: 311 (Volcano Bay); Tchang et al., 1955: 182 (Yellow Sea); Kobayashi, 1962: 257 (Oshoro Bay); Chu et al., 1963: 387, fig. 292 (East China Sea); Ueno, 1971: 83 (southern part of Hokkaido and the Sanriku district). 


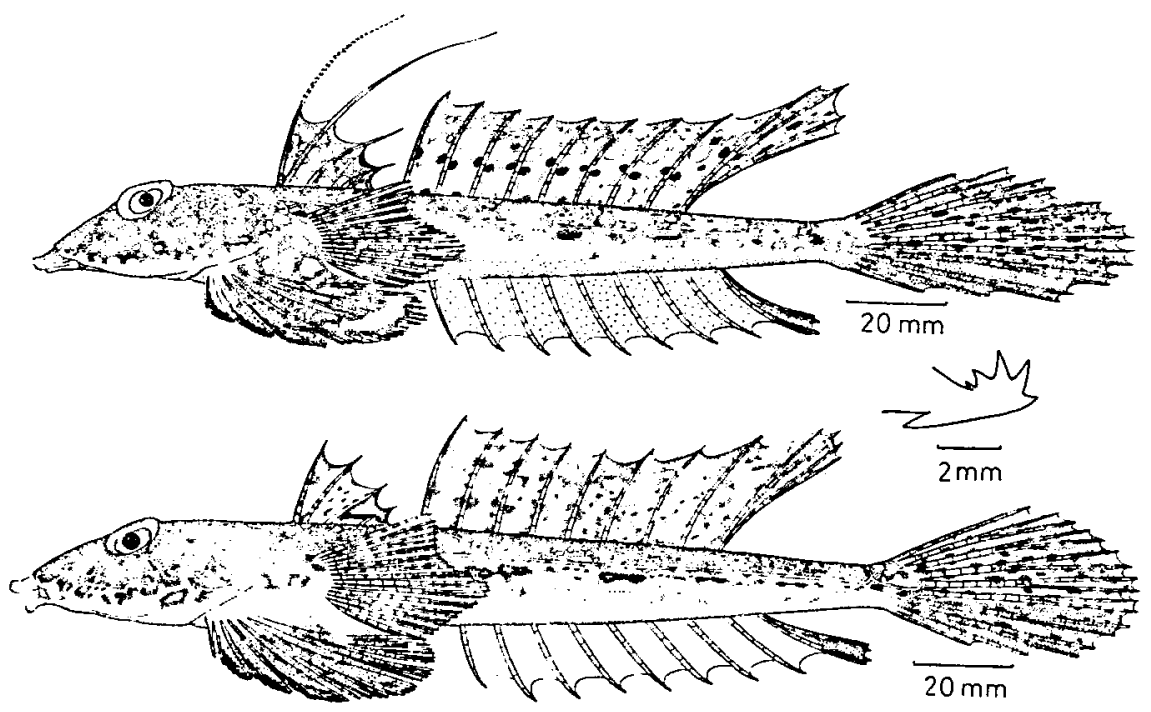

Fig. 21. Repomucenus ornatipinnis (Regan). Upper, a male, $159.8 \mathrm{~mm}$ SL, FAKU 49811 ; middle, preopercular spine of FAKU $49198,88.9 \mathrm{~mm}$; lower, a female, $171.4 \mathrm{~mm}$, FAKU 49823.

Materials examined: FAKU 4695-4696, 2 males, 103.7-110.2 mm, Owase, July, 1936. FAKU 9735-9736, 2 males, 131.7-158.1 mm, Shiogama, Nov. 1, 1944. FAKU 10304, a male, $128.1 \mathrm{~mm}$, Funakawa, June, 1948. FAKU 11541, a male, $141.9 \mathrm{~mm}$, Choshi, at $50 \mathrm{~m}$ depth, May 3, 1949. FAKU 16811-16814, 3 males, 91.5-117.4 mm, Osaka Bay, Oct, 1950. FAKU 49194-49212, 9 males and $10 \mathrm{fe-}$ males, 72.1-113.2 mm, Mogi, May 26, 1976. FAKU 49560-49568, 5 males and 4 females, 75.3-144.0 mm, Katagai, July 31, 1977. FAKU 49811-49833, 11 males and 11 females, off Shimabara, Ariake-kai, May 12, 1977. FAKU 49914-49923, 8 males and 2 females, 86.0-153.7 mm, 26 $36^{\prime}-43^{\prime} \mathrm{N}, 123^{\circ} 04^{\prime}-13^{\prime} \mathrm{E}$, June 4, 1978. FAKU 49946-49950, 5 males, $136.5-142.7 \mathrm{~mm}, 31^{\circ} 10^{\prime} \mathrm{N}, 123^{\circ} 45^{\prime} \mathrm{E}$, July 27, 1978. FAKU 49951-49953, 3 males, $134.0-139.7 \mathrm{~mm}, 31^{\circ} 02^{\prime} \mathrm{N}, 123^{\circ} 33^{\prime} \mathrm{E}$, Aug. 23, 1978. FAKU 49954-49956, 3 males, 126.8-138.6 mm, 30³8'N, $123^{\circ} 52^{\prime} \mathrm{E}$, July 26, 1978. ZUMT 14197, a male $158.0 \mathrm{~mm}$, Volcano Bay, Nov., 1924. HUMZ 16898-16901, 3 males and a female, 116.7-127.9 mm, Okushiri Isl., Aug. 1959. HUMZ 65115, a male, 138.4 mm, Volcano Bay, 1951-1953. HUMZ 70352-70354, 2 males and a female, 103.4-123.2 mm, Oshoro Bay, July 24-28, 1970.

Description: D. IV, 9 (rarely 10 ); A. 9 (rarely 10); $\mathrm{P}_{1}$. i+18-21; P. I, 5; G. $\mathrm{i}+7+\mathrm{ii}$.

Preopercular spine short, with an antrorse process at base, 2-4 upward processes on inner side; posterior end slightly curved upward. Infraorbital canal extending to anterior part of eye with a downward branch near ventroposterior part and an antrorse short branch at posterior edge.

Anterior 2 dorsal spines filamantous in males, but not in females. Pectoral fin reaching 2 nd anal ray. Pelvic fin short, not reaching 1 st anal ray. Caudal fin rounded. 
Color in 10\% formalin. Body marbled brown above like the surface of a sandy bottom. Ventral surface of body behind origin of anal fin dark in males, uniformly white in females. Some dark marks on mid-axis of lateral side of body. Many white oblong marks on lower part of lateral side of body in females. First dorsal fin dark with some white spots in males (some specimens with a small black spot on 3rd membrane); in females anterior half transparent with some small dark spots, posterior half black. Second dorsal fin with a median row of dark marks in males, faintly dark with many cloud-like darker marks in females. Upper half of pectoral fin with many dark spots. Pelvic fin dark with some white marks at base, darker band near margin in males, only faintly dark in females. Anal fin faintly dark in males, transparent in females (some specimens faintly dark); posteriormost membranes dark in both sexes. Upper half of caudal fin with many dark spots, lower half faintly dark.

Remarks: This species is closely related to Repomucenus beniteguri (Jordan and Snyder) in its general physiognomy. Ochiai et al. (1955) regarded this as a synonym for $R$. beniteguri. It differs from $R$. beniteguri in the colors of the 2 nd dorsal and anal fins in males, and in the length of the dorsal ray: therefore, the two are separate species.

This species is distributed in the East China Sea and Japanese waters. My comparison of the distribution of this species and of $R$. beniteguri, shows that the latter is not distributed in northern Japanese waters, whereas the former is. The records of $R$. beniteguri from northern Japanese waters by Snyder (1912), Izuka and Matsuura (1920), Hikita (1951), Kobayashi (1962) and Ueno (1971), seem to be ones of this species.

Both Tchang et al. (1955) and Chu et al. (1963) erroneously identified this species with $R$. beniteguri, because their male $R$. beniteguri had a pale anal fin.

\section{Repomucenus valenciennei (Temminck and Schlegel)}

\section{(Japanese name: Hatatate-numeri)}

(Fig. 22)

Callionymus valenciennei Temminck and Schlegel, 1845: 153, pl. 78, fig. 3 (type locality: Nagasaki); Jordan and Hubbs, 1925: 317 (Kobe and Toba markets,); Schmidt, 1931 : 122 (Obama).

Repomucenus valenciennei: Nakabo, 1982: 81 (listed).

Callionymus valenciennesi: Katayama, 1940: 24 (Toyama Bay); Kuroda, 1951: 386 (Suruga Bay); Honma, 1952: 226 (Niigata Prefecture); Matsubara, 1955: 713 (key); Ochiai et al., 1955: 126 (review).

Callionymus flagris Jordan and Fowler, 1903: 952, fig. 7 (type locality: Aomori; Tsuruga; Kobe; Nagasaki; Owari Bay; Matsushima Bay); Jordan and Starks, 1904: 598, fig.; Franz, 1910: 84 (Sagami Bay); Snyder, 1912: 447 (Hakodate and Shimizu markets); Jordan, Tanaka and Snyder, 1913: 376, fig. 335 (listed); Izuka and Matsuura, 1920: 108 (Kesennuma); Ui, 1929: 261 (Kishu); Kuroda, 1931: 124 (Suruga Bay); Böhlke, 1953: 103 (listed); Matsubara, 1955: 713 (key); Ochiai et al., 1955: 114, fig. 11 (Japan); Mori, 1956: 22 (Kasum,, Hyogo Pref.); Tatara et al., 1956: 106 (Seto Inland Sea); Katayama and Fujioka, 1958: 1157 (Oshima-gun, Yamaguchi Pref.); Takegawa and Morino, 1970: 382 (Wakasa Bay); Ueno, 1971: 83 (south of Shakotan Peninsula).

Callionymus kitaharae Jordan and Seale, 1906a: 148, fig. 6 (type locality: Nagasaki Harbor). 


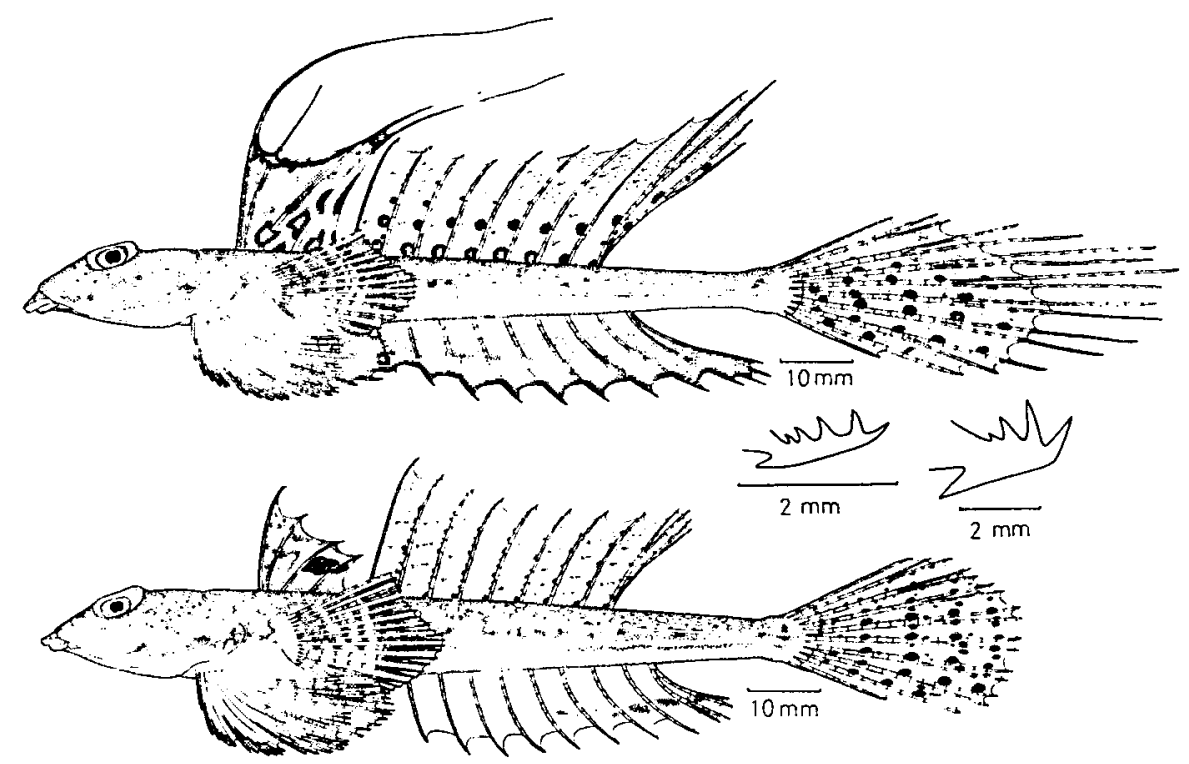

Fig. 22. Repomucenus valenciennei (Temminck and Schlegel). Upper, a male, $99.8 \mathrm{~mm} \mathrm{SL}$, FAKU 49898; middle, preopercular spines of a young, $17.5 \mathrm{~mm}$, FAKU 50610 (left) and an adult, $91.1 \mathrm{~mm}$, FAKU 49219 (right); lower, a female, $99.6 \mathrm{~mm}$, FAKU 49217.

Callionymus kitaharai: Matsubara, 1955: 714 (key); Ochiai et al., 1955: 129 (reference).

Callionymus lunatus (not of Temminck and Schlegel): Regan, 1905: 24 (Inland Sea of Japan).

Materials examined: FAKU 48769, a female, $108.7 \mathrm{~mm}$ in standard length, Mogi market, Nagasaki Pref., May 23, 1975. FAKU 49213-49226, 6 males and 8 females, 67.0-102.2 mm, Mogi market, Nagasaki Pref., May 26, 1976. FAKU 49357-49361, 3 males and 2 females, 58.8-83.5 mm, Obama, Fukui Pref., June 14, 1976. FAKU 49749, 49751, 49753, 49777, 4 females, 66.2-87.6 mm, Negishi Bay, Kanagawa Pref., July 15, 1977. FAKU 49898, a male, 99.8 mm, Wakasa Bay, June 18, 1973. FAKU 50610 (only in preopercular spine), a young, $17.5 \mathrm{~mm}$, Wakasa Bay, Kyoto Pref., Aug. 20, 1973.

Description: D. IV, 9 ; A. 9 (rarely 8,10 ); $\mathrm{P}_{1} . \mathrm{i}+16-19 ; \mathrm{P}_{2} . \mathrm{I}, 5 ;$ C. $\mathrm{i}+7$ + ii.

Preopercular spine short, with an antrorse process at base and 2-3 upward processes on the inner side; posterior end slightly curved upward. Infraorbital canal extending to preorbital region, with an antrorse short branch near ventroposterior edge of eye and 3 downward branches below eye.

Dorsal spines and median 6 caudal fin rays elongate and filamentous in males, but not in females. Pectoral fin reaching 2nd anal ray. Pelvic fin reaching Ist anal ray in males, but not in females. Caudal rays filamentous in males, but not in females.

Color in life. Body marbled brown above like the surface of a sandy bottom, white below. Floor of mouth transparent. Some oblong blue marks with yellowish margin on cheek in males. Longitudinal blue line on mid-axis of lateral side of 
body; gold around this line in males. First dorsal fin with many yellow-margined black marks; distal margin black in males, but a white-margined large black mark between 3rd and 4th spines and some vague brown marks in females. Upper half of each membrane of 2 nd dorsal fin with two yellow oblong marks and two light blue ones, lower half with about three dark blotches in males; many white oblong lines on each membrane and many small dark spots on each ray in females. Upper half of pectoral fin with many small dark spots. Pelvic fin and lower half of anal fin bluish-black in males; pelvic fin pale with vague light brown marks and posterior half of anal fin with a dark spot on lower part of each membrane.

Color in 10\% formalin: Yellow, gold and light blue disappeared. Bluishblack changed to black.

Remarks: Repomucenus valenciennei is closely related to $R$. lunatus in its general physiognomy, particularly in its infraorbital canal and preopercular spine, but it differs in the first dorsal and caudal fins. In addition, $R$. valenciennei does not grow as large as $R$. lunatus.

Temminck and Schlegel's (1845) original description is insufficient. Particularly, the original figure has no filamentous caudal fin rays. Jordan and Fowler (1903) therefore erroneously identified it with Repomucenus richardsonii (Bleeker) and described this species as their new species, Callionymus flagris. Later, Jordan and Hubbs (1925) regarded $C$. flagris as a synonym for Callionymus valenciennei, but many reports have given $C$. flagris as the scientific name of this species. Boeseman (1947) stated that the lectotype of $C$. valenciennei, a male, (RMNH 2078) agreed well with the description of $C$. flagris in its having filamentous dorsal spines, and he regarded $C$. flagris as a synonym for $C$. valenciennei. He also stated that the female specimens of C. valenciennei in the Fauna Japonica should belong to C. beniteguri (RMNH 2079a) and to C. punctatus Richardson (RMNH 2079b, c and 1011). Since he did not note whether RMNH 2078 had filamentous caudal rays, Ochiai et al. (1955) disagreed with his classification. They identified this species with C. flagris. They regarded the $C$. valenciennei in the original description of Temminck and Schlegel as another species and gave it Hatatate-damashi as its common Japanese name. The lectotype of $R$. valenciennei, RMNH 2078 (a male) has filamentous caudal fin rays and the same cephalic lateral line pattern as the specimens examined in my study, which agree well with $C$. flagris (M. Boeseman, personal communication). Therefore, the species name, valenciennei is valid, and $C$. flagris is a synonym for Repomucenus valenciennei.

Callionymus kitaharai Jordan and Seale (1906) shows a young stage of $R$. valenciennei based on the result of my examination of the holotype CAS-SU 9261. The holotype differs slightly from the original figure in its first dorsal fin. It has a black blotch between the 3rd and 4th dorsal spines and the same cephalic lateral line as $R$. valenciennei. Therefore, C. kitaharai is a synonym for $R$. valenciennei. The C. kitaharae of Tchang et al. (1955) seems to be Repomucenus macdonaldi (Ogilby).

Callionymus valenciennei meridionalis Suwardji (1965) is not related to Repomucenus valenciennei as judged from his description. Only the first dorsal spine is filamentous 
in $C . v$. meridionalis, but it is not in the $R$. valenciennei from Japan. Furthermore, these two differ from each other in the preopercular spine and the color of the anal fin. Consequently, Suwardji's species is not a subspecies of $R$. valenciennei, but some other species.

The Callionymus flagris reported by Chu et al. (1962) from the South China Sea is a doubtful identification.

Fowler (1941) recorded C. valenciennei from China, but his identification also is doubtful because his list of synonym includes various species.

Therefore, $R$. valenciennei is distributed only along the coasts of Japan and adjacent waters.

\section{Repomucenus lunatus (Temminck and Schlegel)}

(Japanese name: Numeri-gochi or Nezuppo)

(Fig. 23)

Callionymus lunatus Temminck and Schlegel, 1845: 155, pl. 78, fig. 4 (type locality: Japan); Gunther, 1861: 146 (Japan); Jordan and Fowler, 1903: 949, fig. 5 (Tsuruga; Wakanoura; Nagasaki; Same; Niigata); Jordan and Starks, 1904: 598 (Owari Bay); Smith and Pope, 1906: 493 (Yamagawa); Franz, 1910: 84 (Sagami Bay); Snyder, 1912: 446 (Nagasaki); Jordan, Tanaka and Snyder, 1913: 374, fig. 332 (listed); Jordan and Thompson, 1914: 294, fig. 70 (Misaki); Izuka and Matsuura, 1920: 108 (Ajiro, Izu); Jordan and Hubbs, 1925: 316 (Tokyo market; Mikawa Bay; Misaki; Noo; Obama); Ui, 1929: 261 (Kishu); Kuroda, 1931: 124, (Suruga Bay); Mori and Uchida, 1934: 21 (Pusan, Korea); Koike, 1936: 13 (listed); Kamohara, 1938: 656 (Mimase and Urado, Kochi); Katayama, 1940: 24 (Toyama Pref.); Oshima, 1940: 630 (reference); Boeseman, 1947: 133 (review); Honma, 1952: 225 (Niigata Pref.); Mori, 1952: 132 (Pusan, Korea); Kamohara, 1952: 90 (Kochi Pref.); Matsubara, 1955: 714 (key); Ochiai et al., 1955: 120, figs. 14-15 (Japan); Mori, 1956: 22 (Kasumi; Tsuiyama); Katayama and Fujioka, 1958: 1157 (Oshima-gun, Yamaguchi Pref.); Tatara et al., 1965: 106 (listed); Kosaka, 1967: 152 (Sendai Bay); Takegawa and Morino, 1970: 382 (Wakasa Bay); Ueno, 1971: 83 (Maritime Province; Japan Sea coast of Hokkaido; Pacific coast of Tohoku district).

Callionymus lunatus form lunatus: Kuroda, 1951: 386 (Suruga Bay).

Callionymus lunatus form usuiro Kuroda, 1951: 386 (type locality: Suruga Bay); Kuroda, 1952: 173, fig. 6 (Suruga Bay).

Repomucenus lunatus: Nakabo, 1982: 81 (listed).

Materials examined: FAKU 48803, a female, $94.5 \mathrm{~mm}$ in standard length, Mimase, Kochi, Nov. 12, 1975. FAKU 49085-49094, 8 males and 2 females, 44.0 $54.5 \mathrm{~mm}$, Kochi, Mar. 23, 1976. FAKU 49121, a female, 107.5mm, Akaoka, Kochi, Nov. 14, 1975. FAKU 49334-49339, 4 males and 2 females, 121.2-156.3 mm, Nishimaizuru, Kyoto Pref., May 17, 1974. FAKU 49379-49399, 49432, 9 males and 13 females, 98.0-118.0 mm, Mimase, Kochi, Oct. 22, 1976. FAKU 49899-49900, a male and a female, 137.4-145.5 mm, Wakasa Bay, May-June, 1978. FAKU 50046, a male, $115.8 \mathrm{~mm}$, Samchenpo, Korea, Feb. 27, 1980. FAKU 50047, a male, 123. $5 \mathrm{~mm}$, Pusan, Korea, Feb. 28, 1980. FAKU 50094, a male, $114.4 \mathrm{~mm}$, Choshi, Chiba Pref., May 8-9, 1980.

Description: D. IV, 9; A. 9; $\mathrm{P}_{1}$. i $+17-20 ; \mathrm{P}_{2}$. I, 5; C. $\mathrm{i}+7+\mathrm{ii}$.

Preopercular spine short, with an antrorse process at base, 2-3 upward processes 

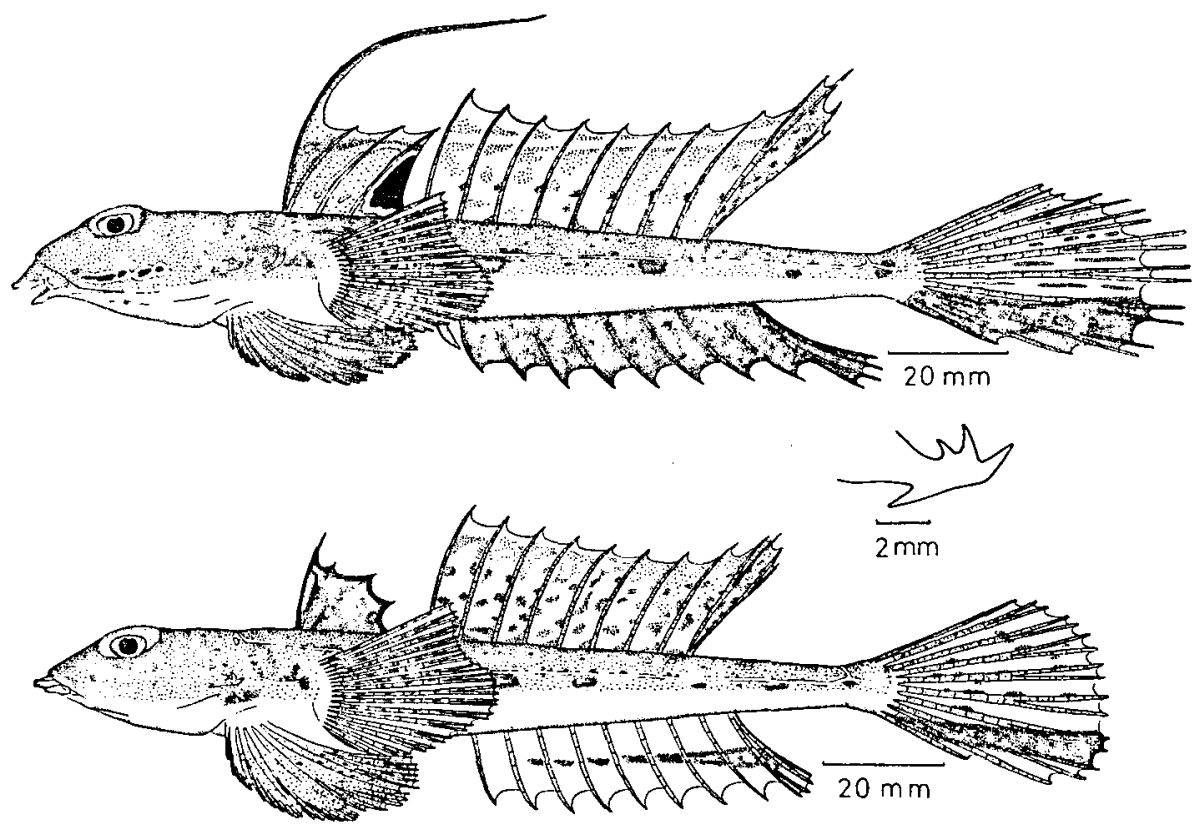

Fig. 23. Repomucenus lunatus (Temminck and Schlegel). Upper, a male, $145.5 \mathrm{~mm}$ SL, FAKU 49900; middle, preopercular spine of FAKU 49397, $93.6 \mathrm{~mm}$; lower, a female, $137.4 \mathrm{~mm}$, FAKU 49899.

on inner side; posterior end slightly curved upward. Infraorbital canal extending to preorbital region with an antrorse short branch near ventroposterior edge of eye and 3 downward branches below eye.

First dorsal spine elongate and filamentous in males, but not in females and young males. Pectoral fin reaching 2nd anal ray. Pelvic fin not reaching lst anal ray. Median 6 caudal rays slightly filamentous in males; caudal fin rounded in females.

Color in life. Body marbled brown above like the surface of a sandy bottom, white below. Floor of mouth transparent. Some oblong blue marks with yellowish margin on cheek in males, but not in females. Longitudinal light blue line on mid-axis of lateral side of body, lower part gold in males. Some dark marks on mid-axis of lateral side of body in both sexes. First dorsal fin yellow with some undulating white lines and white-margined black crescent mark behind 4th dorsal spine in males; uniformly black, or black with some oblong white marks in females. Second dorsal fin with 2 or 3 yellow spots and 2 or 3 light blue spots on each membrane, a longitudinal yellow line near distal margin in males; about 3 yellowish-brown marks on each membrane and yellow distal margin in females. Upper half of pectoral fin with many small dark spots. Pelvic fin bluish-black in males, faintly dark in females. Anal fin unifromly bluish-black in males; a longitudinal dark line on its middle part in females. Upper half of caudal fin with small dark and yellow marks; lower half bluish-black in males, with a longitudinal broad black band in females. 
Color in $10 \%$ formalin. Yellow and blue colors disappeared. Bluish-black color changed to black.

Remarks: A female specimen, reported as $R$. lunatus from Tsuruga, Japan, by Schmidt and Lindberg (1930), appears to be a female of Repomucenus beniteguri as judged by the coloration of its first dorsal fin.

Three females of Callionymus lunatus, reported by Regan (1905) from Inland Sea of Japan, are the females of Repomucenus valenciennei judging from the first dorsal spine length and coloration of the first dorsal fin.

Günther (1880) and Macleay (1884) reported this species from Port Jackson, Australia. Their specimens, however, should belong to a species yet to be identified, because during my research for Australian dragonets $I$ have not been able to find any specimens of this species and the coloration of the specimen described by Macleay (1884) does not agree with that of the specimens examined in this study which agree with the original description.

This species is distributed along the coasts of Japan and adjacent waters.

\section{Repomucenus planus (Ochiai)}

(Japanese name: Hera-numeri)

(Fig. 24)

Callionymus planus Ochiai, 1955: 106, figs. 4-5 (type locality: Miya, Aichi Pref.; in Ochiai et al., 1955).

Repomucenus planus: Nakabo, 1982: 81 (listed).

Materials examined: FAKU 16960, 16961, 17167 (paratypes), 3 females,
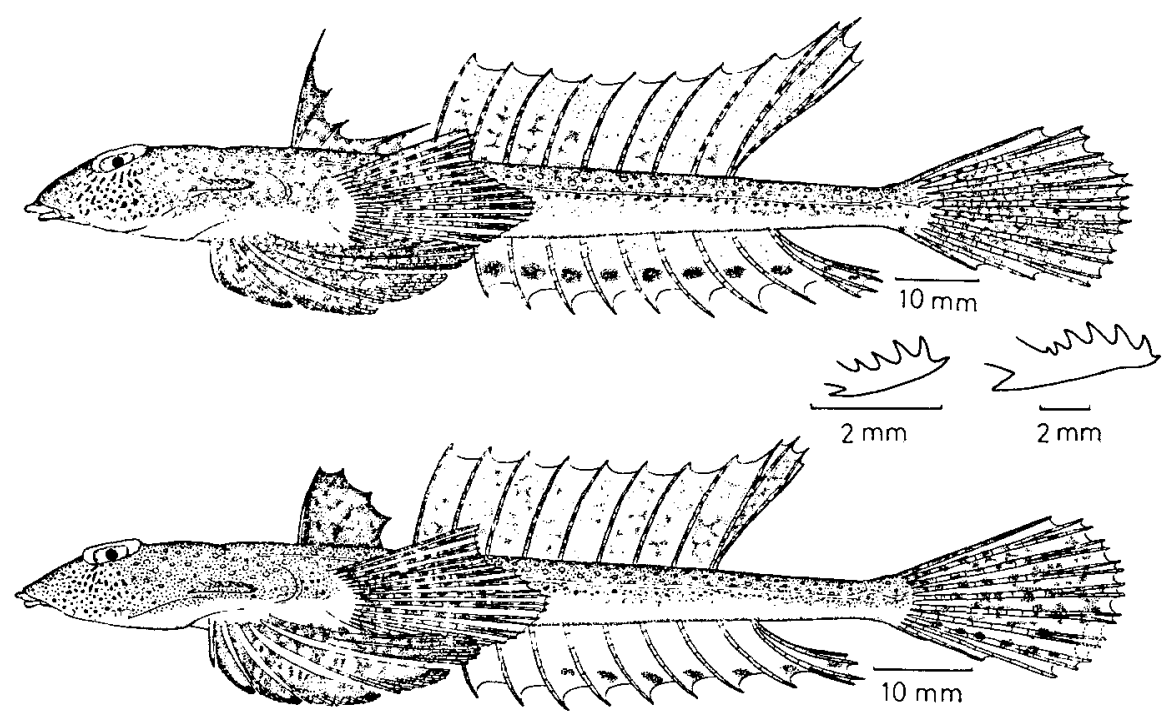

Fig. 24. Repomucenus planus (Ochiai). Upper, a male, $102.1 \mathrm{~mm} \mathrm{SL,} \mathrm{FAKU} \mathrm{49707;}$ middle, preopercular spines of a young, $23.4 \mathrm{~mm}$, FAKU 48812 (left) and an adult, $81.4 \mathrm{~mm}$, FAKU 49061 (right); lower, a female, $86.7 \mathrm{~mm}$, MU 5389. 
88.2-95.9 mm, Miya, Aichi Pref., Jan.-Sep., 1951. FAKU 21893 (paratype), a female, 86.3 mm, Mimase, Kochi Pref., Apr. 15, 1954. FAKU 23638, 23641, 23642 (paratypes), 3 females, 70.6-77.5 mm, Owase, Mie Pref., Oct. 20, 1954. FAKU 26755, 26756, 2 males, 65.8-79.2 mm, Mimase, Oct. 5, 1956. FAKU 48810-48818, 49362, 49363, 7 males and 4 females, 23.4-76.3 mm, Akaoka, Kochi Pref., Nov. $12-$ 14, 1975. FAKU 49061-49063, 49082-49084, NSMT-P 21031-21032, 3 males and 5 females, 43.7-90.5 mm, Aoshima, Miyazaki Pref., July 23, 1975. FAKU 49707, a male, $102.1 \mathrm{~mm}$, Yatsushiro Bay, Kumamoto Pref., June 30, 1976. MU 3431, 3432, 4145, 4269, 5382-5385, 5389, 5 males and 4 females, 71.2-95.6 mm, Aoshima, Miyazaki Pref., Apr. 17-June 23, 1975. BSKU 7132, 13794, 13835-13837, 5 males, 63.5-76.0 mm, Mimase, July-Oct., 1956.

Description: D. IV, 9 (rarely 10); A. 9; $\mathrm{P}_{1}$. i $+17-21$; $\mathrm{P}_{2}$. I, 5; C. i+7+ii.

Body strongly depressed. Preopercular spine long, with an antrorse process at base, 3-6 upward processes on inner side. Infraorbital canal extending to preorbital region with an antrorse branch near posterior edge of eye and 3 downward branches below eye.

First dorsal fin small and strongly emarginated in males. Pectoral fin reaching 3rd-4th dorsal rays. Pelvic fin reaching 1st anal ray. Caudal fin rounded.

Color in $10 \%$ formalin. Dorsal surface of body brown with many small white spots like the surface of a sandy bottom, ventral surface white. Floor of mouth transparent. First dorsal fin with cloud-like dark marks in males, uniformly black in females. Second dorsal fin dark with many small white spots. Upper half of pectoral fin with many small dark spots. Pelvic fin dark with many white marks. Anal fin with a dark mark on each membrane in both sexes, but some females and young males without these dark marks. Caudal fin dark with many small white spots like the surface of a sandy bottom.

Remarks: This species is closely related to Repomucenus macdonaldi (Ogilby) and Repomucenus schaapii (Bleeker) in its general physiognomy, particularly in the preopercular spine, cephalic lateral line pattern and strongly depressed body, but differs from them in the first dorsal fin.

This species is very like $R$. lunatus and $R$. valenciennei in its cephalic lateral line pattern.

This species is distributed only along the southern Pacific coast of Japan, in very shallow waters. Takegawa and Morino (1970) reported this species from Wakasa Bay, but this is a doubtful recording as I could find no examples of this species in the western part of the Sea of Japan.

12) Genus Spinicapitichthys Fricke, 1980

Spinicapitichthys draconis (Nakabo)

(Japanese name: Tatsu-numeri)

(Fig. 25)

Callionymus draconis Nakabo, 1977: 98, figs. 1, 2 (type locality: Mimase market, Kochi Pref.). 

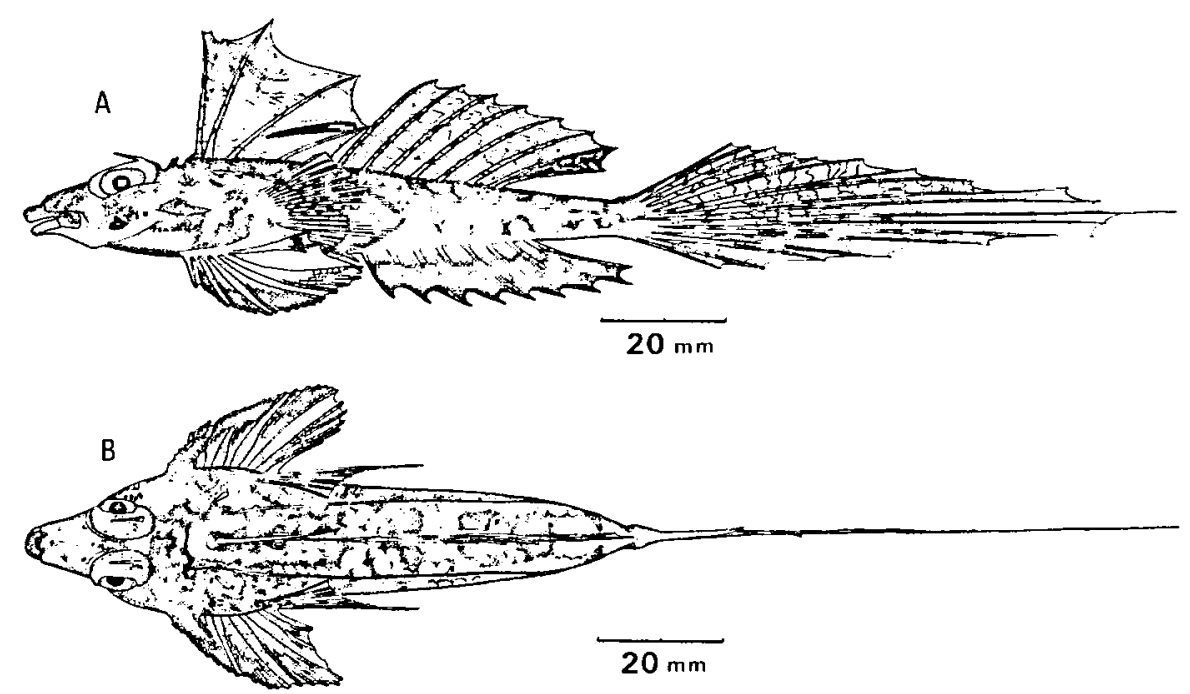

Fig. 25. Spinicapitichthys draconis (Nakabo). A, lateral view of a male, $93.8 \mathrm{~mm}$ SL, FAKU 48882 (holotype); B, dorsal view of a male, FAKU 48882. After Nakabo, 1977.

Spinicapitichthys draconis: Nakabo, 1982: 82 (listed).

Material examined: FAKU 48882 (holotype), a male, $93.8 \mathrm{~mm}$, Mimase market, Kochi Pref., Nov. 13, 1975.

Description: D. IV, 7; A. 8; $\mathrm{P}_{1}$. ii $+19 ; \mathrm{P}_{2}$. I, 5; C. $8+\mathrm{ii}$.

A thread-like cirrus on dorsoposterior edge of eye. Occipital region with a pair of bicuspid processes. Gill-opening located behind beginning of 1st dorsal fin. Preopercular spine with 5-6 processes on both inner and outer sides. Supraorbital canal extending to a little behind nasal pore. Infraorbital canal simple, not extending below eye. Lateral line reaching distal end of median caudal ray.

No dorsal spine filamentous. Pectoral fin reaching 4th dorsal ray. Pelvic fin reaching 1st anal ray. Caudal fin elongate and lanceolate.

Color in life. Body marbled dark brown, whitish below, several white circles on lower side of body. Surface of throat dark brown. First dorsal fin with several undulating elongated yellow marks, one oblong black mark on middle part of membrane between 3rd and 4th spines. Second dorsal with 3-4 series of yellow spots; 3-4 dark brown spots on each ray; membrane between last two rays blackish. Upper half of pectoral fin with many small dark spots. Pelvic fin dark. Anal fin black with pale proximal part. Caudal fin with yellow spots and brown cross-bars.

Color in $10 \%$ formalin. Body marbled blackish dark brown, whitish below. Faded yellow spots.

REMARKs: Nakabo (1977) mistakenly described the lateral line in this species. He said it reached the base of the caudal fin, but it really reaches the distal end of a median caudal ray. 
13) Genus Anaora Gray, 1835

\title{
Anaora tentaculata Gray
}

(Japanese name: Tanzaku-teguri)

(Fig. 26)

\begin{abstract}
Anaora tentaculata Gray, 1835: "Directions for arranging the plates" of "Illustrations of Indian zoology"; Herre, 1953: 781 (listed); Nakabo and Iwata, 1979: 89, figs. 1, 2 (Ishigaki Isl., Okinawa); Nakabo, 1982: 82 (listed).

Amora tentaculatı Gray, 1835: pl. 90, figs. 1, 1a, 1b (type locality: Amboina, Indonesia); Bleeker, 1879: 107 (reference); Fowler, 1941: 30 (Port Calton; Port Galea, Mindoro; Romblon; Sandakan Bay, Borneo; Great Tobea Isl.).

Callionymus tentaculatus: de Beaufort, 1951: 67 (Sandakan, Borneo; Sulu Isls.; Makassar, Celebes). Callionymus fimbriatus Herre, 1934: 93 (type locality: Shitankai Reef).
\end{abstract}

Materials examined: MTUF 23470, 23471, 2 females, 28.5-34.2 mm, Mar. 21, 1977. MTUF 23472, a female, $26.3 \mathrm{~mm}$, Aug. 17, 1977. YCM-P 1450, a male and a female, 28.7-38.5 mm, Apr. 25, 1974. All the above specimens were taken from Kabira Bay, Ishigaki Isl. USMN 139346, a male and 7 females, 19.0-30.4 mm, Buton Straight Region, Great Tobea Is., Dec. 15, 1909. USNM 139347, a female, $34.9 \mathrm{~mm}$, Pandanon Isl. (between Cebu and Bohd), Dec. 15, 1909. CASSU 25516 (holotype of Callionymus fimbriatus), a female, $29.4 \mathrm{~mm}$, Shitankai Reef, the Philippines, Aug., 1931.

Description: D. IV, 8 (rarely 9); A. 7 (rarely 6); $\mathrm{P}_{1}$. ix $-\mathrm{xiii}+1-7+\mathrm{v}-\mathrm{x}$
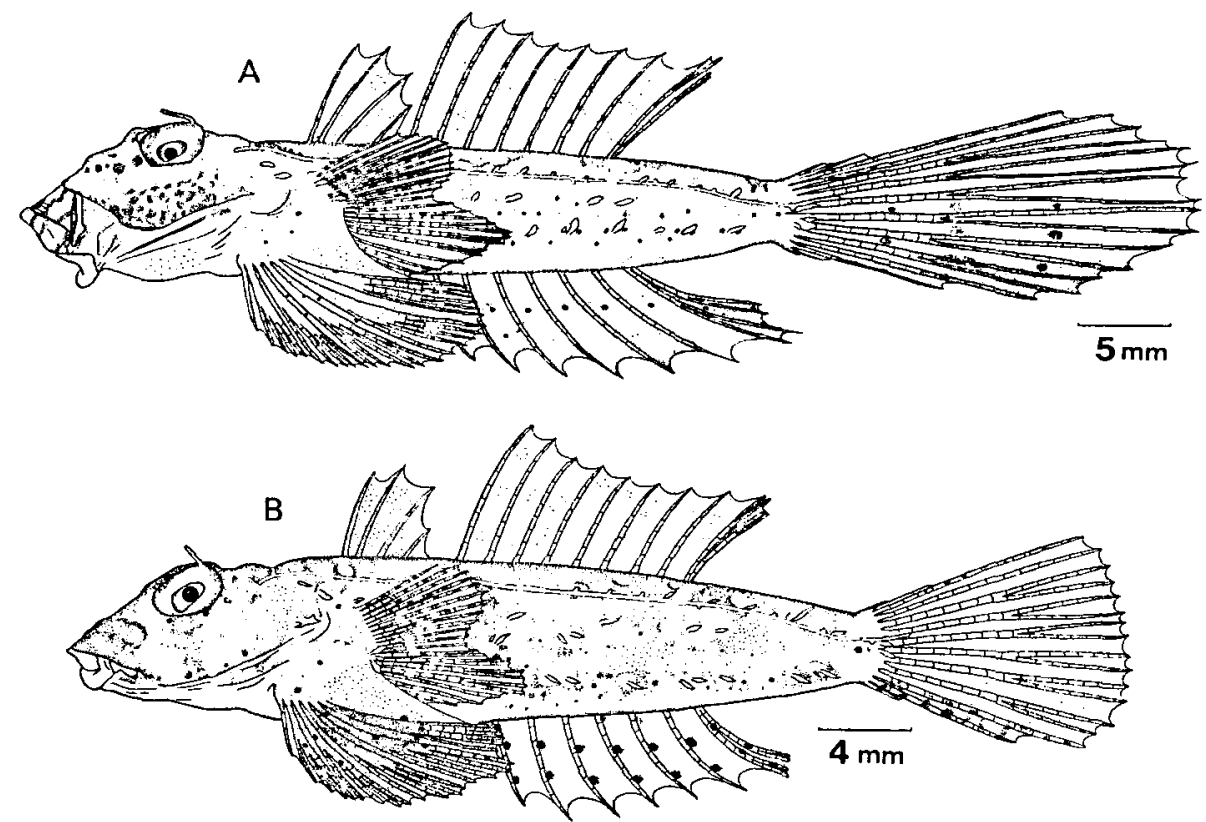

Fig. 26. Anaora tentaculata Gray. A, a male, $38.5 \mathrm{~mm} \mathrm{SL}$, YCM-P $1450 \mathrm{a}$; B, a female, 34.2 mm, MTUF 23470. After Nakabo and Iwata, 1979. 
(total, 2l-25); $\mathrm{P}_{2}$. I, 5; G. ii $+6+\mathrm{ii}$ (rarely, $\mathrm{l}+\mathrm{i}+6+\mathrm{ii}, \mathrm{ii}+\mathrm{l}+\mathrm{i}+4+\mathrm{ii}$ ).

Several short cirri on lateral side of body behind preopercular spine. Preopercular spine with an antrorse process at base, an upward process on inner side. Lateral line reaching beginning of median caudal ray. Infraorbital canal simple, extending to ventroposterior edge of eye.

First dorsal fin beginning after gill-opening; No dorsal spine filamentous in either sex. Pectoral fin notched: upper half round, lower half lanceolate; reaching $3 \mathrm{rd}$ anal ray in males, 2 nd in females. Pelvic fin reaching $2 \mathrm{nd}$ anal ray in males, 1st in females. Caudal fin round, much longer in males than in females.

Color in 10\% formalin. Body marbled sepia-brown, whitish below. Many dark brown spots on cheek in males, but not in females. Three series of dark spots on caudal fin membrane in males, but not in females. Lower margin of caudal fin dark brown in males, but striped in females. In males, lower half of anal fin dark brown with one or two black spots on each membrane, but transparent with two or three series of black spots in females. In specimens from the Philippines, preserved in $70 \%$ alcohol, body pinkish in both sexes.

\section{4) Genus Eleutherochir Bleeker, 1879}

Key to the species of Eleutherochir

$A_{1}$ First dorsal fin present, 9 dorsal and 9 anal rays, upper jaw protruded

E. opercularis (Valenciennes) (p. 250)

$\mathrm{A}_{2}$ First dorsal fin absent, 12-14 dorsal and 12-14 anal rays, lower jaw protruded E. mirabilis (Snyder) (p. 252).

\section{Eleutherochir opercularis (Valeciennes)}

(New Japanese name: Ohkuchi-numeri)

(Fig. 27)

Callionymus opercularis Valenciennes, 1837: 228 (type locality: mouth of Arian-Coupan River); Günther, 1861: 151 (reference); Day, 1875: 323 (Pondicherry and Madras); Weber, 1913: 522 (Menado; Ambon); Ninni, 1934: 51, pl. 11 (Red Sea).

Callionymus operculariotdes Bleeker, 1851 : 32 (type locality; Batjan).

Synchiropus opercularis: Gill, 1860: 130 (reference).

Synchiropus (Eleutherochir) opercularis: Herre, 1953: 781 (listed).

Synchiropus opercularoides: Gill, 1860: 130 (reference).

Eleutherochir opercularis: Fowler, 1941: 26 (Philippines); de Beaufort, 1951: 77 (Pulu Weh; Sumatra; Java; Bali; Celebes; Ternate; Batjan; Ceram; Ambon; Gebe; New Guinea; Philippines); Smith, 1963: 558, pl. 84, fig. N (reference); Munro, 1967: 471 (New Guinea); Nakabo, 1982: 82 (listed). Guebe).

Eleutherochir opercularioides: Bleeker, 1879: 103 (Sumatra; Bali; Celebes; Batjan; Ceram; Amboina;

Brachycallionymus mirus Herre, 1936: 12 (type locality: north coast of Celebes).

Pogonymus goslinei Rao, 1975: 27, fig. 1 (type locality: Ennore estuary, India).

Materials examined: YCM-SP 7600, a male, $66.3 \mathrm{~mm}$ in standard length, 

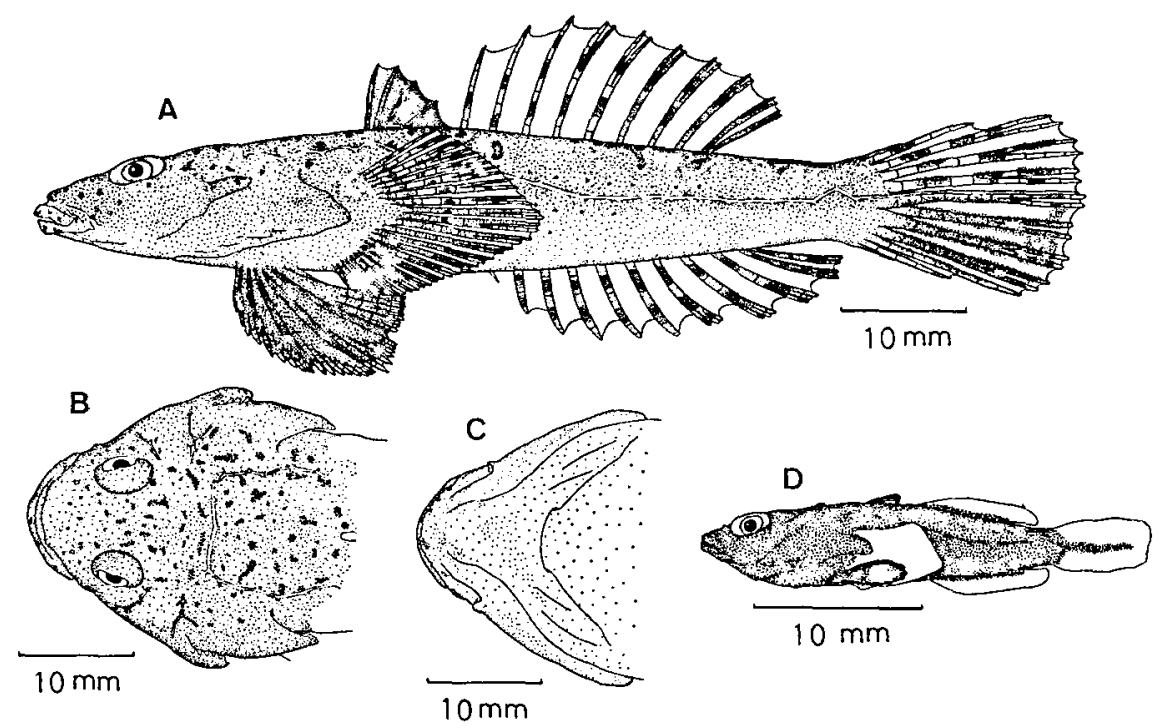

Fig. 27. Eleutherochir opercularis (Valenciennes). A, lateral view of a male, $66.3 \mathrm{~mm} \mathrm{SL}$, YCM-SP 7600; $B$ and C, dorsal and ventral view of the head of a male, YCM-SP 7600 ; D, juvenile specimen, 19.7 mm, FAKU 50423.

mouth of Yona River, Okinawa Pref., May 1980. FAKU 50423, one young, 19.7 mm, Yonehara, Ishigaki Isl., July 5, 1980.

Description: D. IV, 9; A. 9; $\mathrm{P}_{1} . \mathrm{i}+23$ (24 in young); $\mathbf{P}_{2} . \mathrm{I}, 5 ;$ C. $1+7+\mathrm{ii}$ (10 in young).

Body slightly depressed. Head strongly depressed. Upper jaw slightly protruded more anterior than lower jaw. Interorbital width very wide. Preopercular spine with no antrorse process at base, 3-5 upward processes on inner side; posterior end strongly curved upward. Isthmial fold at throat. Infraorbital canal extending below middle part of eye with a short downward branch at anterior part, an antrorse branch at ventroposterior edge of eye. Dorsal part of preoperculomandibular canal with a short antrorse and retrorse branch, below them long retrorse one.

First dorsal fin small, beginning a little behind upper origin of pectoral fin. Tips of dorsal rays at posterior half of fin bifurcate. Pectoral fin double truncate, reaching 3rd dorsal ray. Pelvic fin rounded, not reaching 1 st anal ray. Anal rays of anterior half of fin thick; tips of 6th-8th anal rays trifurcate; tip of each branch of last lay bifurcate. Caudal fin rounded.

Color in $10 \%$ formalin. In adult male, body dark brown with many darker spots above, faintly dark below. First dorsal fin faintly dark at first membrane, otherwise black. Second dorsal fin transparent; dorsal rays with some dark spots. Upper half of pectoral fin transparent with many small dark spots, lower half dark with transparent posterior margin. Pelvic fin uniformly dark brown. Anal fin transparent; anal rays with some dark spots. Upper half of caudal fin with some dark spots, lower half dark with transparent posterior margin. In young, body uniformly blackish-brown. First dorsal fin faintly dark at first membrane, otherwise 
black. Pelvic fin uniformly blackish-brown. Pectoral, second dorsal, anal and caudal fins almost transparent.

REMARKs: Eleutherochir opercularis is closely related to Eleutherochir shango (Davis and Robins), Eleutherochir celetus (Smith) and Eleutherochir mirabilis (Snyder) in having an isthmial fold.

$E$. opercularioides (Bleeker) seems to be a synonym for this species, as it is very alike in the color pattern and preopercular spine. Thus, I agree with the states of Day (1876), Weber (1913), Fowler (1941) and de Beaufort (1951).

Pogonymus goslinei Rao is so similar in its general physiognomy that it must be a synonym for this species.

This species is new to Japan.

\section{Eleutherochir mirabilis (Snyder)}

(Japanese name: Bake-numeri)

(Fig. 28)

Draculo mirabilis Snyder, 1911: 545 (type locality: sandy beach near Tomakomai, Hokkaido); Snyder, 1912: 447, pl. 62, fig. 2 (reference); Mori, 1952: 133 (coast of North Cella Pref.); Böhlke, 1953: 104 (listed); Matsubara, 1955: 716 (key); Tchang et al., 1955: 179, fig. 114 (Hopeh, Po Hai); Kobayashi and Abe, 1962: 161, fig. 5 (southeast coast of Hokkaido); Ueno, 1971: 83 (north coast of the Shakotan Peninsula); Arai, 1971 ; 33, figs. 1-5 (Samani, Hokkaido); Ishikawa, 1978: 1, figs. 1-5 (shallow area of sea along Ibaraki Pref.).

Eleutherochir mirabilis: Nakabo, 1982: 82 (listed).

Draculus mirabilis: Jordan, Tanaka and Snyder, 1913: 377 (listed).
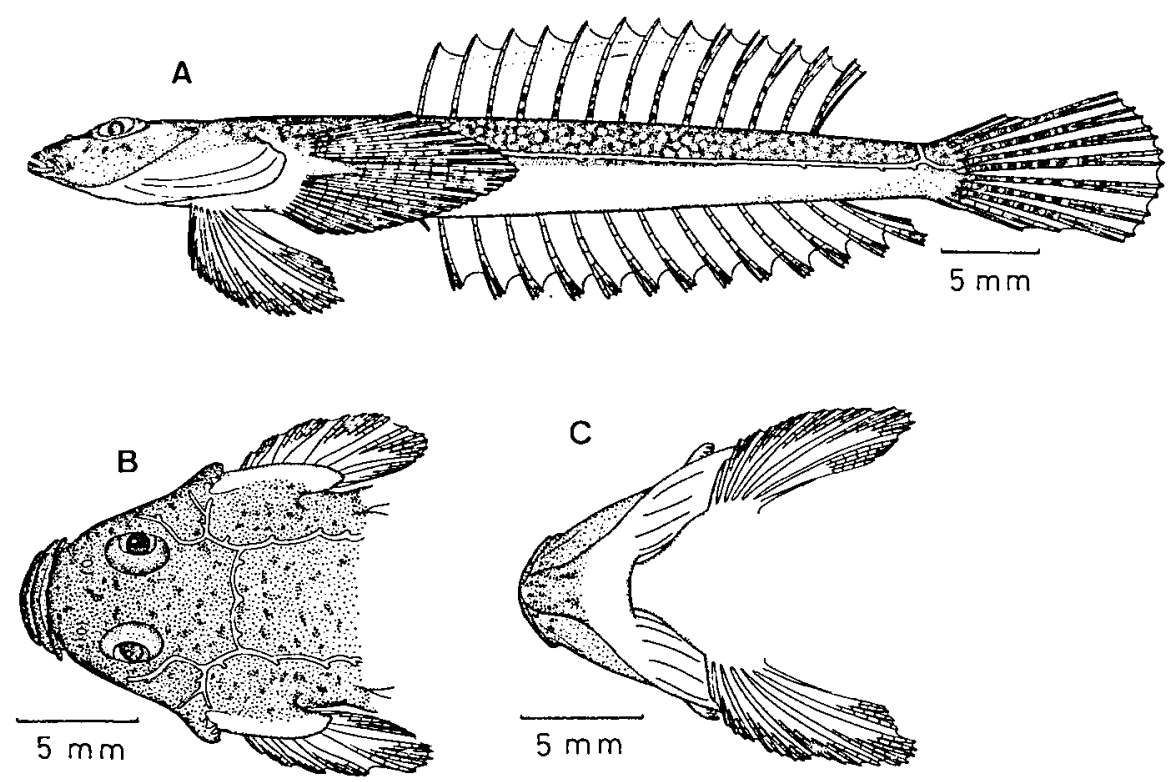

Fig. 28. Eleutherochir mirabilis (Snyder). A, a male, $44.6 \mathrm{~mm}$, FAKU 49995; B and C, dorsal and ventral view of the head of a male, FAKU 49995. 
Materials examined: NSMT-P 10208-10212, 5 females, $37.5-49.5 \mathrm{~mm}$, Nishi-u, Samani, Hokkaido, Aug. 15, 1970. HUMZ 54428, 54429, 2 females, 37.739.9 mm, Usujiri, Funka Bay, Hokkaido, July 13, 1976. FAKU 49995-49996, 2 males, 37.5-46.6 mm, Tokai-mura, Ibaraki Pref., Oct. 22, 1976. FAKU 5037650399, 13 males and 11 females, 40.3-54.1 mm, Oarai, Ibaraki Pref., June 14, 1974.

Description: D. 13 (rarely 12, 14); A. 13 (rarely 12, 14); $\mathrm{P}_{1} . \mathrm{i}+16-20$ (rarely 21); $\mathrm{P}_{2}$. I, $5 ;$ C. $\mathrm{ii}+6+\mathrm{ii}$ or $\mathrm{i}+7+\mathrm{ii}$ (rarely $\mathrm{i}+8+\mathrm{ii}, \mathrm{ii}+3+\mathrm{i}+2+\mathrm{ii}$ ).

Body depressed and more elongate. Head strongly depressed. Preopercular spine with 2-4 upward processes on inner side; posterior end strongly curved upward. Isthmial fold at throat. Infraorbital canal extending below middle part of eye with a downward short branch at anterior part, an antrorse short branch at ventroposterior edge of eye. Dorsal part of preoperculomandibular canal with a short antrorse branch, below it a long retrorse branch. Caudal peduncle compressed.

First dorsal fin absent. Pectoral fin double truncate, reaching 4th anal ray, longer than pelvic fin. Pelvic fin rounded, not reaching 1st anal ray. Tip of each anal ray trifurcate. Caudal fin rounded.

Golor in $10 \%$ formalin. Body brown with many small white circles and dark spots above like the surface of a sandy bottom, white below. Dorsal fin transparent with a longitudinal white line at dorsoanterior part in males, only transparent in females. Pectoral, pelvic and anal fins transparent. Caudal fin with many small dark spots on each ray.

Remarks: This species is closely related to $E$. opercularis, but differs from it in having no first dorsal fin, 12-14 dorsal and 12-14 anal rays, a protruded lower jaw, compressed caudal peduncle and more elongate body. E. mirabilis does not seem to swim like creeping on sandy bottoms, but appears to be free swimming as judged by its compressed caudal peduncle and more elongate body.

\section{Acknowledgements}

I wish to thank Dr. Tamotsu Iwai of Kyoto University who has been a constant source of help throughout this study and made a critical reading the manuscript. Special thanks are extended to Dr. Akira Ochiai of Kochi University and Dr. Eiji Harada of Seto Marine Biological Laboratory.

This study would not have been possible without the generous cooperation of the following people: Dr. James E. Böhlke of the Academy of Natural Sciences of Philadelphia; Mr. Alwyne Wheeler of British Museum (Natural History), London; Dr. William N. Eschmeyer of California Academy of Sciences, San Francisco; Mr. Tetsuo Kuwamura of Chukyo University; Dr. Yasunobu Yanagisawa and Mr. Akihisa Iwata of Ehime University; Dr. Osamu Okamura and Ms. Fusa Yamachi of Kochi University; Mr. Takeshi Yamakawa of Kochi Senior High School; Mr. Masahiro Munekiyo of Kyoto Institute of Oceanic and Fishery Science, Miyazu; Dr. Izumi Nakamura, Messers. Takashi Minami, Ryuzo Fukao, Yoichi Takahashi, Masahiro Ishihara, Takayuki Ariyama, Naozumi Miyabe and Kiyotaka Hatooka of 
Kyoto University; Dr. Akihiro Ohkata and Mr. Koki Ishikawa of Ibaraki Prefectural Fisheries Experiment Station; Mr. Hajime Masuda of Tokai University; Dr. Katsumi Suzuki and Mr. Yoshihisa Shiobara of Marine Science Museum, Tokai University, Shimizu; Dr. Masato Akazaki of Miyazaki University; Drs. Shinji Kudo and Masahiro Toriyama of the Nansei Regional Fisheries Research Laboratory; Dr. Toru Takita and Toshiyuki Suzuki of Nagasaki University; Drs. Teruya Uyeno and Ryoichi Arai of National Science Museum, Tokyo; Dr: Yoshiharu Honma of Niigata University; Drs. Marinus Boeseman and M.S. Hoogmoed of Rijksmuseum van Natuurlijke Historie, Leiden; Messers. Tetsuo Yoshino, Mutsumi Nishida and Hiroshi Senou of University of the Ryukyus; Dr. Fumio Mitani of Sanyo Suiro Sokuryo Inc.; Drs. Shin-ichi Mio, Keiichiro Mori, Messrs. Masanori Azeta, Shuzo Kishida and Umeyoshi Yamada of Seikai Regional Fisheries Laboratory; Dr. Shunpei Kojima and Mr. Koretake Takahashi of Shimane Prefectural Fisheries Experiment Station; Mr. Eiichi Fujii of Suruga Bay Marine Biology Research Group; Dr. Fujio Yasuda of Tokyo University of Fisheries; Dr. Masayoshi Hayashi of Yokosuka City Museum; Dr. Robert R. Miller and Mr. Stuart G. Poss of University of Michigan; Dr. Yoshiaki Tominaga of University of Tokyo; Dr. Muneo Okiyama of Ocean Research Institute, University of Tokyo.

This study was supported in part by grants from the Ito Foundation for the Advancement of Ichthyology.

\section{REFERENGES}

Alcock, A. 1899. A descriptive catalogue of the Indian deep-sea fishes in the Indian Museum. Being a revised account of the deep-sea fishes collected by the Royal Indian Marine Survey Ship "Investigator", Calcutta, iii +211pp.

Arai, R. 1971. Record of the dragonet, Draculo mirabilis Snyder, from Hokkaido, Japan. Japan. J. Ichthyol., 18(1): 33-35.

Arai, R. and T. Abe. 1970. The sea fishes of the Tsushima Islands, Japan. Mem. Nat. Sci. Mus., (3): 83-100. (In Japanese).

Bleeker, P. 1851. Over twee nieuwe soorten van Callionvmus van den Indischen Archipel. Nat. Tijdschr. Ned. Ind., 1: 28-32.

Bleeker, P. 1854. Faunae ichthyologicae japonicae species novae. Nat. Tijdschr. Ned. Ind., 6: 395426.

Bleeker, P. 1859. Vierde bijdrage tot de kennis der ichthyologische fauna van Japan. Act. Soc. Sc. Indo-Neerl. 5: 1-12.

Bleeker, P. 1879. Révision des espèces insulindiennes de la famille des Callionymides. Versl. Meded. Akad. Afd. Nat., 2nd Ser., 14: 79-107.

Blegvad, H. 1944. Fishes of the Iranian Gulf. Danish Scientific Investigations in Iran, Part 3: 1-247.

Boeseman, M. 1947. Revision of the fishes collected by Burger and Von Siebold in Japan. Zool. Meded., 28: 1-242.

Böhlke, J. 1953. A catalogue of the type specimens of recent fishes in the Natural History Museum of Stanford University. Stanford Ichthyol. Bull., 5: 1-168.

Chu, Y. et al. 1962. Fishes of the South China Sea. Scientific Publ. Agency, Peking, xxxxi+1184pp. (In Chinese).

Chu, Y., T. Tchang and C. Cheng. 1963. Fishes of the East China Sea. Scientific Publ. Agency, Peking, xxviii +642pp. (In Chinese).

Davis, W.P. and G.R. Robins. 1966. The R/V Pillsbury deep-sea biological expedition to the Gulf of Guinea, 1964-65. 4. Pogonymus shango, a new Callionymid fish from quartz sand beaches 
of Nigeria, with notes on related species. Stud. Tropical Oceanogr. Miami, 4(1): 106-116.

Day, F., 1875. The fishes of India; being a natural history of the fishes known to inhabit the seas and fresh waters of India, Burma and Ceylon. London, $x x+778 p p$.

de Beaufort, L.F. 1951. Family Callionymidae. pp. 50-81. In L.F. de Beaufort and W.M. Chapman: Fishes of the Indo-Australian Archipelago, Vol. 9, Percomorpbi (concluded), Blennoidea, E.J. Brill, Leiden.

Fowler, H.W. 1928. The fishes of Oceania. Mem. Bernice P. Bishop Mus., 10: i-iii+1-540.

Fowler, H.W. 1938. A list of the fishes known from Malaya. Fisher. Bull., 1: 1-268.

Fowler, H.W. 1941. New fishes of the family Callionymidae, mostly Philippine, obtained by the United States Bureau of Fisheries Steamer "Albatross". Proc. U.S. Nat. Mus., 90(3106): 1-31.

Fowler, H.W. 1943. Descriptions and figures of new fishes obtained in Philippine seas and adjacent waters by the United States Bureau of Fisheries Steamer "Albatross". Contributions to the biology of the Philippine archipelago and adjacent regions. Bull. U.S. Nat. Mus., 14(2): i-iii+ 53-91.

Fowler, H.W. 1946. A collection of fishes obtained in the Riukiu Islands by captain Ernest R. Tinkham A.U.S. Proc. Acad. Nat. Sci. Philad., 98: 123-218.

Franz, V. 1910. Die Japanischen Knochenfische der Sammlungen Haberer und Doflein. Beitr. Naturgesch. Ost. Abhandlungen der match.-phys. Klasse der K. Bayer Akad. der Wisse., IV, Suppl-Bd, $1: 1-135$.

Fricke, R. 1981a. Revision of the genus Synchiropus (Teleostei: Callionymidae). Theses Zoologicae, 1. J. Gramer, Braunschweig, 194pp.

Fricke, R. 1981b. The kaianus-group of the genus Callionymus (Pisces: Callionymidae), with description of six new species. Proc. Calif. Acad. Sci., 42(14): 349-377.

Fricke, R. 1981c. Four new species of the genus Callionymus (Teleostei: Callionymidae) from the Philippine Islands and adjacent areas. Zool. Beitr., Neue Folge, 27(1): 143-170.

Fricke, R. 1982. New species of Callionymus, with a revision of the variegatus-group of that genus (Teleostei: Callionymidae). J. Nat. Hist., 1982, 16: 127-146.

Fujita, T. and Y. Wakiya. 1915. List of fishes found in province Kii. Suisan-gakkaiho, 1(1): 25-37. (In Japanese).

Gill, T.N. 1860. On the genus Callionymus of authors. Proc. Acad. Nat. Sci. Philad. 1859: 128-130.

Giltay, L. 1933. Poissons. Mem. Mus. Roy. Hist. Nat. Belge. Hors. ser., 5(3): 1-129.

Gray, J.E. 1835. Illustrations of Indian Zoology; chiefly selected from the collection of Major-General Hardwicke, F.R.S. Vol. 2. Adolphus Richiter, London.

Günther, A. 1861. Calalogue of the fishes in the British Museum, 3, London, xxv +586pp.

Günther, A. 1876. Andrew Garrett's Fische der Südsee II. J. Mus., Godeffroy, 4: i-ii +129-256.

Günther, A. 1880. Report of the shore fishes procured during the Voyage of H.M.S. "Challenger" in the years 1873-76. Rep. Sci. Expl. Voy. H.M.S. "Challenger," Zool., 1(6): 1-82.

Herre, A.W. 1927. A new genus and three new species of Philippine fishes. Philip. J. Sci., 32(3): 413-419.

Herre, A.W. 1934. Notes on fishes in the Zoological Museum of Stanford University. 1. The fishes of the Herre Philippine Expedition of 1931. Newspaper Enterprise, Hong Kong, 106pp.

Herre, A.W. 1936. Notes on fishes in the Zoological Museum of Stanford University. IV. A new catostomid from Mexico and a new callionymid from Celebes and Philippines. Proc. Biol. Soc. Wash., 49: 11-14.

Herre, A.W. 1940. Additions to the fish fauna of Malaya and notes on rare or little known Malayan and Bornean fishes. Bull. Raffles Mus., (16): 27-61.

Herre, A.W. 1953. Check list of Philippine fishes. Fish and Wildlife service, U.S. Dept. Inst., Res. Rep., (20): 1-977.

Hikita, T. 1951. Fishes of Volcano Bay in Hokkaido. Japan. J. Ichthyol., 1(5): 306-313.

Honma, Y. 1952. A list of fishes collected in the province of Echigo, including Sado Island, Japan. Japan. J. Ichthyol., 2(4,5): 220-229 (In Japanese).

Houttuyn, M. 1782. Beschrijiving van eenige Japansche visschen en andere zee-schepzelen. Verh. Holl. Maatsch. Wet. Haarlem, 20(2): 1-18.

Hubbs, C.L. and K.F. Lagler. 1947. Fishes of Great Lakes region. The University of Michigan 
Press, Ann Arbor, xv+213pp.

Ishikawa, C. and K. Matsuura. 1897. Preliminary catalogue of fishes including Dipnoi, Cyclostomi and Cephalochorda in the collection of the Natural history Department, Imperial Museum. Tokyo Imperial Museum, 64pp. (In Japanese).

Ishikawa, K. 1978. Record of the dragonet, Draculo mirabilis Snyder, in the shallow sea area of Ibaraki Prefecture, Japan. Bull. Fish. Exp. st. Ibaraki-ken, 22: 1-6.

Izuka, A. and K. Matsuura. 1920. Catalogue of the zoologiacl specimens exhibited in the Natural History Department, Tokyo Imperial Museum (Vertebra). Tokyo Imperial Museum, 192pp. (In Japanese).

Johnson, C.R. 1971. Revision of the callionymid fishes referable to the genus Callionymus from Australian waters. Mem. Qd. Mus., (16): 103-140.

Johnson, C.R. 1972. The status of Callionymus phasis (Callionymidae) in Japanese waters. Japan. J. Ichthyol., 19(2): 135 .

Jordan, D.S. and H.W. Fowler. 1903. A review of the dragonets (Callionymidae) and related fishes of the waters of Japan. Proc. U.S. Nat. Mus., 25(1305) : 939-959.

Jordan, D.S. and C.L. Hubbs. 1925. Records of fishes obtained by David Star Jordan in Japan, 1922. Mem. Carnegie Mus., 10(2): 93-347.

Jordan, D.S. and C.W. Metz. 1913. A catalogue of the fishes known from the waters of Korea. Mem. Carnegie Mus., 6(2): 1-65.

Jordan, D.S. and R.E. Richardson. 1908. Fishes from islands of the Philippine Archipelago. Bull. Bur. Fish., 27(1907) : 233-287.

Jordan, D.S. and A. Seale. 1906a. Descriptions of six new species of fishes from Japan. Proc. U.S. Nat. Mus., 30 (1445): 143-148.

Jordan, D.S. and A. Seale. 1906b. The fishes of Samoa. Description of the species found in the archipelago, with a provisional check-list of the fishes of Oceania. Bull. Bur. Fisher., 25(1905): 173-455.

Jordan, D.S. and A. Seale. 1907. Fishes of the islands of Luzon and Panay. Bull. Bur. Fisher., 24 (1906): $1-48$.

Jordan, D.S. and J.O. Snyder. 1900. A list of fishes collected in Japan by Keinosuke Otakj, and by the United States Steamer Albatross, with descriptions of fourteen new species. Proc. U.S. Nat. Mus., xxiii: 335-380.

Jordan, D.S. and E.C. Starks. 1904. List of fishes dredged by the steamer "Albatross" off the coast of Japan in the summer of 1900 , with descriptions of new species and a review of the Japanese Macrouridae. Bull. U.S. Fish Comm. for 1902, 22: 577-628.

Jordan, D.S. and E.C. Starks. 1905. On a collection of fishes made in Korea, by Pierre Louis Jouy, with descriptions of new species. Proc. U.S. Nat. Mus., 28(1391): 193-212.

Jordan, D.S., S. Tanaka and J.O. Snyder, 1913. A catalogue of the fishes of Japan. J. Coll. Sci., Imp. Univ. Tokyo, 33(1): 1-497.

Jordan, D.S. and W.F. Thompson. 1914. Record of the fishes obtained in Japan in 1911. Mem. Carnegie Mus., 6(4): 205-313.

Kamohara, T. 1936a. Commercial fishes dredged by motor trawlers in prov. Tosa. Suisan Kenkyu Shi, 31(3): 1-10. (In Japanese).

Kamohara, T. 1936b. Two new deep-sea fishes from Japan. Annot. Zool. Japan, 15(4): 446-448.

Kamohara, T. 1938. On the offshore bottom-fishes of prov. Tosa, Shikoku, Japan. Maruzen, Tokyo, 86pp.

Kamohara, T. 1951. Notes on some rare fishes from Prov. Tosa, Japan. Rept. Kochi Univ., Nat. Sci., (1): 1-8.

Kamohara, T. 1952a. Revised description of the offshore bottom-fishes of Prov. Tosa, Shikoku, Japan. Rep. Kochi Univ., Nat. Sci., (3): 1-122.

Kamohara, T. 1952b. Additions to the fish fauna of Prov. Tosa, Japan. Rept. Kochi Univ., Nat. Sci., (2): $1-10$.

Kamohara, T. 1954. A list of fishes from the Tokara Islands, Kagoshima Prefecture, Japan. Publ. Seto Mar. Biol. Lab., 3(3) : 265-299.

Katayama, M. 1940. A catalogue of the fishes of Toyama Bay. Toyama Hakubutsu Gakkaishi, (3): 
1-28. (In Japanese).

Katayama, M. and Y. Fujioka. 1958. Fishes of Ooshima-gun, Yamaguti Prefecture. Bull. Fac. Agr. Yamaguti Univ,, (9): 1147-1168 (In Japanese).

Kimura, S. and K. Suzuki. 1980. Fish fauna of Ago Bay and its adjacent waters, Mie Prefecture, Japan. Rep. Fish. Res. Lab. Mie Univ., (2): 1-58.

Kobayashi, K. 1962. Ichthyofauna of Oshoro Bay and adjacent waters. Bull. Fac. Fish. Hokkaido Univ., 12(4): 253-264.

Kobayashi, K. and K. Abe. 1962. Studies in the larvae and young of fishes from the boundary zones off the southeastern coast of Hokkaido, Japan. Bull. Fac. Fish., Hokkaido Univ., 13: 165-179 (In Japanese).

Koike, M. 1936. List of aquatic animals of Fukui Pref. (Vertebrata), 15pp. (In Japanese).

Kosaka, M. 1967. Zoogeogarphical Studies on the Demersal Fishes of Sendai Bay. J. Coll. Mar. Sci. \& Tech., Tokai Univ., (2): 147-159. (In Japanese).

Kuroda, N. 1931. A catalogue of the fishes of Shizuura, Suruga Japan. Amoeba, 3(1-2): 85-127 (In Japanese).

Kuroda, N. 1951. A nominal list with distribution of the fishes of Suruga Bay, inclusive of the fresh water species found near the coast. Japan J. Ichthyol., 1(6): 376-394. (In Japanese).

Kuroda, N. 1952. Additions to the fishes of Suruga Bay (10), with corrections. Zool. Mag. 61(6): 169-177. (In Japanese).

Kuroda, N. 1954. On the life colours of some fishes, -III. Japan J. Ichthyol., 3(3-5) : 153-161. (In Japanese).

Macleay, W. 1884. Supplement to the descriptive catalogue of the fishes of Australia. Proc. Linn. Soc. N.S.W., 1(9): 2-64.

Marshall, T.C. 1965. Fishes of the Great Barrier Reef and coastal waters of Queensland. Livingston, Narberth, xvi+566pp.

Masuda, H., C. Araga and T. Yoshino. 1975. Coastal fishes of southern Japan. Tokai Univ. Press, Tokyo, 379pp.

Matsubara, K. 1955. Fish Morphology and hierarchy. pt. 1. Ishizaki Shoten, Tokyo, xi $+789 \mathrm{pp}$. (In Japanese).

McCulloch, A.R. 1915. Report on some fishes obtained by the F.I.S. "Endeavour" on the coasts of Queensland, New South Wales, Victoria, Tasmania, south and south-western Australia. Biological Results of the Fishing Experiments carried on by the F.I.S. "Endeavour" 1909-14, 3(3): 97-170.

McCulloch, A.R. 1926. Report on some fishes obtained by the F.I.S. "Endeavour" on the coasts of Queensland, New South Wales, Victoria, Tasmania, south and south-western Australia. Biological Results of the Fishing Experiments carried on by the F.I.S. "Endeavour" 1909-14, 5(4): 157-216.

Mori, T. 1952. Check list of the fishes of Korea. Mem. Hyogo Univ. Agri., 1(3): 1-228.

Mori, T. 1956. Fishes of San-in District including Oki Islands and its adjacent waters (Southern Japan Sea). Mem. Hyogo Univ. Agri. 2(3), Biol. Ser. No. 2: 1-62.

Mori, T, and K. Uchida. 1934. A Revised Catalogue of the Fishes of Korea. J. Chosen Nat. Hist. Soc., (19): 1-23.

Munro, I.S.R. 1955. The marine and fresh water fishes of Ceylon. Dept. External Affairs, Camberra, xvi $+352 \mathrm{pp}$.

Munro, I.S.R. 1967. The fishes of New Guinea. Dept. Agri. Stock Fishr., Port Moresby, xxxvii + 650 pp.

Nakabo, T. 1977. A new dragonet, Callionymus draconis, taken from Kochi Prefecture, Japan. Japan. J. Ichthyol., 24(2): 98-100.

Nakabo, T. 1982. Revision of genera of the dragonets (Pisces: Callionymidae). Publ. Seto Mar. Biol. Lab., 27(1/3): 77-131.

Nakabo, T. and A. Iwata. 1979. New record of Anaora tentaculata (Callionymidae) from the Ryukyu Islands, Japan. Japan. J. Ichthyol., 26(1): 89-93.

Nalbant, T.T. 1980. Studies on the fishes of Tanzania. II. Neosynchiropus bacescui gen. n., sp. n., and interesting dragonet fish from Makatumbe coral reefs (Pisces, Perciformes, Callionymidae). Trav. Mus. His. Nat. "Grigore Antipa”, Bucuresti, 20(1): 349-352.

Ninni, E. 1934. Callionymus dei mari d'Europa. Notas y Resumenes, Publ. Instituto Espanol de Oceanografia, 85: 1-59. 
Nyström, E. 1887. Redogörelse för den Japaniska Fiskamligen, I, Upsala Universitates Zoologiska Museum. Bihang till K. Sveuska Vet. Akad. Handlingar. 13-4(4): 1-54.

Ochiai, A. 1963. Two dragonet fishes obtained from the tidal zone of the Amami Islands. Bull. Misaki Mar. Biol. Inst. Kyoto Univ,, (4): 63-74.

Ochiai, A., C. Araga and M. Nakajima. 1955. A review of the dragonets referable to the genus Callionymus found in the waters of Japan. Publ. Seto Mar. Biol. Lab., 5(1): 95-132.

Okada, Y. and H. Ikeda. 1937. Notes on the fishes of the Riu-Kiu Islands, II. Pomacentridae and Callionymidae. Bull. Biogeograph. Soc. Japan, 7(7): 67-95.

Ogilby, J.D. 1910. On new or insufficiently described fishes. Proc. Roy. Soc. Qld., 23: 1-55.

Oshima, M. 1940. Pisces. System of the vertebrate. Sanseido, Tokyo, $10+661+46+x x x x i v$ pp. (In Japanese).

Pallas, P.S. 1770. Spicilegia zoologica, quibus novae imprimis et obscurae animalium species iconibus, descriptionibus atque commentariis illustrantur, 1(8):3-54.

Rao, V.V. 1975. Pogonymus goslinei, sp. nov. (Pisces: Callionymidae) from Ennore estuary, Madras. Matsya $1: 27-29$.

Regan, C.T. 1905. On a collection of fishes from the inland sea of Japan made by Mr. Gordon Smith. Ann. Mag. Nat. Hist. Ser. 7,15: 1-26.

Richardson, J. 1844. Ichthyology, pp. 50-150. In the zoology of the voyage of H.M.S. "Sulphur", under the command of Captain Sir Edward Belcher, during the years 1836-42, 1.

Richardson, J. 1846. Report on the ichthyology of the seas of China and Japan. Rep. Birtish Assoc. Adv. Sci. for 1845: 187-320.

Roxas, H.A. and C. Martin. 1937. A check list of Philippine fishes. Commonwealth of the Philippines Department of Agriculture and Commerce, Manila, Technical Bull., 6: 1-314.

Schmidt, P. 1931. A list of fishes, collected in Japan and China by Dr. A. Bunge and N. Grebnitzky. Bull. de l'Acad. Sci. de l'URSS, 1931: 101-123.

Schmidt, P. and G. Lindberg. 1930. A list of fishes, collected in Tsuruga (Japan) by W. Roszkowski. Bull. de l'Acad. Sci., de l'URSS, 1930: 1135-1150.

Schultz, L.P. 1960. Family Callionymidae. pp. 397-410. In L.P. Schultz and collaborators: Fishes of the Marshall and Marianas Islands, Vol. 2, U.S. Nat. Mus. Bull., 202(2).

Schultz, L.P. and L.P. Woods. 1948. A new name for Synchiropus altivelis Regan, with a key to the genera of the fish family Callionymidae. J. Wash. Acad. Sci., 38(12): 419-420.

Smith, J.L.B. 1963. Fishes of the families Draconettidae and Callionymidae from the Red Sea and the western Indian Ocean. Rhodes Univ. Ichthyol. Bull. 28: 547-564.

Smith, H.M. and T.E.B. Pope. 1906. List of fishes collected in Japan in 1903, with descriptions of new genera and species. Proc. U.S. Nat. Mus., 31(1489): 459-499.

Snyder, J.O. 1911. Descriptions of new genera and species of fishes from Japan and the Riu Kiu Islands. Proc. U.S. Nat. Mus., 40(1836) : 525-549.

Snyder, J.O. 1912. Japanese shore fishes collected by the United States Bureau of Fisheries steamer "Albatross" expedition of $1906 . \quad$ Proc. U.S. Nat. Mus. 42 (1909): 399-450.

Suvatti, C. 1936. Index to fishes of Siam. Bureau of Fisheries, Bankok, F+226pp.

Suwardji. 1965. Notes on the genus Callionymus (Pisces, Callionymidae) mostly from Indonesian Waters with the description of three new species and a new subspecies. Vidensk. Medd. Dansk. Naturhist. Foren., 128: 303-323.

Takegawa, Y. and H. Morino. 1970. Fishes from Wakasa Bay, Japan Sea. Publ. Seto Mar. Biol. Lab., 17(6) : 373-392.

Tanaka, S. 1917. Eleven new species of fishes from Japan. Zool. Mag., 29(339): 7-12 (In Japanese).

Tanaka, S. 1928. Figures and Descriptions of the Fishes of Japan, Vol. 42: 809-830.

Tatara, K., R. Kitamori, K. Nagata, S. Mito, T. Hayashi and S. Kudo. 1965. A catalogue of fishes in Seto Inland Sea and adjacent waters, with a list of molluscan. Naikai Reg. Fish. Res. Lab., Publ., G. (3): 77-123. (In Japanese).

Tchang, T., C. Cheng, P. Cheng., S. Li, W. Cheng and W. Wang. 1955. Fishes of the Yellow Sea and Pohai, China. Scientific Publ. Agency, Peking, 362pp. (In Chinese).

Temminck, C.J. and H. Schlegel. 1845. Pisces. Pt. 7-9, pp. 113-172. In Siebold's Fauna Japonica, Leiden. 
Tominaga, Y. and T. Uyeno. 1981. List of Japanese fishes, pp. 453-574. In Dictionary of Japanese fish names and their foreign equivalents, Sanseido, Tokyo.

Ueno, T. 1971. List of the marine fishes from the waters of Hokkaido and its adjacent regions. Sci. Rep. Hokkaido Fish. Exp. Sta., (13): 61-102.

Ui, N. 1929. Fishes of Kisyu, Wakayama Prefecture. Takahashi Nan-ekisha, Osaka, 248+45pp. (In Japanese).

Valenciennes, A. 1837. Histoire naturelle des poissons. 12. pp. 197-232. In Cuvier, G. and A. Valenciennes: Histoire naturelle des Poissons. F.G. Leurault, Paris.

Weber, M. 1913. Die fische der Siboga-Expedition. Siboga-Expeditie 57. E.J. Brill, Leiden, xii + $710 \mathrm{pp}$.

Whitley, G.P. 1928. Studies in ichthyology. No. 2. Rec. Aust. Mus., 16(4) : 211-239.

Yanai, R. 1950. Fishes of San-in District. Zool. Mag., 59(1): 17-22. (In Japanese).

Yoshino, T. 1976. Five unrecorded fishes from Japan, collected from Sesoko Island, Okinawa. Biol. Mag. Okinawa (14): 33-40.

Yoshino, T., S. Nishijima and S. Shinohara. 1975. Catalogue of fishes of the Ryukyu Islands. Bull. Sciences \& Engineering Div., Univ. of the Ryukyus. (Math \& Nat. Sci., 20): 61-118. (In Japanese). 